Hom

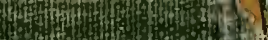





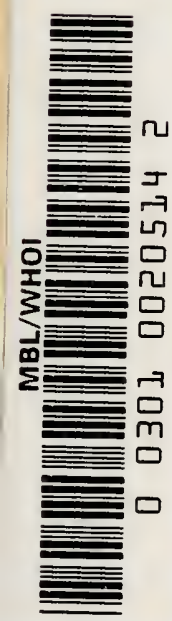





\section{QUANTITATIVE LAWS}

IN

BIOLOGICAL CHEMISTRY 



\section{QUANTITATIVE LAWS}

IN

\section{BIOLOGICAL CHEMISTRY}

BY

SVANTE ARRHENIUS

Pн.D., M.D., LL.D., F.R.S.

NOBEL LAUREATE

DIRECTOR OF THE NOBEL INSTITUTE OF PHY'SICAL CHEMISTRY

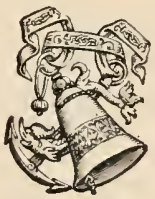

LONDON

G. BELL AND SONS, Ltd.

I 915 



\section{PREFACE}

ThE development of chemical science in the last thirty years shows a steadily increasing tendency to elucidate the nature and reactions of substances produced by living organisms. The problem has been attacked in two different ways, firstly, by the aid of the highly developed synthetic methods of organic chemistry-it will be enough to mention the brilliant work of Emil Fischer, Kossel, and their pupilsand secondly, by the powerful technical means afforded by the modern development of physical chemistry. The studies founded on the methods of organic chemistry aim at investigating the structural composition of the molecules of the chief products of organic origin and subsequently building them up synthetically. The physico-chemical methods, on the other hand, give an insight into the nature of the chemical processes which play an important rôle in the living world. The work of organic chemists in this region has been generally recognized as being of high scientific interest, but the same cannot be said regarding the work of physical chemists in the domain of physiological chemistry. It may be enough to cite one of the least aggressive utterances, 
namely that of FRIEDEMAN in the Handbuch der Hj'giene (3rd vol. Ist part, p. 777, I9 I 3). "The onesided (ausschliesslich) interest which has been directed to this problem" (the neutralization of antigens and antibodies) "is not justified by its biological importance." Yet I am convinced that biological chemistry cannot develop into a real science without the aid of the exact methods offered by physical chemistry. The aversion shown by biochemists, who have in most cases a medical education, to exact methods is very easily understood. They are not acquainted with such elementary notions as "experimental errors," "probable errors," and so forth, which are necessary for drawing valid conclusions from experiments. The physical chemists have found that the biochemical theories, which are still accepted in medical circles, are founded on an absolutely unreliable basis and must be replaced by other notions agreeing with the fundamental laws of general chemistry.

I was very glad to find on my last visit to England that interest in an exact treatment of biochemistry is rapidly growing, and therefore I received with great satisfaction the proposal of Messrs. G. BELL \& SoNs to publish a book founded on the Tyndall lectures given by me in the Royal Institution in May 19I4. 'They contain a short résumé of my own work in this field, supplemented by the investigations of others on neighbouring ground.

The reader who wishes to consult the literature of the subject will find references in : 
S. Arrhenius: Immunochemistry, New York, I907, The Macmillan Co.

"Anwendungen der physikalischen Chemie in der Immunitätslehre," Zeitschrift fïr Chemotherapie, vol. 3, p. I 57 , I9I4.

Hoppe-Seyler's Zeitschrift fiir physiologische

Chemie, vol. 63, p. 324, 1909.

Memoirs published in Meddelanden frän $K$.

Suenska Vetenskapsakademiens Nobelinstitut, vols. I and 2.

Harriette Chick: "The Factors conditioning the Velocity of Disinfection," Eighth International Congress of Applied Chemistry, vol. 26, p. I67, I 9 I 2.

Harriette Chick and Martin : Memoirs published in Journal of Physiology, vols. 40, 43, and 45 , I9IO-I9I 2.

Madsen and his pupils: Memoirs in the Communications de l'institut sérothérapique de l'État danois, 1907-19I3.

In the hope that this little book will evoke interest for the new discipline and stimulate continued work, I lay the results of my efforts before the benevolent public.

I must also express my thanks to Dr. E. N. da C. Andrade for his valuable assistance in the preparation of this monograph.

SVANTE ARRHENIUS.

Stockhola, May I9I5. 



\title{
CONTENTS
}

\author{
CHAPTER I
}

\section{INTRODUCTION}

Necessity of quantitative methods. Material treated. Use of the physico-chemical methods. Graphical methods. Enzymes. Toxins. Antibodies. Specificity.

\section{CHAPTER II}

\section{VELOCITY OF REACTIONS}

Historical remarks regarding biochemistry. Reactions in vivo and in vitro. Spontaneous decompositions. Coagulation. Disturbing influences. Inversion of canesugar by invertase. Influence of acids and bases. Influence of concentration. The rule of Schütz and its generalization. The $q t$-law.

\section{CHAP'TER III}

The Influence of Temperature on the Velocity of Reactions. Reactions of Cells

General law, approximate expression of it. Spontaneous decompositions. Destruction of cells at high temperature. Table of $\mu$-values. Optimum temperatures. Fermentation by yeast cells. Haemolysis of red blood-corpuscles. Agglutination of bacteria. Killing of micro-organisms. Different sensibilities. Theoretical explanation. 


\section{CHAPTER IV}

The Quantitative Laws of Digestion and ReSORPTION

The school of Pawlow. Khigine's, Lönnquist's, and London's experiments on digestion of different foodstuffs. The square-root rule. Secretion of pancreatic juice (Dolinsky). Digestion of small quantities calculated as a monomolecular process. Digestion and resorption of carbohydrates. Secretion of enteric juice (London and Sandberg).

\section{CHAPTER V}

\section{Chemical Equilibria}

Equilibria in enzymatic processes. Taylor's, Robinson's, and Gay's experiments. Maltose and isomaltose, lactose and isolactose. Partition of substances between two phases. Agglutinins and amboceptors. Adsorption. Neutralization of toxins by their antibodies. Ehrlich's experiments. Diphtheria poison. Neutralization of strong bases by acids. Cobra poison. Neutralization of ammonia by boracic acid. "P'oison spectra." Tetanolysin. Prototoxoids. Toxons. Syntoxoids. Danysz's phenomenon. Neutralization of monochloracetic acid. 'The supposed plurality' of toxins. Compound haemolysins. Complement and amboceptor. Equilibrium between haemolysin, amboceptor, and complement. Influence of the relationship of the animals, which have delivered the erythrocytes and the amboceptor. Isolysins. Lecithin as "sensitizer." l'recipitins. Blood relationship. Equilibrium between precipitate, precipitin, and precipitinogren. Calculation of Hamburger's measurements. The relationship bet ween sheep, goat, and ox. Agglutinins. Diversion of complement. Wassermann's reaction. 


\section{CON'TEN'TS}

\section{CHAPTER VI}

Passive immunization. Influence of the method of injection. Experiments of Bomstein, von Dungern, and Bulloch. Rapid decrease and subsequent regular monomolecular decrease. Influence of relationship. Passive immunization with typhoid agglutinin. Fate of red blood-corpuscles in a non-related animal. Time of incubation. Vaccination. Negative phase. Active immunization. Rapid increase of the antitoxin content proceeding uniformly with time. Madsen's and Jörgensen's experiments on active immunization with cholera and typhoid bacilli. Antibodies in the blood of patients after a bacterial disease. Persistent immunity. 



\section{CHAPTER I}

\section{INTRODUCTION}

The content of this little book is founded on three Tyndall Lectures, given in the Royal Institution, London, on the I4th, 2 Ist, and 28th of May igi 4.

The aim of these lectures was to give a short review of the new chapters in Biochemistry in which quantitative measurements have been carried out, and subsequently discussed at some length from the points of view adopted in Physical Chemistry.

As long as only qualitative methods are used in a branch of Science, this cannot rise to a higher stage than the descriptive one. Our knowledge is then very limited, although it may be very useful. This was the position of Chemistry in the alchemistic and phlogistic time before DaLTON had introduced and Berzelius carried through the atomic theory, according to which the quantitative composition of chemical compounds might be determined, and before LAvorsier had proved the quantitative constancy of mass. It must be confessed that no real chemical science in the modern sense of the word existed before quantitative measurements 
were introduced. Chemistry at that time consisted of a large number of descriptions of known substances and their use in the daily life, their occurrence and their preparation in accordance with the most reliable receipts, given by the foremost masters of the hermetic (i.e. occult) art.

In the same manner Biochemistry up to a quite recent time consisted of a great number of descriptions of different products accompanying living organisms, their properties, use, and their composition, i.e. their content of hydrogen, oxygen, nitrogen, sulphur, phosphorus or perhaps other elementary substances. If possible this composition was expressed by means of a chemical formula.

But even the quantitative element which is contained in an analysis of the composition of a substance was lacking in cases where the substances investigated occur in such small proportions that it is not possible to isolate them in a pure form. We have no other possibility of describing these substances than by indication of their occurrence and mode of preparation in the most concentrated and purest possible form, with an indication of their characteristic properties, unless we employ methods other than those belonging to the old classical science of Chemistry. Only by the use of the methods introduced by the modern physical chemistry is it possible to form an opinion of the manner in which these substances react, and thereby to get a clear scientific idea of their nature. The fundamental fact must here be recalled that these substances 
are in many cases so unstable, that their solutions do not permit a heating to $60^{\circ} \mathrm{C}$., that they are in most cases rapidly destroyed by acids or bases, and that if one tries to free them from accompanying albuminous substances by precipitating these, they are often carried down with the precipitate. Common chemical methods are therefore of a very limited value. On the other hand, physical chemistry allows us to follow quantitatively the influence of temperature and of foreign substances upon these interesting organic products, which are of the greatest importance in industry, in the physiological processes of daily life, and in diseases and their therapy.

The quantitative relations between the properties of these substances and their concentration, temperature, and the concentration of substances exerting an influence upon them are given by mathematical formulae. These formulae give a concise description of the phenomenon investigated. From their form it is in most cases possible to understand the mode of action of the temperature, concentration, and of foreign substances, which is the aim of our investigations. A knowledge of the differences between the magnitude of the observed quantities and the corresponding calculated values is useful in a twofold manner. On the one hand, it allows us to determine the probable value of the experimental errors and thereby to improve the methods of investigation. Amongst different methods in which the experimental conditions are changed we 
have to choose those which give the smallest values of the probable errors. In this manner the exactitude of our scientific methods are improved, and thereby the accuracy of our conclusions. On the other hand, the experimental laws found and expressed by our formulae very often are true only for a limited region of the field examined. By means of the deviations between the calculated and the observed values it is possible to form an idea of the cause of the said deviations - which in this case ought to exceed the experimental errors-and thereby to find new laws of a wider application than the old ones, and even to discover new, i.e. previously unknown phenomena.

In the following pages I have made extensive use of a graphical illustration of the mathenatical formulae, representing the laws accepted, as compared with the observed data, marked by crosses or points. Now there is only one line, for deviations from which the eye is extremely sensible, so that it may be used to prove the corresponding law with a great strictness, and this line is the straight one. If now a variable quantity $y$ is dependent upon another quantity $x$, which we may change as we wish, for instance temperature or concentration, so that the formula expressing this dependency possesses the form

$$
y=a+b x,
$$

where $a$ and $b$ are two experimentally determined constant values, then the graphical interpretation 
of this formula is a straight line (Fig. I). Here $a$ is the value of $y$, when $x=0$, i.e. the distance of the point, in which the straight line cuts the axis of ordinates, from the axis of abscissae-in Fig. I $a=1.5$. If we put $x=\mathrm{I}$, then $y=a+b$, i.e. $b$ is the distance of the point in which the straight line $y=a+b x$ cuts a vertical line $x=\mathrm{I}$ going through the point I of the $x$-axis, from a horizontal line

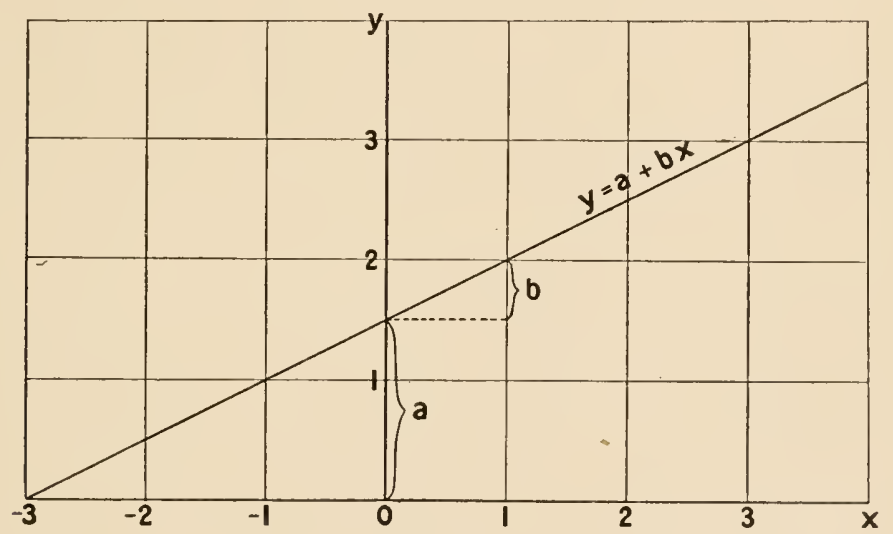

FIG. I.

$y=a$ running at a distance $a$ above the $x$-axis. In Fig. $\mathrm{I}, b=0.5$.

But in most cases this very simple formula does not represent the phenomenon which we wish to describe. For instance, if a substance such as sulphuric acid acts upon cane-sugar, this is transformed into glucose and fructose in such a manner that if we call the initial quantity of sugar Ioo, then after a certain time $t$ (say, one hour) only the quantity So remains unchanged; after the time $2 t$ ( 2 hours) 
only So per cent of So, i.e. the quantity 64 per cent, remains; after the time $3^{t}$ ( 3 hours) So per cent of 64 , i.c. the quantity $5 \mathrm{I} \cdot 2$, remains of the sugar; after the time $4^{t}$ ( 4 hours) So per cent of $5 \mathrm{I} \cdot 2$, i.e. the quantity 40.96, and so forth. We say then that when time increases in an arithmetic series, the quantity of cane-sugar decreases in a geometric series. If the quantity of cane-sugar is called $z$ and the quantity at the beginning of the experiment $z_{0}$ (we have in this case put $z_{0}=100$ ), then the said law regarding the progress of the inversion of the cane-sugar with time, $t$, is expressed by means of the formula

$$
\log z_{0}-\log z=b t
$$

For the time $t=0$, i.e. when the sulphuric acid is added to the solution of cane-sugar we have $\log z_{0}=\log z$, i.c. $z=z_{0}=100$.

Now if we translate the said law into a graphical expression, we gret the $z$-curve as a function of the time $t$ (Fig. 2, the lower curve). This $z$-curve is a so-called exponential curve. Even to an eye accustomed to curves it is rather difficult to distinguish this exponential z-curve from another curve indicating a regular decrease of the quantity of cane-sugar, $z$, with increasing time, $t$. The curve does not tell us very much in its general character; only if we measure special points on it, and determine corresponding values of $z$ and $t$, do we get a real representation of the meaning of the curve. In this case a table giving the comparison of calculated 
figures with observed ones is of a greater use and clearness.

But we can proceed more simply by putting $y=\log z$, i.e. plotting $\log z$ as a function of $t$, in which case we get a straight line (the continuous line in Fig. 2), beginning at the point $y_{0}=\log z_{0}=$ $\log \mathrm{IOO}=2$ and cutting the $t$-axis in the point $\log z$

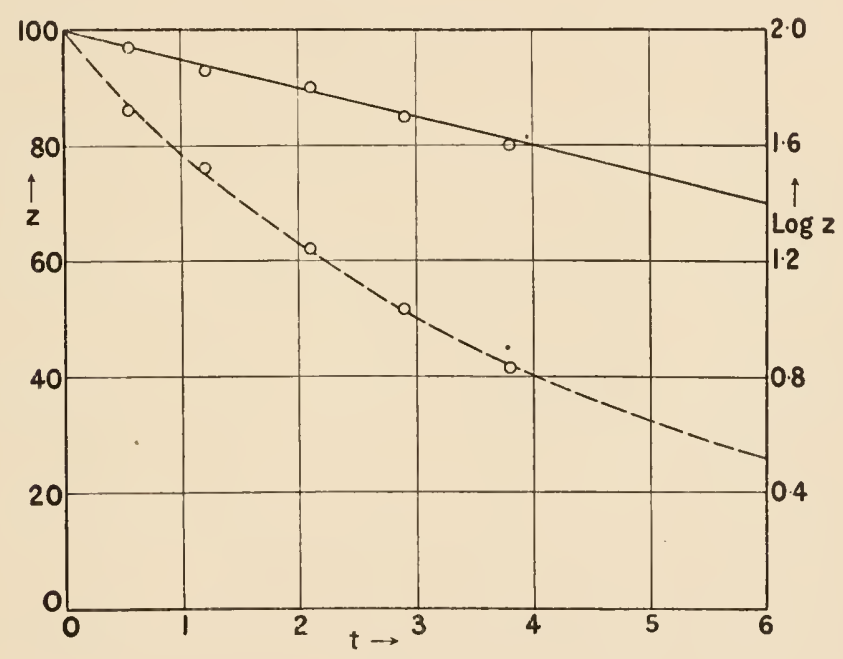

FIG. 2.

$=0$, i.e. $z=\mathrm{I}$, and $2-\mathrm{O}=b t_{0}$, i.e. $t_{0}=2 / b$ (in Fig. 2 $t_{0}=20 \cdot 6, t_{0}$ lies so far to the right that it does not appear in the figure). Here the value of $b$ is very simple, namely, $b=2 / t_{0}, b$ is the so-called velocity of reaction, it is equal to 2 divided by the time in which the quantity of cane-sugar has sunk to one per cent of its original value. Evidently the shorter the time for decomposing 99 per cent 
of the cane-sugar, the greater is the velocity of reaction. ${ }^{1}$

In this case we get immediately, by means of the $\log z$-curve, a general view of the progress of the reaction, and we see at once how well the law, represented graphically, agrees with experience (the dots in Fig. 2 represent some experiments of WILHELMY carried out in I850; the unit of time is here $72 \mathrm{~min}$.). Another example we find in the representation of Schürz's rule, which says that at constant temperature the digestion of egg-albumen by the aid of pepsin proceeds so that if the quantity $a$ is digested in one hour, it takes four hours to digest the double quantity $2 a$, nine hours for the threefold quantity $3 a$, sixteen hours for the fourfold quantity $4 a$, and in general $n^{2}$ hours for digesting the $n$-fold quantity $n a$. If we take the time, counted from the beginning of the experiment as abscissa, and the digested quantity $y$ as ordinate, we get a curve (a parabola) expressing that the square of $y^{\prime}$ is proportional to time, i.e. $y^{2}=a^{2} t$. This curve does not give a good representation to the eye. To begin with, it rises extremely rapidly-its tangent is vertical in the point $t=0$, then it increases more slowly, and at higher values of $t$ so slowly that it seems to reach a certain maximum value asymptotically, which is not true. But if instead of plotting $y$ as a

1 It would be more exact to use natural logaritlins instead of the common ones. With natural logarithms the value of $b$ (the velocity of reaction) is 2.3 times greater than with common logarithms, which are still generally used on accuunt of their convenience. In the following we always use common logarithms. 
function of $t$, we plot $y^{2}$ as a function of $t$, then the $y^{2}$-curve is a straight line, running through the origin, $y=0, t=0$, and we easily see that the $y^{2}$ value does not approach to a limit. In this case we might just as well have tabulated $y$ as a function of the square root of $t, y=a \sqrt{t}$ and have obtained a straight line. In the figure 7 representing Schürz's rule, some experiments of E. SсHütz are indicated by points. Here the quantity $x$ digested in a given time is represented as a function of the square root, $\sqrt{q}$, of the quantity, $q$, of pepsin used for the digestion.

In general if we have a formula expressing a connection between two quantities of which we change the one $u$ experimentally, while we observe the corresponding magnitude of the other, $z$, which formula may be

$$
f(z)=\mathrm{K} \cdot \rho(u)+b,
$$

we shall always be able to illustrate this formula graphically by a straight line by choosing $y=f(z)$ and $x=\rho(u)$, for then we have the linear formula

$$
y=\mathrm{K} \cdot x+b .
$$

But in most cases it is preferred to plot $z$ as a function $\psi(u)$ of $u$ and to draw a curve through the plotted points, indicating the values actually observed by means of points or crosses. This method is preferred as soon as the functions $f(z)$ or $\rho(u)$ are at all complicated, so that we are not 
acquainted with them and therefore lose sight of the relation connecting $z$ with $u$, which is, however, presented to the eye by the curve representing $z=\psi(u)$.

In some cases the function $f(z)$ or $\rho(u)$ within a certain interval coincides very nearly with a function which is familiar to us. Thus, for instance, when we investigate the influence of temperature upon the velocity of a reaction, we find that the velocity of reaction, $\mathrm{K}$, increases nearly in a geometrical progression, when the temperature, $t$, increases in an arithmetical one. For small intervals of temperature this rule is very nearly exactly true. Then we make use of this circumstance, and as in Fig. 2 we plot $\log \mathrm{K}$ as a function of $t$. When, as below in Fig. 9, the observations fall within an interval of temperature less than $10^{\circ} \mathrm{C}$., the deviation of the strict formula from a linear equation is so small, that it falls wholly within the errors of observation, and we make use of the rectilinear representation. But if the said interval exceeds $10^{\circ} \mathrm{C}$. the divergence between the strict formula and a linear equation is so great that we cannot use the straight line as a true expression of the observed data, but make use of the representation of the strict formula. But even in this case we use $\log K$, and not $K$ itself, for the representation, because the curve then has a nearly rectilinear form, that is, its curvature is very insignificant, and the smaller the curvature is, the clearer is the representation given by the curve to the eye, and correspondingly, the easier it is 
to use the curve for finding values by means of interpolation.

Therefore in all the curves which represent the velocity of reaction as dependent on temperature, I have taken as the ordinate $y=\log \mathrm{K}$, and when the interval of temperature was relatively great, I have drawn the curve giving the exact equation (see Fig. IO). Something similar has been done when the progress of digestion with time (cf. Fig. 8) has been graphically represented. In this case the square root of the time, $\sqrt{t}$, has been chosen as abscissa. If the rule of Sснüтz were absolutely strict the representative curves, giving the digested quantity as ordinate, ought to be straight lines. But this is only approximately true; it holds only for small values of the time $t$. This is easily verified by the eye if we follow the curve representing the exact formula, and drawn in the figure, down to values in the neighbourhood of the origin.

In the diagrams, indicating the change of the velocity of reaction, $\mathrm{K}$, with temperature, I have drawn many lines representing different substances. This has been done in order to save space and also to give a more general view of the phenomenon represented. But this concise representation has only been possible by changing the origin. This is indicated for each curve by a formula expressing how many centigrade degrees of temperature have to be added to that given by the abscissa, in order that the figures may represent the observations. In one case the scale is reduced to the half magnitude, which 
is indicated by putting $y_{1}^{\prime}=2 y$ and $\mathrm{T}=a+2 x$ (see Fig. 9, coagulation of haemoglobin). In the next figure other reductions of the scale have been introduced which are easily seen from the indications.

In some cases the differences between observed and calculated values are so snall that they cannot be represented in diagrams if these are not given on a very large scale. Under such circumstances it is preferable to give the values observed side by side with those calculated.

Before we consider the laws governing the reactions of the substances treated below, which have not been prepared in a pure state, it will be worth while to recall their general properties in order that we may be familiar with them and understand why so much work has been done on their examination. It is quite clear that if these substances did not exert some very obvious and important actions, they would probably have escaped our observation. In reality these substances, products of animal or vegetal bodies, are found to govern the chemical processes going on in living bodies. The most important for animal life are the juices secreted by the digestive tract. To begin with, the salivary glands give a juice containing ptyalin, which transforms the insoluble starch of the food into the soluble sugar maltose. Then glands in the walls of the stomach secrete the stomachical juice, which contains two active substances, the pcpsin, which decomposes the albuminous substances of the food into 
albumoses and peptones, and even coagulates the casein of milk, and a lipase, i.e. an enzyme decomposing fats-in this special case the fats of the milk are chiefly attacked-into glycerol and fatty acids. On its way through the intestine the food subsequently comes into contact with the pancreatic juice, containing new enzymes, the trypsin, which decomposes the albuminous substances still furthernamely, to amino-acids - than the pepsin, and further a lipase, decomposing all kinds of fats, and another enzyme, maltase, which decomposes one molecule of maltose into two molecules of $d$-glucose, whereby one molecule of water is also taken up. The enteric juice, with which the food later on is mixed, contains the enzymes invertase, lactase, and maltase, which break down the molecules of cane-sugar, milk-sugar, and maltose into hexoses of simpler composition, and a very active proteolytic ferment, erepsin, which decomposes peptones into amino-acids. When the food-stuffs have been decomposed into their simple compounds-amino-acids for the proteids, glycerol and fatty acids for the fats, and hexoses for the starches and sugars-they are taken up by the animal body and, by means of new ferments, partly built up to living substances contained in the different tissues, partly burnt down or otherwise decomposed to give the heat necessary to sustain the temperature of the body or to supply it with energy for doing work. Cellulose, which enters into the food of a great number of animals, is partially rendered useful to these by the aid of micro-organisms 
introduced by the food or growing in the digestive tract, and secreting special enzymes.

In the vegetable kingdom, the chlorophyll acts as an enzyme in the production of carbohydrates from carbonic acid and water. But chlorophyll occurs in such large quantities that it has been possible to subject it to ordinary chemical analysis (cf. the work of WiLLSTÄTTER and others), and therefore it does not belong to the substances with which we deal in this book. But the vegetable kingdom produces and uses ferments or enzymes of the same action as those known from the animal kingdom. Well known are the very active lipase contained in castor beans, the proteolytic ferment papayotin from Carica Papaya, and another proteolytic ferment in growing seedlings of barley. Further, we know a great number of katalases, oxydases, and reductases both from the animal and from the vegetable kingdom. Of high importance are the enzymes furnished by the yeast-cells, namely, zymase, which causes alcoholic fermentation; invertase, which decomposes cane-sugar; and maltase, which splits up maltose.

In general, micro-organisms produce a large number of substances of high chemical activity. Amongst these a great many are of the highest interest for us, as, for instance, the diphtheria toxin or the tetanus-poison, which cause the terrible diseases diphtheria and lock-jaw. Even higher organisms, as snakes or spiders or insects, produce similar poisons, as do also some plants, e.g. Abrus pracea- 
torius, Ricinus, etc. In general it may be said that the diseases caused by pathogenic bacteria are caused not so much by the bacteria themselves as by the products secreted during their lifetime or set free after their death.

The human or animal body possesses means of combating the action of these poisons. If they are injected into the body, or even if the bacteria themselves are injected, the blood after some time contains substances which neutralize the poisons or act upon the bacteria. Such substances are called antibodies, whereas the injected poisons or bacteria are called antigens, i.e. bodies which cause the formation of antibodies. Later it has been found that the injection into an animal of albuminous substances, e.g. milk or egg-white, or serum or corpuscles from the blood of non-related animals, which seem to be comparatively harmless for the animal, causes the production of antibodies. The antigens and the antibodies are of extreme importance for the welfare of man, and they have therefore been the object of very extensive studies, mostly only of a qualitative, but in recent time also of a quantitative character.

The antibodies are divided into different groups, according to their mode of action on the antigens, as lysins (bacteriolysins, which cause the destruction of the bacteria, or haemolysins, which let the haemoglobin, the red colouring matter of the blood-corpuscles, go out into the surrounding fluid); precipitins, which produce a precipitate with their antigens, agglutinins, by the influence of which the antigens-in this 
case bacteria-are gathered together into lumps; and antitoxins, which neutralize the injected toxins. These substances have been subjected to quantitative studies, especially the haemolysins, which give an easily measurable colorimetric reaction. Other antibodies, such as opsonins and antianaphylactogens, have not yet been investigated in a manner adapted to quantitative calculations. The agglutinins behave very similarly to the precipitins, and are therefore probably only a special kind of precipitins. The socalled compound haemolysins and the bacteriolysins also behave nearly in the same manner, except that the action of the haemolysins is directed against red blood-corpuscles, that of bacteriolysins against bacteria.

After the injection of an antigen the serum generally contains substances giving different actions of this kind, e.g. an agglutinin and a lysin. Most investigators regard these substances as different from each other, and an enormous number of different substances has in this manner been recorded. On the other hand, it would be much more simple to suppose that the same substance may have many different reactions even on the same substrate. Thus, for instance, mercuric chloride agglutinates red blood-corpuscles in less dilute solutions, but haemolyzes them in very dilute solutions. Something similar is true of the acids; and in this case the presence of a trace of lecitin hampers the agglutination, and aids the haemolysis. The presence or absence of a seemingly indifferent 
substance may exert a great influence on the reaction. Thus, for instance, agglutination of bacteria does not occur in absence of salts and is also prohibited by the presence of salts in higher concentration. The first circumstance is analogous to the sedimentation of suspended particles by salts in solution, the second one is probably due to the dissolution of the albuminous precipitate, which causes the agglutination-strong solutions of salts are good solvents for albuminous precipitates.

Even if we try to avoid new hypotheses regarding the presence of a great number of antibodies (or antigens) as much as possible, we find that it is characteristic that every antigen has its special antibody, which does not react with other antigens. This so-called specificity is of the greatest importance, for it is possible to discover an antigen amongst an immense number of other organic substances by means of its specific antibody. The blood of different animals, the secretions of different bacilli may in this manner be discriminated from each other with perfect certainty. In this case ordinary chemical analysis leaves us absolutely helpless. It may therefore be maintained that this new department of science opens for us an immense new field of chemistry of the very highest importance to mankind. This circumstance explains the exceptional interest of the investigation of this field. As has been said above, it is physical chemistry which gives us the mighty instrument for these investigations. This science itself has been greatly 
enriched by this work. For there is no part of chemical science which offers such a variety of examples illustrating the physico-chemical theories as this new branch of chemistry which has been called Immuno-chemistry. 


\section{CHAPTER II}

VELOCITY OF REACTIONS

In the following pages we will treat one of those problems which have been open to discussion ever since the beginnings of science. Our special question is, if living matter obeys the same fundamental quantitative laws as those which govern the reactions of inanimate matter. In other words, we will look upon the problem of vitalism from a chemical standpoint. We will limit this investigation to such laws as are expressed by formulae, giving the relations between quantities dependent the one on the other. It is chiefly with laws of this kind that we are concerned in exact science.

After the discovery of relationships in biological chemistry, of which we do not know an analogy in general chemistry, it was naturally maintained that the general laws are different in these two domains, and the physiologists have generally had a tendency in this direction. But a still better method of working is to seek for an analogy in general chemistry. If this has been found, it is in most cases much easier to explain, and after 
a satisfactory explanation has been discovered, it is natural to apply it to the corresponding biochemical problem, which thereby becomes elucidated. Now it has been found in so many cases that the laws of general mechanics, those of the indestructibility of matter and energy and those of osmotic pressure, are absolutely as valid for living as for dead matter, that many scientists regard it as an evident truth that life is in reality only a form of matter and motion. Therefore it is often maintained that living matter has developed from common matter, notwithstanding that no experimental proof has been given for this assertion. It was a great merit of TyNDALL to show experimentally that everywhere where life was observed to grow up it was caused by germs originating from living organisms.

It is necessary in this question to keep the golden middle course, not to assert as self-evident anything which has not been demonstrated, but also not to deny the possibility of an agreement between the laws in the two said domains before a very earnest effort has been made to reconcile them.

Biochemistry is of very ancient origin. In reality we may count as biochemical a great many of the experiments of the iatro-chemists, who sought to apply chemical principles to the elucidation of vital processes. Francis DE LA Bö̈ Sylvius discovered that the arterial blood differs from the venous blood through its content of some of the 
constituents of air, which gave the arterial blood its brilliant red colour. VAN HeLmont described the carbonic acid, gas sylvestre, which is evolved in the process of fermentation of wine or beer. In his famous work, Experiments and Observations on different Kinds of Air, Priestley described the action of plants on air deteriorated through the respiration of animals. He showed that the green parts of the plants in sunlight decompose carbonic acid and give off oxygen to the air. In this way the plants and the animals counteract each other and help to keep the composition of the air unchanged. This problem attracted, by its great practical importance, the chief interest of biochemists for a long time. The most important investigations in this chapter we owe to SENEBIER and InGENhouss in the eighteenth century, to $\mathrm{DE}$ Saussure, Dumas, Liebig, Daubeny, Draper, Sachs, Baeyer, Pfeffer, Engelmann, and PringsHEIM in the nineteenth century. BAEYER expounded the prevailing theory that the plant products from carbonic acid and water are oxygen and formaldehyde, which through polymerisation gives the different carbohydrates, such as sugar or starch or even cellulose. In recent time DaniEL Berthelot, Stoklasa, and others have succeeded in carrying this process through without the help of green plants by means of ultra-violet light.

In an analogous manner Duclaux imitated the chief fermentation process, by which alcohol is produced from sugar by the agency of yeast-cells, by 
letting ultra-violet light act upon glucose in the presence of bases, such as caustic soda, ammonia or lime water.

Before the nineteenth century it was believed that some products of animals or plants could not be prepared without the interaction of life-processes. WöHLER in I 828 was the first to break down this belief, when he prepared urea from ammoniumcyanate. The synthesis of alizarin by Graere and Lieberaian (i869), of indigo by Baeyer ( I 878), and still more of the fats by PÉLOUze and Gélis ( 1843 ) and Berthelot (I 854 ), and of the different sugars by Emil Fischer (i 890), who has even succeeded in building up polypeptides, giving the reactions of albuminous substances, and a multitude of other syntheses, have completed this work in the most striking manner. It is now generally recognized that the synthesis of organic products from inorganic matter will always be possible if we devote sufficient work to the solution of this question, and even that the tools of the chemist surpass the living organism in multiplicity of effects. Ultra-violet light and the silent discharge of electricity are in this special case very mighty factors. The enormous success in this domain has created the conviction that we are complete masters of these problems, and that in the course of time we shall be able to prepare synthetically any product of Nature, living or inanimated.

But a given compound may be produced in many different ways, and it is therefore very possible 


\section{VELOCI'TY OF REAC'TIONS}

that the method of working in the organism differs from that used in the chemical laboratory. This question is of a much more recent date than that mentioned above, because the progress of chemical processes has not been thoroughly investigated before the last great development of physical chemistry. Therefore our chief task will be to see if the physico-chemical laws regarding the progress of chemical processes in general chemistry are also applicable to biochemical processes, and we shall especially try to elucidate such biochemical processes as have been considered exceptions from known physico-chemical laws.

In this case we have not only to regard the processes going on in the living organism, for these are in most cases very difficult to examine thoroughly, but also to investigate chemical processes, characteristic of organic products which react upon each other outside of the living body, or, as it is called, "in vitro" (in a glass vessel). As far as is known, biochemical processes develop in the same manner in the living body, "in vivo," as "in vitro" if the same reagents are used under the same circumstances. Without the aid of experiments "in vitro" we should really know very little of the much less accessible reactions "in vivo." The characteristic feature of these reactions is that they are bound up with the action of certain organic products, which have not so far been produced synthetically, because they occur in such small proportions, and are so difficult to isolate from other organic products, that 
we do not know their composition and therefore are, so far, unable to prepare them. These organic products have been characterized above.

In most cases these substances are very unstable, so that they are rapidly decomposed, especially at higher temperatures. This spontaneous decomposition has often been regarded as characteristic of these substances, but closer investigation indicates, as we will see below, that they behave just in the same manner in their reactions as do well-defined substances known from the general chemistry. Even from inorganic chemistry we know a great number of products which are stable only at low temperatures.

As regards the progress with time of this decomposition it behaves precisely as an ordinary monomolecular reaction, as the following figures and diagrams indicate. They give the rate of destruction of tetanolysin at $49.8^{\circ} \mathrm{C}$. and of a haemolytic antibody, found in the serum of a goat after injection of blood-corpuscles from a rabbit, at $51^{\circ} \mathrm{C}$. The law of monomolecular reactions states that the curves representing the logarithm of the quantity of the substance in decomposition, e.g. the tetanolysin or the haemolytic antibody, as a function of time, is a straight line (cf. p. 6). 


\begin{tabular}{|c|c|c|}
\hline \multicolumn{3}{|c|}{ Decomposition of Tetanolysin at $49 \cdot 8^{\circ} \mathrm{C}$} \\
\hline Tine in mins. & \multicolumn{2}{|c|}{ Quantity $q$ of Lysin. } \\
\hline$t$ & obs. & calc. \\
\hline 2 & 100 & 100 \\
\hline 20 & So & $80 \cdot 6$ \\
\hline 40 & $6 \mathbf{I} \cdot \mathbf{I}$ & $64 \cdot 8$ \\
\hline 60 & $52 \cdot I$ & $52 \cdot 3$ \\
\hline 80 & $46 \cdot 3$ & $42 \cdot \mathrm{I}$ \\
\hline I 20 & $26 \cdot \breve{S}$ & $26 \cdot 7$ \\
\hline I 80 & I $7 \cdot 6$ & $14 \cdot 3$ \\
\hline \multicolumn{3}{|c|}{$K=0.00474$} \\
\hline
\end{tabular}

\begin{tabular}{|c|c|c|}
\hline \multicolumn{3}{|c|}{ Decomposition of a Haemolysin at $51^{\circ} \mathrm{C}$. } \\
\hline \multirow{2}{*}{ Time in mins. } & \multicolumn{2}{|c|}{ Quantity $q$ of Haemolysin. } \\
\hline & obs. & calc. \\
\hline o & IOO & IOO \\
\hline 5 & $74 \cdot 3$ & $73 \div 4$ \\
\hline IO & $5^{8} \cdot 3$ & $62 \cdot 5$ \\
\hline 15 & 48.8 & $53 \cdot 3$ \\
\hline 20 & $44 \cdot 9$ & $45 \cdot 4$ \\
\hline 25 & $40 \cdot 0$ & $38 \cdot 7$ \\
\hline 30 & 33.7 & $33^{\circ} 0$ \\
\hline 35 & $28 \cdot 4$ & $2 S \cdot I$ \\
\hline 40 & $25 \cdot 2$ & $24 \cdot 0$ \\
\hline \multicolumn{3}{|c|}{$\mathrm{K}=0.0154$} \\
\hline
\end{tabular}

The curves (Fig. 3) are evidently very nearly straight lines. This is especially clear for the decomposition of tetanolysin. The differences between the observed and the calculated values fall well within the errors of observation. On the curves we see that the logarithm of the quantity of haemolysin reaches the value $\mathrm{I} \cdot 4$ in 37 minutes, whereas the corresponding line for the tetanolysin needs I 30 minutes for the same purpose. From that we conclude that the velocity of decomposition of the haemolysin (at $5 \mathrm{I}^{\circ} \mathrm{C}$.) is $\mathrm{I} 30: 37=3.5$ times greater than that for tetanolysin (at $49.8^{\circ}$ C.). In this manner the constant of the velocity of reaction $\mathrm{K}$ is determined.

An analogous case has been investigated by Miss Chick and Dr. Martin, who determined the rate of coagulation of haemoglobin and of egg-albumen. The quantity of protein present in the solution at a certain time was determined by taking out a small part of the solution and coagulating it at $100^{\circ} \mathrm{C}$. 
The quantity was measured simply by measuring the intensity of colour or by weighing the coagulate. The curves are very nearly straight lines, as is seen from the diagram, Fig. 4. The coagulation depends upon a decomposition of the protein. As water

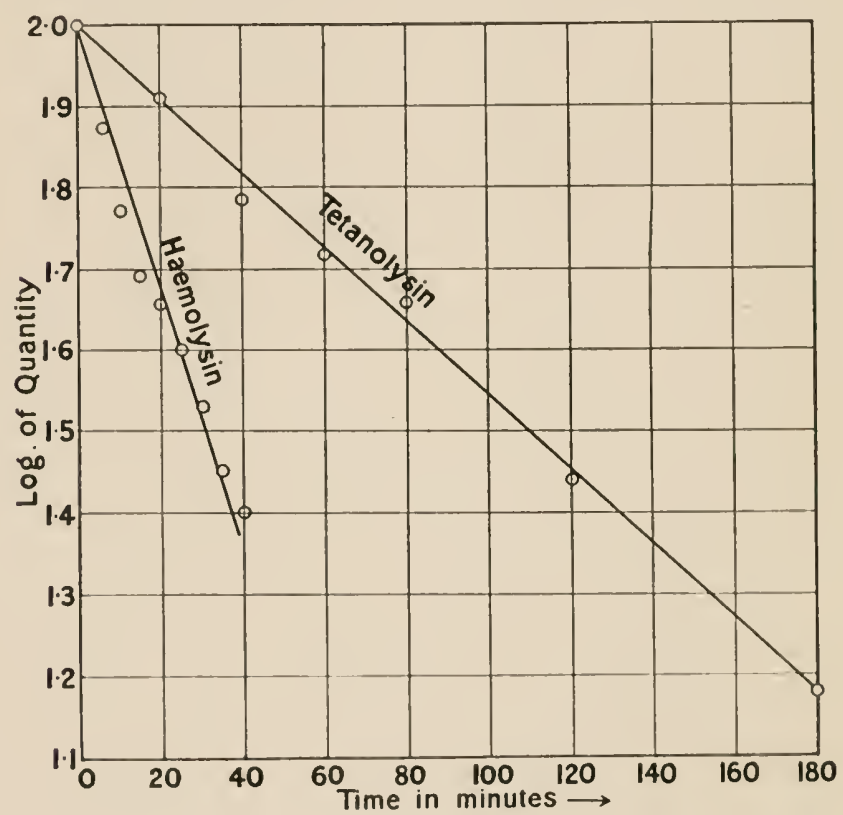

FIG. 3 .

seems necessary for it, it is probably connected with hydration.

The experiment succeeded at once with haemoglobin at $70.4^{\circ} \mathrm{C}$. The constant was $K=0.145$. But with the egg-albumen the investigation gave at first very irregular results. The rate of decomposition diminished very rapidly as the coagula- 
tion process went on. Now it was known from experiments of different authors that the reaction of the solution becomes more and more basic with time during the coagulation, and it was also known that in many cases the velocity of reaction

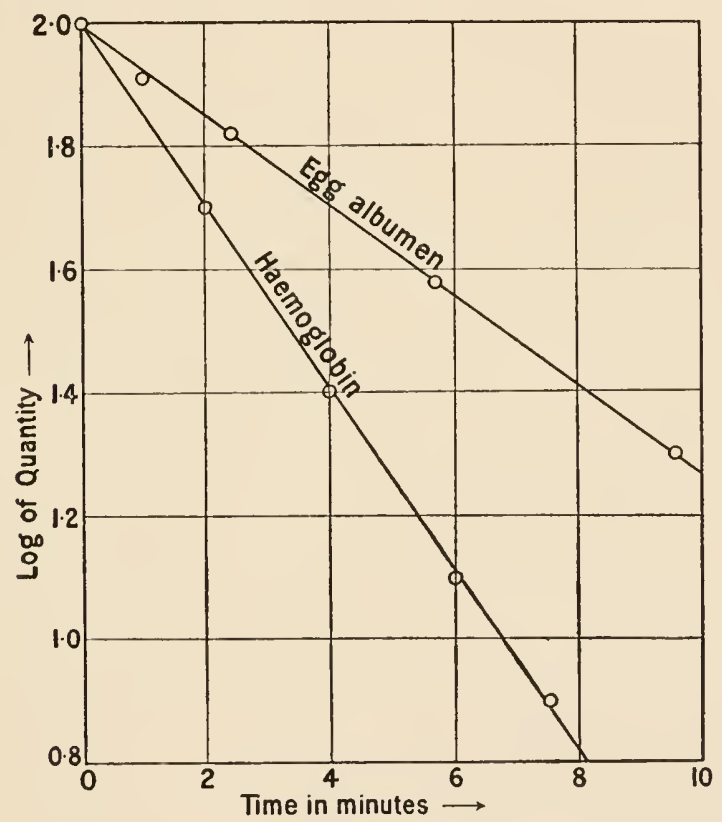

FIG. 4.

depends in a high degree on the acidity or alkalinity of the solution. Therefore instead of asserting that the reaction does not follow the laws known from general chemistry, as has been done in many similar cases before, Miss CHilck and Dr. Martin tried if the rate of coagulation was constant at a constant degree of acidity. This was attained by adding 
boracic acid to saturation. In this manner these investigators found the regular values reproduced in the diagram. In an analogous manner they obtained regular results by adding powder of magnesium oxide.

This example is very characteristic and indicates the special difficulties in experiments with organic matter. The molecular weight of the organic preparations is in general very high, so that there are relatively few molecules present in the solutions used. These preparations react with other substances present, such as salts, and especially with acids and bases. Even when the concentration of these substances is very low, the number of their molecules is of the same order of magnitude as that of the organic molecules, so that these may for a great part be transformed and give quite unexpected reactions. Very often the preparations are taken from a bouillon-culture, which has an alkaline reaction. In this case the rate of decomposition generally increases with the alkalinity. Therefore in such a case, which was investigated by MADsen, namely, that of the spontaneous decomposition of a specimen of vibriolysin, the constant of reaction was double as great for the original solution as for this solution diluted to half its strength. The alkali present had been diluted at the same time as the solution of the lysin.

A very interesting case of this kind has been observed by Miss Culck and Dr. MArTin, when they examined the coagulation of egg-white (in acid 


\section{VELOCI'TY OF REAC'TIONS}

solution). The quantity coagulated in unit time is proportional to the quantity of egg-white in solution and, further, nearly proportional to the acidity of the solution. Now the quantity of acid diminishes when the egg-white becomes coagulated. Within certain limits the quantity of acid is nearly proportional to the quantity of egg-white remaining in the solution during the process. It therefore looks as if the quantity coagulated in unit time should be proportional to the square of the concentration of the egg-white, which is characteristic of a so-called bimolecular chemical process. If the acidity is kept constant the process is, as we have seen above, monomolecular, i.e. the logarithm of the concentration is a linear function of time.

Even the diluting water itself may interact with the preparation. It is well known that in most cases the preparations of organic origin resist decomposition much better when in a dried state than when dissolved. On this ground the anti-diphtheric serum used for standardizing diphtheria-poison is dried with phosphoric anhydride in a vacuum and also kept at a low temperature. Very instructive in this respect are the experiments of MADSEN and WALBUM regarding the stability of different solutions of rennet.

They found the following reaction constants $K$ at $46 \cdot 15^{\circ} \mathrm{C}$. for different concentrations :

$\begin{array}{lllllllll}\text { Concentration } & 7 & 5 & 3 & 2 & \text { I } & 0.25 & 0.125 & 0.063\end{array}$ Rate of Decom-

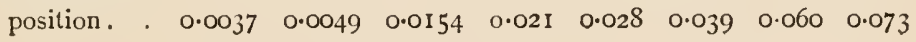


Dried rennet is extremely slowly decomposed at that temperature. At $158^{\circ} \mathrm{C}$. the constant is $\mathrm{K}=$ $0.04 \mathrm{I}$. This circumstance recalls the "denaturation" of egg-albumen at high temperatures, for which also the presence of water is necessary.

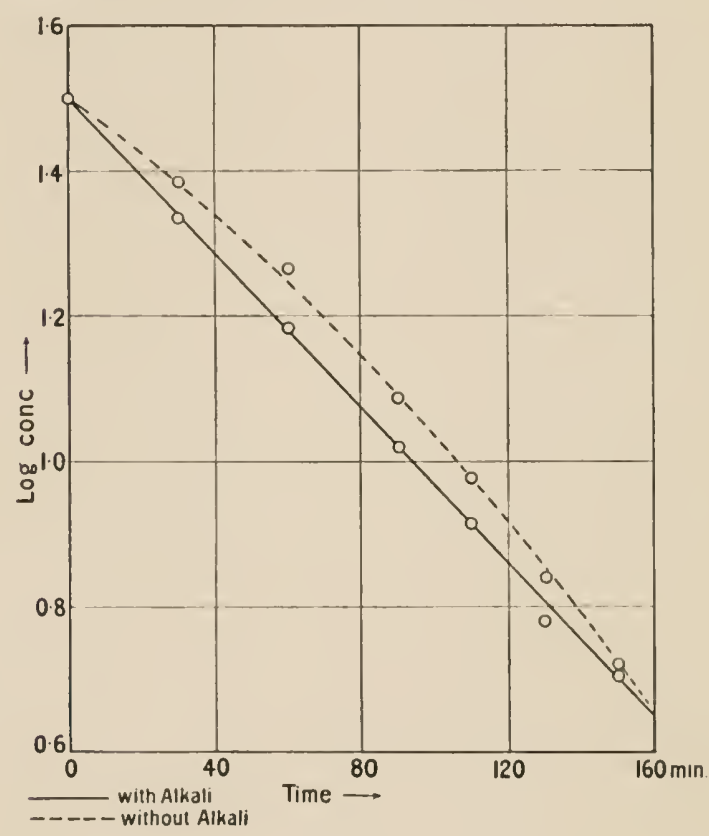

FIG. 5.

The enzymatic reaction which has been most thoroughly investigated is that of invertase on canesugar. The invertase was prepared from yeast-cells. Victor Henri determined (1902) the velocity of inversion of sugar with this enzyme and observed that it behaves in a manner quite different from a monomolecular reaction. This experiment was controlled 
by Hudson, who observed that the glucose formed during the beginning of the process shows the phenomenon of mutarotation, and that its quantity therefore cannot be determined immediately with the aid of a polarimeter, as HENRI had done. In order to eliminate the mutarotation it is necessary to add some trace of alkali before the polarimetric determination. This is made very evident by the following figures of Hudson, and diagram, Fig. 5.

\begin{tabular}{|c|c|c|c|c|}
\hline \multirow{2}{*}{$\begin{array}{l}\text { Time of Inversion } \\
\text { in Mlinutes. }\end{array}$} & \multicolumn{2}{|c|}{ Rotation at $30^{\circ} \mathrm{C}$. } & \multicolumn{2}{|c|}{$\begin{array}{c}\text { Calculated Velocity of Reaction } \\
\text { K. } 10^{5} \text { at } 30^{\circ} \mathrm{C} \text {. }\end{array}$} \\
\hline & Without Alkali. & With Alkali. & Without Alkali. & With Alkali. \\
\hline $\mathrm{o}$ & $27 \cdot 50$ & $27 \cdot 50$ & $\ldots$ & $\ldots$ \\
\hline 30 & 16.85 & $14 \cdot 27$ & 396 & 558 \\
\hline 60 & 10.95 & $7 \cdot 90$ & 399 & 530 \\
\hline 90 & $4 \cdot 75$ & $3 \cdot 00$ & 464 & 539 \\
\hline I IO & $\mathbf{I} \cdot 95$ & 0.80 & 482 & 534 \\
\hline I 30 & -0.55 & $-I \cdot 49$ & 5 I I & 559 \\
\hline 150 & $-2 \cdot 20$ & $-2 \cdot 40$ & 522 & 533 \\
\hline$\infty$ & $-7 \cdot 47$ & $-7 \cdot 47$ & $\ldots$ & $\ldots$ \\
\hline
\end{tabular}

As is easily seen from the figures and Fig. 5 the experiments in which the mutarotation was eliminated by addition of a trace of alkali give a fairly good constant (mean value $542 \cdot 1 \mathrm{O}^{-5}$ ), whereas the figures in the fourth column, representing the observed rotation without addition of alkali, give a steadily increasing value. As early as i 890 O'Sullivan and Tompson had recognized the error caused through mutarotation, and their measurements, which had fallen into oblivion, have been verified by HuDSon.

Not only the mutarotation exerts an influence on 
the velocity of reaction in this case, but also the acidity of the solution, as is seen from the following figures, borrowed from Sörensen. A series of experiments was carried out with invertase and a small addition of sulphuric acid at $30^{\circ} \mathrm{C}$. As independent variable is taken the hydrogen-ion concentration. As is seen from those figures a very flat maximum is obtained at the hydrogen concentration $0.00003 n$.

Influence of Acidily on Velocity of Reaction.

Inversion of Cane-Sugar (at $30^{\circ} \mathrm{C}$.).

Conc. of II-ions

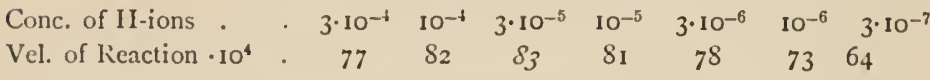

Decomposition of Tetanolysin (at $50^{\circ} \mathrm{C}$.).

$\begin{array}{llllllll}\text { Normality } \mathrm{NaOHI} & \text {. } & 0.02 & 0.01 & 0.005 & 0 & -0.0 \mathrm{I} & -0.02: \mathrm{H}_{2} \mathrm{SO}_{4}\end{array}$ $\begin{array}{llllllll}\text { Velocity of Reaction } \cdot 10^{4} & \text {. } & 112 & 97 & S_{5} & 47 & 71 & 435\end{array}$

Digestion by means of Pepsin (at $52^{\circ} \mathrm{C}$ ).

Conc. of H-ions . . $\quad 0.17 \quad 10^{-1} \quad 6 \cdot 10^{-2} \quad 2 \cdot 10^{-2} \quad 5 \cdot 10^{-3} \quad 8 \cdot 10^{-5}$ $\begin{array}{llllllll}\text { Digested quantity } f & \text { I hour } & S .5 & 9.3 & 12.3 & 15.2 & 15.0 & 10.8\end{array}$ $\begin{array}{lllllll}\text { in mgms. after } \mathrm{l}_{49} \text { hours } \ldots & 30.3 & 31 \cdot 3 & 30.9 & 28 \cdot 1 & \text { I6.1 }\end{array}$

50 per cent Decomposition of Hydrogen Peroxide with Colloidal Platinum (at $25^{\circ} \mathrm{C}$ ).

Conc. of $\mathrm{NaOH}$. $\quad \begin{array}{llllllll}0 & 0.002 & 0.008 & 0.031 & 0.125 & 0.25 & 0.5 & 1 \cdot 0\end{array}$ $\begin{array}{llllllllll}\text { Time in mins. } & . & 255 & 34 & 25 & 22 & 34 & 70 & 162 & 520\end{array}$

For comparison similar figures for three other processes are given: the first concerns the influence of bases $(\mathrm{NaOH})$ or acids $\left(\mathrm{H}_{2} \mathrm{SO}_{4}\right.$, indicated by a sign) on the rate of decomposition of tetanolysin at $50^{\circ} \mathrm{C}$., according to some measurements of my own. The addition of small quantities of both bases and of acids increases the decomposition in a marked degree. 
The third example is borrowed from Sörensen, and concerns the well-known influence of acids on the peptic digestion at $52^{\circ} \mathrm{C}$. The maximum occurs at a concentration of the hydrogen-ions equal to about O.OI normal, when the time of digestion is short ( $\mathrm{r}$ hour). If this time increases, the maximum moves to higher concentrations and lies at about 0.06 normal for 49 hours.

In order to show that similar effects are known from general chemistry, I have added an example dealing with the decomposition of hydrogen peroxide by means of colloidal platinum at $25^{\circ} \mathrm{C}$., according to measurements by Bredig and v. Berneck. Here we find a maximum of the velocity of reaction or a minimum of the time necessary to decompose 50 per cent (the quantity tabulated) when sodium hydrate is present to the concentration of about 0.02 normal.

If we investigate the influence of the concentration on the velocity of reaction we discover a new discrepancy between these reactions and ordinary monomolecular reactions. If we use sugar solutions of moderate concentration (about ro per cent) and vary the concentration of the invertase, we find that the reaction constant remains unchanged, i.e. the quantity of sugar decomposed in unit of time is proportional to the concentration of the enzyme. But if we change the concentration of sugar, keeping that of invertase constant, we arrive at quite different results, as is seen from the following figures of Henki, which indicate the number $(n)$ of milligrammes of sugar inverted during the first minute, 
if the concentration of the sugar is c-normal. $c=I$ indicates 342 grammes per litre.

$$
\begin{array}{lcccccccc}
c=0.01 & 0.025 & 0.05 & 0.1 & 0.25 & 0.5 & \text { I } & 1.5 & 2 \\
n=0.5 S & 1.41 & 2.40 & 2.96 & 4.65 & 5.04 & 4.45 & 2.82 & 1.15
\end{array}
$$

As will be seen from these figures, $u$ is at first nearly proportional to $c$, then it slowly reaches a very flat maximum at $c$ about $=0.5$ normal, and subsequently falls at very high concentrations, at which the solvent may be regarded as changed. ADrian J. Brown has reached similar results.

In general chemistry we are accustomed to find that the transformed quantity is proportional to the concentration of the reacting substance, as is the case in the figures above, when $c$ does not exceed 0.03 normal or about I per cent. But this is not at all true at higher concentrations. It has been found that this peculiar effect is due to the formation of a compound of the invertase with the sugar or its products of decomposition. The compound, into which the cane-sugar enters, is really the substance subject to decomposition. With small quantities of sugar (and not too insignificant quantities of enzyme) the quantity of the compound is proportional to the concentration of the sugar; later on the said quantity tends to a maximum, dependent on the quantity of enzyme present. Therefore also the quantity of sugar decomposed in one minute tends to reach a flat maximum as is also indicated by the observations.

Micinelis and Mentinen have investigated this question very thoroughly, and found that all observations are in good agreement with the hypothesis here 
adopted. We may therefore say, that the observed discrepancy from the general laws is more seeming than real.

The compounds of enzyme and reacting substance seem to play a very important rôle in this domain, and there is still much work to be done in order to elucidate the consequences of this circumstance. Peculiarly enough some experiments of MADSEN and Teruuchi on the decomposition of vibriolysin by means of animal charcoal give similar results, namely, that the decomposed quantity $(\mathrm{K} c)$ in unit of time is nearly independent of the concentration of the lysin, as is seen from the following figures obtained at $\mathrm{I} 2.5^{\circ} \mathrm{C}$. $c$ is the concentration in arbitrary units, $\mathrm{K}$ the velocity of reaction.

\begin{tabular}{|c|c|c|}
\hline $\begin{array}{c}\text { Concentration of } \\
\text { Lysin } c .\end{array}$ & K. $10^{4}$ & $\mathrm{~K} c .10^{6}$. \\
\hline 0.01 & 704 & 704 \\
\hline 0.02 & 375 & 750 \\
\hline 0.04 & 219 & 876 \\
\hline 0.06 & I 43 & 858 \\
\hline 0.08 & 105 & 840 \\
\hline 0.10 & 87 & 870 \\
\hline 0.12 & 62 & 744 \\
\hline O. I 4 & 56 & 722 \\
\hline
\end{tabular}

The velocity of reaction is nearly inversely proportional to the concentration, so that the product $\mathrm{K} c$, which is proportional to the quantity of lysin decomposed in unit time, is nearly independent of the concentration. At very small concentrations we observe an increase of $\mathrm{K}$ with the concentration 
and thereafter a flat maximum. Every particle of carbon decomposes a certain quantity of lysin in unit time, independently of its concentration. Here it is difficult to suppose that the carbon-particles enter into compounds with the lysin. Probably the explanation is that the decomposed lysin forms a covering of the particles, and that this covering

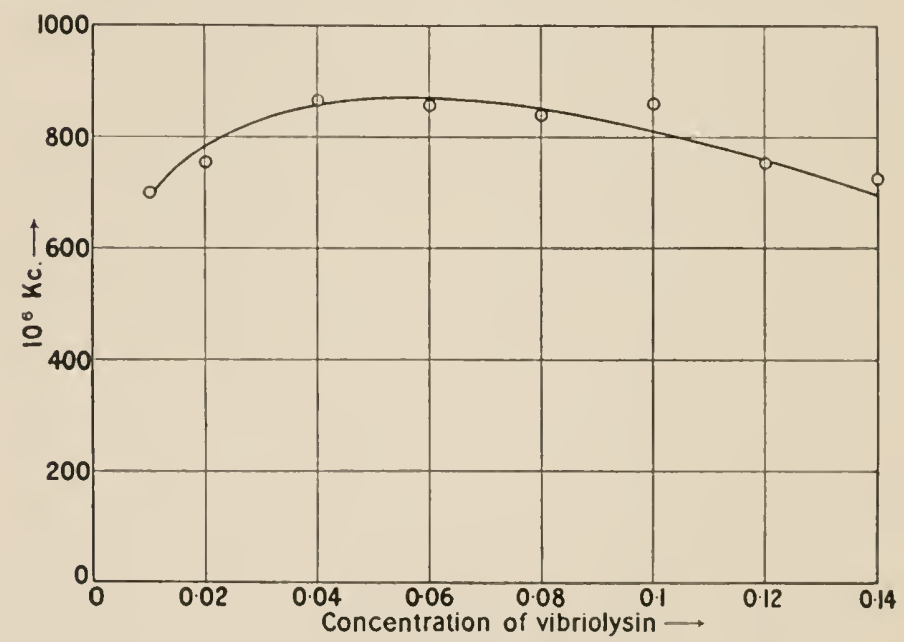

Fig. 6.

diffuses away, giving place for new lysin-molecules at a certain rate nearly independent of the concentration of the solution. The velocity of decomposition is proportional to the number of carbon-particles, which regularity is easily understood. Fig. 6 gives a graphic representation of the value Kc. $10^{6}$.

The problem of this kind which has attracted the greatest interest among biochemists is that of digestion. As is natural, most experiments on that 


\section{VELOCITY OF REACTIONS}

question have been made "in vitro." In ${ } S_{5}$ E. Sснütz added different amounts of pepsin to solutions of a given quantity of egg-albumen. The mixture was then diluted to Ioo cc. and kept at $37.5^{\circ} \mathrm{C}$. for sixteen hours. After this the albumen was removed and the quantity of its product of decomposition, peptone, determined polarimetrically. SchüTz found that this quantity $x$ is proportional to the square root of the quantity $q$ of pepsin added. His experiments were repeated by Julius Schütz in 1900 . He determined the quantity of peptone as proportional to the quantity of nitrogen remaining in the solution after coagulation of the albumen. His results are seen from the following table:

\begin{tabular}{|c|c|c|c|c|c|c|}
\hline$q$. & x. & 4. & 9. & 16. & 25. & $3^{6 .}$ \\
\hline $10^{4} x$ (observed) & 212 & $47 \mathrm{I}$ & 652 & 799 & 935 & $103 \mathrm{I}$ \\
\hline IO $x$ (calculated) & 213 & 426 & 639 & 852 & 1065 & 1278 \\
\hline
\end{tabular}

As is seen from the diagram (Fig. 7) representing the so-called "Schürz's rule," which says that the action is proportional to the square root of the quantity of enzyme, this rule is only approximatively true. At higher values of $q$ the digested quantity $x$ falls short of the one calculated in accordance with the rule.

In I895 SjöQvist made a very elaborate investigation on peptic digestion. He varied both the quantity of pepsin and the length of time. The temperature was $37^{\circ} \mathrm{C}$., i.e. that of the human 
body. In JoO cc., which were 0.05 normal with reference to hydrochloric acid and contained 2.23 grammes of egg-albumen, he ciissolved $2 \cdot 5,5$, I 0 , or $20 \mathrm{cc}$. of a pepsin preparation. He determined the molecular electric conductivity of the solution

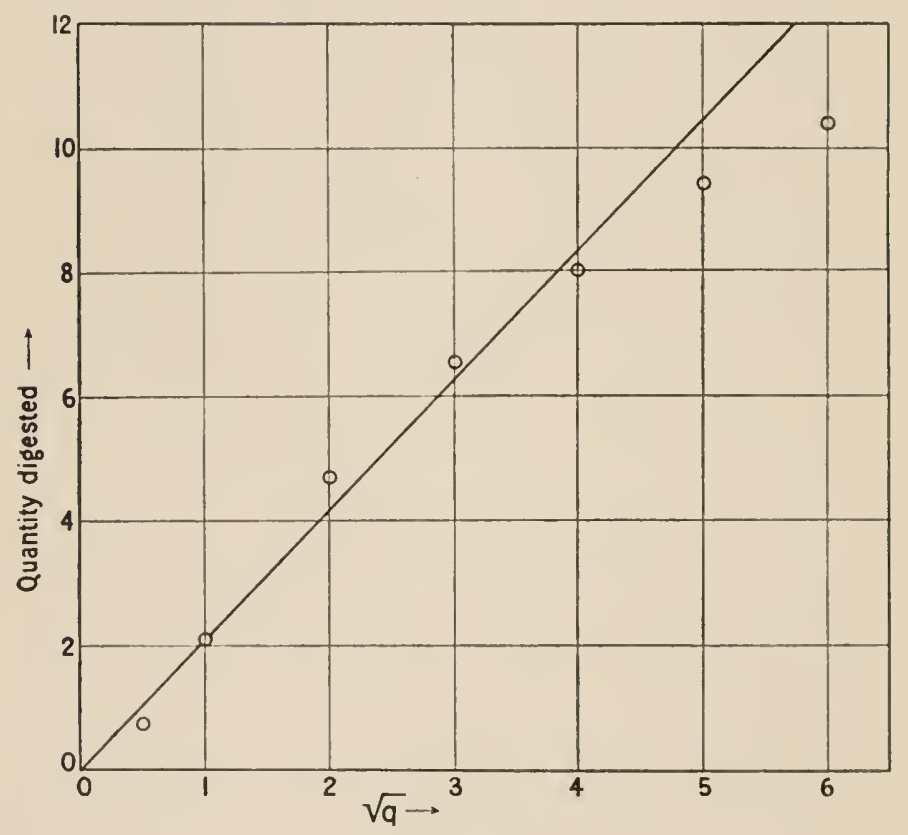

FIG. 7 .

which fell from an initial value of $\mathrm{ISS}_{4} 4$ units (Siemens) to an end-value of about $S_{3} \cdot 4$ units. The change of conductivity was taken as a measure of the quantity digested. In the accompanying diagram (Fig. 8) the square root of the time from the beginning of the experiment is taken as abscissa, the change $\Delta$ of conductivity from the original 
value I 88.4 as ordinate. The curves drawn are calculated by means of a formula given below. The rule of Schütz is given by the tangent at the origin to the curve; it is represented by a broken line and agrees with experiment till about 50 per cent are digested.

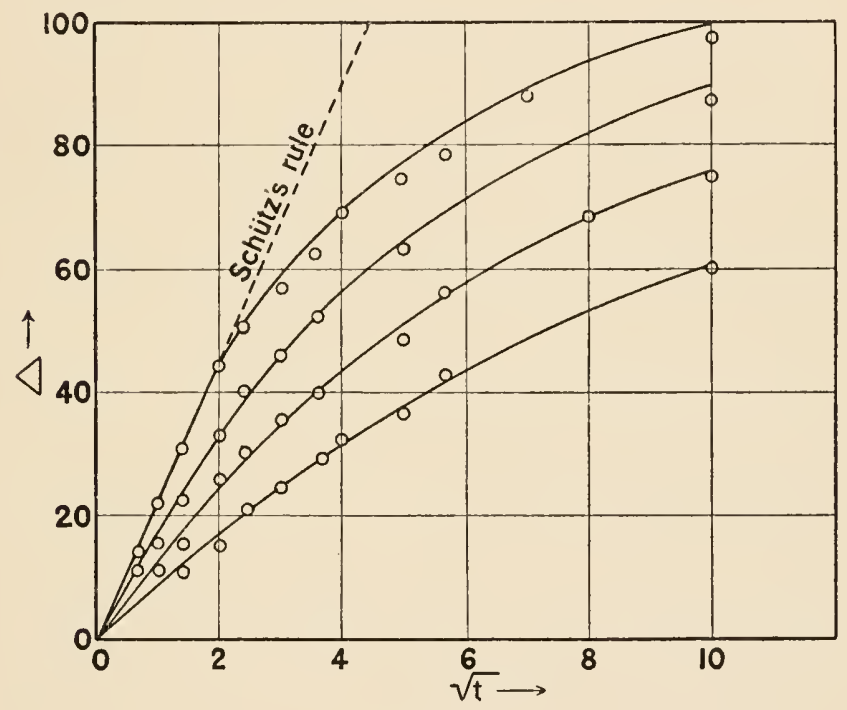

FIG. 8.

As is seen from the diagram, the observed values indicated by circles lie below the theoretical curve represented by the formula on p. 42 (the line drawn) for high values of $t$ and above it for low values of $t$. The explanation of this behaviour is obvious. It is supposed that every molecule of the peptone, formed by the decomposition of the albumen, binds an equivalent quantity of the 
hydrochloric acid present and thereby diminishes the conductivity just as the addition of a base, $\operatorname{c.g}$. ammonia, would do. Now peptone is a so-called amphoteric electrolyte, which acts both as an acid and as a base. But its acid character is much stronger than the basic one, which is extremely weak. Therefore, the salts of peptone with acids are hydrolysed in a very high degree. With a great excess of acid $(\mathrm{HCl})$, as for the parts of the peptone first formed, the binding may be nearly complete, but the salt of the last parts is highly hydrolysed, and a great deal of them, and therefore also of the acid, remains in a free state. Consequently, the values of $\Delta$ are lower than those given by the hypothesis on which the calculation of the quantity of peptone formed is based. Even the neutralization of the acid hampers the reaction (cf. p. 32 ).

If we now compare the values of $\Delta$ for equal values of $q t$ in the four different series, we find that $\Delta$ is equal in the four cases, as is seen from the following table :

\begin{tabular}{|c|c|c|c|c|c|c|c|c|c|c|}
\hline$g t=$ & 0.05 & 0.1 & 0.2 & 0.4 & 0.8 & 1.6 & 3.2 & $4 \cdot 8$ & 6.4 & $9 \cdot 6$ \\
\hline $\begin{aligned} y= & 0.025,1= \\
& 0.05 \\
& 0.1 \\
& 0.2\end{aligned}$ & $\begin{array}{r}11 \cdot 1 \\
10 \cdot 2 \\
9 \cdot 2 \\
\ldots\end{array}$ & $\begin{array}{l}17 \cdot 3 \\
15 \cdot 6 \\
14 \cdot 2 \\
12 \cdot 4\end{array}$ & $\begin{array}{l}23 \cdot 9 \\
23 \cdot 7 \\
22 \cdot 5 \\
20 \cdot 6\end{array}$ & $\begin{array}{l}32 \cdot 0 \\
32 \cdot 9 \\
33 \cdot 6 \\
30 \cdot 3\end{array}$ & $\begin{array}{l}42 \cdot 2 \\
43 \cdot 2 \\
45 \cdot 2 \\
43 \cdot 7\end{array}$ & $\begin{array}{l}53 \cdot 4 \\
55 \cdot 3 \\
57 \cdot 5 \\
55 \cdot 4\end{array}$ & $\begin{array}{l}67 \cdot 0 \\
69 \cdot 0 \\
66 \cdot 5\end{array}$ & $\begin{array}{l}\cdots \\
74 \cdot 0 \\
75 \cdot 3 \\
73 \cdot 6\end{array}$ & $\begin{array}{c}\cdots \\
79 \cdot 3 \\
78.6\end{array}$ & $\begin{array}{l}\text { S6.6 } \\
\text { S6.I }\end{array}$ \\
\hline $\begin{array}{l}\text { Mean value of } \\
د= \\
49 \cdot 2 \sqrt{y t}=\end{array}$ & $\begin{array}{l}102 \\
11\end{array}$ & $\begin{array}{l}14.9 \\
15.6\end{array}$ & $\begin{array}{l}22 \cdot 7 \\
22\end{array}$ & $\begin{array}{l}32 \cdot 2 \\
31 \cdot 1\end{array}$ & $\begin{array}{l}43 \cdot S \\
44\end{array}$ & $\begin{array}{l}55 \cdot 4 \\
62 \cdot 2\end{array}$ & $\begin{array}{l}67 \cdot 6 \\
58\end{array}$ & $\begin{array}{c}74 \cdot 3 \\
\ldots\end{array}$ & $\begin{array}{l}79 \cdot 0 \\
124.4\end{array}$ & 86.4 \\
\hline
\end{tabular}

From this we observe that the rule of Scrüry 
is very nearly right till $q t$ reaches the value $0 \cdot 8$, when about 50 per cent of the end-value of $\Delta$ is reached, as is seen in comparing the last two lines.

We have here a typical example of two laws of peptic digestion which have long been stated. The second one, that at constant temperature $\Delta$ is dependent only on the value of $q t$, is in perfect agreement with the general laws of the velocity of reaction. But the first one, which is represented by Schütz's rule, before 50 per cent are transformed, was regarded as absolutely incompatible with those laws. It was said that the organic ferments behave in quite a different manner from common catalytic substances.

In order to show that this assertion is not true I investigated the case when ammonia acts upon ethyl acetate in great excess. I found that the rule of SchüTz is valid also in this case until about 50 per cent of the ammonia is used up by the formation of ammonium acetate. (See the fourth column in the following table, which is calculated according to Schürz's rule; $x$-obs. are the observed values.) I had therefore found a case absolutely analogous to that of peptic digestion. The circumstance which causes the deviation from the common law of a monomolecular reaction is that the quantity of $\mathrm{OH}$-ions dissociated from the ammonia is much diminished by the presence of the ammonium acetate. In reality this quantity is nearly inversely proportional to the quantity of ammonium acetate formed, except for the first 
moments. With help of this regularity it is easy to deduce the general law for the phenomenon. It is given by the formula

$$
\mathrm{A} \log _{e} \frac{\mathrm{A}}{\mathrm{A}-x}-x=\mathrm{K} q t,
$$

where $\mathrm{A}$ is the quantity of ammonia at the beginning of the experiment, $x$ the quantity of ammonia transformed into ammonium acetate at the time $t, \mathrm{~K}$ the constant of the reaction and $q$ the quantity of the ester. The $x$-values calculated by means of this formula are tabulated in the third column and agree very well with $x$-obs. At the commencement, before $x$ has reached too high values, this equation gives

$$
x=\sqrt{\mathrm{K} \cdot \mathrm{A} \cdot q \cdot t},
$$

which is the rule of ScHürz, according to which $x$ is proportional to the square root of $\mathrm{A} t$ for constant value of the quantity $q$ of ethyl acetate or eggalbumen. 
Inorganic Analogy to Schütz's Rule, $\mathrm{NH}_{3}$ AND

Ethyl Acetate

\begin{tabular}{|c|c|c|c|}
\hline $\begin{array}{c}\text { Time, } t \\
\text { (minutes). }\end{array}$ & $x$-Obs. $\%$ & $x$-Calc. & $\begin{array}{c}17.3 \sqrt{t} \\
\text { (Schütz's rule). }\end{array}$ \\
\hline I & $17 \cdot 5$ & I 9.4 & $17 \cdot 3$ \\
\hline 2 & $25 \cdot 5$ & $25 \cdot 2$ & $24 \cdot 5$ \\
\hline 3 & 30.7 & 30.4 & $29 \cdot 7$ \\
\hline 4 & $34 \cdot 7$ & 34.9 & $34 \cdot 6$ \\
\hline 6 & $4 I \cdot 5$ & $4 \mathrm{I} \cdot 7$ & $42 \cdot 4$ \\
\hline 8 & $47 \cdot 0$ & $46 \cdot 9$ & 48.0 \\
\hline IO & $5 \mathrm{I} \cdot 2$ & $5 \mathrm{I} \cdot 3$ & $54 \cdot 7$ \\
\hline I 5 & 59.6 & $59 \cdot 7$ & 67.0 \\
\hline 22 & $67 \cdot 5$ & $68 \cdot 0$ & $8 \mathrm{I} \cdot \mathrm{I}$ \\
\hline 30 & 74.5 & $74 \cdot 7$ & $94 \cdot 7$ \\
\hline 40 & $80 \cdot 7$ & $80 \cdot 7$ & $109 \cdot 4$ \\
\hline 60 & 88.2 & 88.2 & 134.0 \\
\hline
\end{tabular}

$x$-Calc. from $\mathrm{A} \log _{e}[\mathrm{~A}:(\mathrm{A}-x)]-x=\mathrm{K} q t$.

This deduction not only proves that the rule of Scrütz is the indication of a special case of a monomolecular process, but it shows also that the transformed quantity is proportional to the square root of the quantity $q$ of the substrate. Further, it gives the general law for the whole process and not only for its beginning. Whenever we find that the transformed quantity is a function of A $q t$ only this circumstance gives an indication that the process studied is of the monomolecular type.

We will in the following find a great number of very important biochemical processes which show this characteristic feature.

As we have seen above, peptic digestion is also, to a great extent, dependent on the presence of free 
acid. Its optimum lies at a hydrogen-ion concentration of about $\mathrm{IO}^{-2}$ at the beginning and $6 \cdot \mathrm{IO}^{-2}$ after forty-eight hours. This probably depends upon the binding of the hydrochloric acid by the formation of peptone. The action of the acid probably depends upon the circumstance that the salt of albumen with an acid is more easily digested than the albumen itself. A great excess of acid diminishes the activity of the enzyme, probably by its decomposition. In this way the presence of an optimum is easily understood.

BAyliss has investigated the process of tryptic digestion. In this case an excess of base is necessary for the reaction. His figures indicate that digestion by means of trypsin proceeds in a manner analogous to the peptic one; the process is therefore probably a monomolecular one. The following little table from MADSEN's and WALBUm's investigations prove the validity of the $q t$-law in this case as well as for peptic digestion. Here $t$ is the time which, at a given temperature, is necessary for reaching a certain degree of digestion, characterized by a corresponding degree of liquefaction of the gelatinous jelly, when the concentration $q$ of the enzyme is used.

According to the qt-rule, the half quantity of enzyme needs the double time for producing the same effect as the whole quantity, and so forth. 
Digestion OF THYMOL-GELATINE

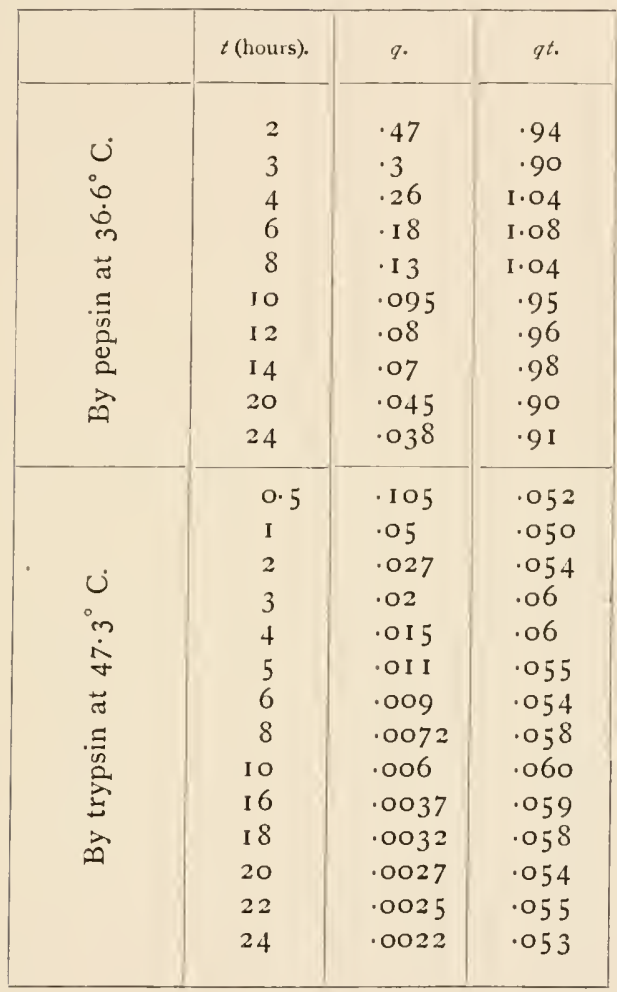

The same is the case with the action of rennet on milk. The $q t$-rule, which indicates that the action is only dependent on the product $q t$, is proved by a great number of experiments of MADSEN and WaLbum, as is indicated by the following table. In this case the liquid slowly loses its fluidity. Therefore we measure the time needed for producing a certain easily observable degree of stiffness of the milk. 
Coagulation of Milk by Rennet, $36.55^{\circ} \mathrm{C}$.

\begin{tabular}{|c|l|l||c|c|c|}
\hline$t$ (minutes). & $3 \cdot$ & $q t$. & $t$ (minutes) & $q$. & $q t$. \\
\hline 4 & 8 & 32 & 50 & .5 & 25 \\
6 & 5 & 30 & 70 & $\cdot 4$ & 28 \\
9 & $3 \cdot 3$ & 30 & 80 & $\cdot 32$ & 26 \\
12 & $1 \cdot 9$ & 23 & 100 & .28 & 28 \\
20 & $1 \cdot 3$ & 26 & 120 & .25 & 30 \\
30 & .7 & 21 & 180 & .185 & 33 \\
35 & .7 & 25 & 240 & .167 & 40 \\
\hline
\end{tabular}

The same rule is valid for the digestion of gelatine by a substance produced by Bacillus pyocyaneus. By its action the gelatine is liquefied. The time of liquefaction $t$ is inversely proportional to the quantity $q$ of pyocyaneus ferment used. The figures given in the following table, borrowed from Madsen and Walbum, give a proof of the $q$ t-law.

Digestion of Thymol-gelatine by Means of Pyocyaneus CUITURE AT $34.5^{\circ} \mathrm{C}$.

\begin{tabular}{|l|l|l||l|l|l|}
\hline$t$ (hours). & $q$. & $q t$ & $t$ (hours). & $q$. & $\eta t$ \\
\hline & & & & \\
\hline 0.5 & 1.6 & .80 & 8 & .11 & .88 \\
1 & .8 & .80 & 10 & .09 & .90 \\
2 & .46 & .92 & 12 & .08 & .96 \\
3 & .3 & .90 & 16.5 & .06 & .99 \\
4 & .22 & .88 & 18 & .044 & .79 \\
4.5 & .2 & .90 & 20 & .042 & .84 \\
6 & .165 & .99 & 25 & .035 & .88 \\
\hline
\end{tabular}

The saponification of fats by the steapsin from the pancreatic juice is another example of the 
applicability of Schürz's rule and of the $q t$-law. In this case the fat is suspended in the form of drops in the liquid. Also, according to SjöQvist's investigation, the digestion of coagulated egg-albumen (i.e. in a solid form) obeys the same laws.

In general we find that the generalization of Schürz's rule and the $q t$-law are valid for a large number of processes which are of importance for animal life, such as the action of stomachical or pancreatic juice on albuminous substances or on fats.

Even for digestion "in vitro" the simple monomolecular formula is sometimes found to hold good, just as strong bases such as sodium hydrate follow this law when saponifying a great excess of ester. Thus, for instance, EUler found this to be the case in the digestion of glycyl-glycine by means of erepsin, an enzyme from the intestinal mucous membrane. The same is true for the saponification of triacetate of glycerol by means of powdered castor-beans, whereas higher fats under similar conditions are subject to ScHütz's rule.

In order to illustrate this regularity we give some figures of Euler. The first table refers to the katalytic action of a "katalase" contained in the juice of the mushroom Boletus scaber on the decomposition of hydrogen peroxide at $15^{\circ} \mathrm{C}$. The quantity $q$ of hydrogen peroxide present in a solution containing $3 \mathrm{cc}$. of the mushroom juice in $200 \mathrm{cc}$. was determined at different times $(t$ in minutes) by means of titration with permanganate. 
The second table gives the results of an experiment on saponification of a concentrated aqueous solution of ethyl butyrate at $35^{\circ} \mathrm{C}$. by means of a lipase extracted from lard. $q$ indicates the quantity of non-decomposed ethyl butyrate determined by measuring the butyric acid set free after a time of $t$ minutes. The acidity was measured by titration with a solution of barium hydrate. In both tables $K$ represents the value of the constant of velocity of reaction calculated by means of the formula for monomolecular reactions :

$$
\mathrm{K}=\frac{\mathrm{I}}{t} \log \frac{q_{0}}{q}
$$

KATALYSIS OF $\mathrm{H}_{2} \mathrm{O}_{2}$ AT

$15^{\circ} \mathrm{C}$.

\begin{tabular}{|c|c|c|c|}
\hline$t$ & g. & & K. \\
\hline $\mathrm{O}$ & 8.0 & & $\ldots$ \\
\hline 6 & 6.9 & & 0.0107 \\
\hline 12 & $5 \cdot 8$ & & 0.0116 \\
\hline 19 & 5.0 & & 0.0107 \\
\hline \multirow[t]{2}{*}{55} & $2 \cdot 5$ & & 0.0100 \\
\hline & & Mean & 0.0107 \\
\hline
\end{tabular}

SAPONIFICATION OF ETHYL BUTYRATE AT $35^{\circ} \mathrm{C}$.

\begin{tabular}{|c|c|c|c|}
\hline$t$. & q. & & K. \\
\hline o & 2.70 & & $\ldots$ \\
\hline 2 & 2.40 & & 0.0256 \\
\hline 6 & I.95 & & 0.0235 \\
\hline 9 & 1.65 & & 0.0237 \\
\hline \multirow[t]{2}{*}{16} & 1.05 & & 0.0250 \\
\hline & & Mean & 0.0245 \\
\hline
\end{tabular}

The constant $K$ does not in either case vary more than may be due to experimental errors. The constancy of $\mathrm{K}$ in each case indicates that the law for monomolecular reactions is really fulfilled. This is due to the circumstance that the products of reaction do not chemically interfere with the reagents. 


\section{CHAPTER III}

THE INFLUENCE OF TEMPERATURE ON THE VELOCITY OF REACTIONS-REACTIONS OF CELLS

In general reactions proceed very much more rapidly at higher than at lower temperatures. A very wellknown exception is the breaking down of radioactive substances, which seems to be wholly independent of temperature. The influence of the temperature is given by the formula

$$
K_{1}=K_{0} e^{\frac{\mu}{2}\left(\frac{T_{1}-T_{0}}{T_{0} T_{1}}\right)}
$$

where $T_{0}$ and $T_{1}$ are two temperatures reckoned from the absolute zero. $\mathrm{K}_{0}$ is the velocity of reaction at the temperature $T_{0}$, and $\mathrm{K}_{1}$ that at $\mathrm{T}_{1} ; \mu$ is a constant. The greater $\mu$ is the more rapidly the velocity of reaction increases with temperature. For radioactive substances $\mu$ is zero.

If $\mathrm{T}_{0}$ and $\mathrm{T}_{1}$ are not too far from each other, the value of $\mathrm{T}_{0} \mathrm{~T}_{1}$ does not change very much in the interval from $T_{0}$ to $T_{1}$ and then the formula may be written :

$$
\mathrm{K}_{1}=\mathrm{K}_{0} e^{c\left(\mathrm{~T}_{1}-\mathrm{T}_{0}\right)} \text { or } \log \mathrm{K}_{1}-\log \mathrm{K}_{0}=c\left(\mathrm{~T}_{1}-\mathrm{T}_{0}\right)
$$




\section{INFLUENCE OF 'TEMPERA'TURE}

with sufficient accuracy. $\log \mathrm{K}$ is therefore very nearly a linear function of the temperature, as represented by the diagrams Figs. 9 and 10.

We may give some few instances showing this relation. In Fig. 9 the value of $\mathrm{T}_{0}$ is $5 \mathrm{I}^{\circ} \mathrm{C}$. for haemolysin, $45 \cdot 15^{\circ} \mathrm{C}$. for vibriolysin and $60^{\circ} \mathrm{C}$. for haemoglobin. In the last case the scale is reduced

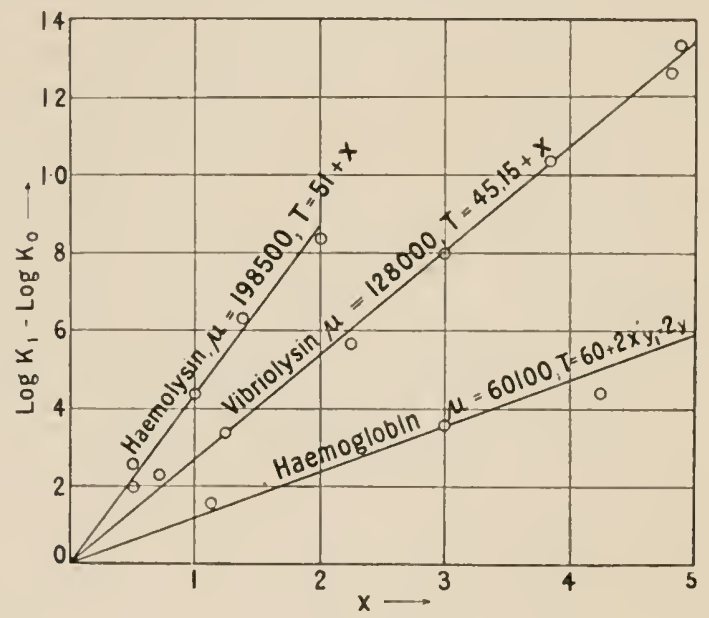

Fig. 9.

to half size by putting $y_{1}=2 y$ and $\mathrm{T}=60+2 x$. In Fig. Io the $T_{0}$ values are $0.5^{\circ} \mathrm{C}$. for vibriolysin with blood-corpuscles, $14.5^{\circ} \mathrm{C}$. for egg-white, $3.3^{\circ} \mathrm{C}$. for vibriolysin with carbon, and $13.9^{\circ} \mathrm{C}$. for the precipitin. In the third case the scale is reduced to two-thirds by putting $y_{1}^{\prime}=1 \cdot 5 y^{\prime}$ and $\mathrm{T}=3 \cdot 3+\mathrm{I} \cdot 5 x$.

As is seen from the diagram (Fig. 9), for the spontaneous decomposition of a hacmolysin from goat's 


\section{INFLUENCE OF TEMPERA'TURE 51}

serum, the spontaneous decomposition of vibriolysin and the coagulation (by heat) of haemoglobin, which process may also be regarded as due to a spontaneous decomposition (with hydration), the value $\left(\log K_{1}-\log K_{0}\right)$ as a function of temperature may be represented by a straight line. In these cases the observed interval of temperature is only about

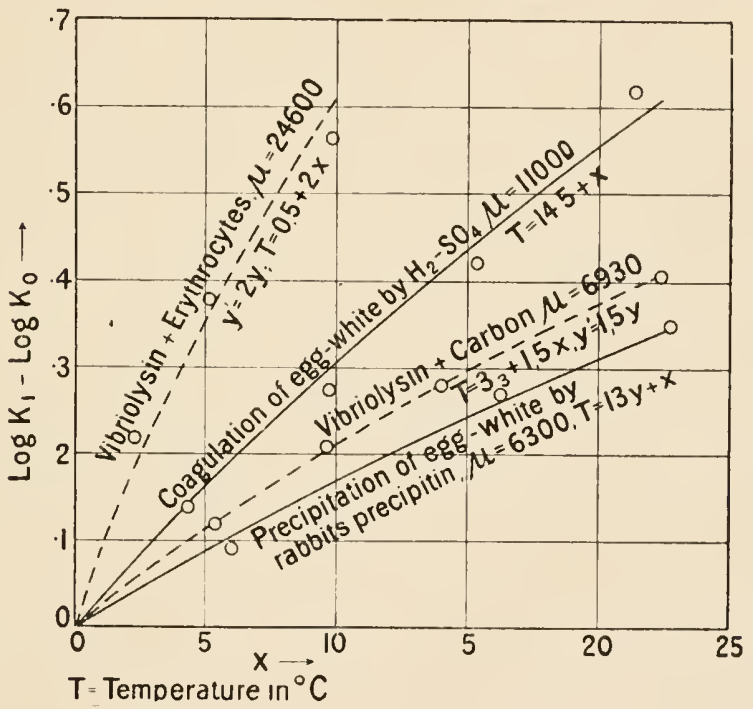

FIG. 10.

$9^{\circ}$ C. or less. In the next diagram (Fig. Io) the range of temperature is greater, $20^{\circ}-30^{\circ} \mathrm{C}$. Here the straight line does not fit so well; the general formula given above represents the observations better. The values calculated from this formula are given by the lines drawn in the diagram. These are dotted for the heterogeneous systems, which behave just as the homogeneous ones. 
Instead of measuring the velocity of reaction by means of determinations at arbitrary stages of the reaction, we may also determine it by evaluating the time which is necessary for reaching a certain point of the process, for instance that at which 50 per cent of the original substance is transformed. It is also sometimes possible to decide how long the process takes to reach practically its end-value, as is, for instance, done in the measurement on the time of fermentation by Jodlbauer (cf. p. 60). This method has also been used in MADsEn's experiments on the digestion of gelatine, where he determined how long it took for a certain quantity of pepsin or trypsin or another proteolytic ferment to liquefy the jelly. An analogous case is also the observation of the time necessary for clotting milk by means of rennet. In the same manner we determine the time for total haemolysis or total bacteriolysis, when all bacteria are killed.

In these cases the velocity of reaction is inversely proportional to the time necessary for the reaction. In this manner Gros determined the time necessary for total haemolysis in hot water at different temperatures. His determinations give a value $\mu=63,700$. I have repeated these determinations over a greater interval of temperature. I found the following values:

$$
\begin{array}{lllll}
\text { Tempcraturc }\left({ }^{\circ} \mathrm{C} .\right) & \cdot 50 \cdot 6 & 54 \cdot 3 & 58 \cdot 2 & \\
\text { Time (minutes) } & \cdot 570 & 188 & 57 & \mu=64,200 .
\end{array}
$$

The logarithms of these times are plotted in the following diagram (Fig. I1), which gives a very 
good straight line for the haemolysis. In the same diagram are included some determinations by $\mathrm{M}$ iss $\mathrm{H}$. CHIck regarding the time necessary for killing Bacillus typhosus in hot water at different temperatures. As the observed interval of temperature is

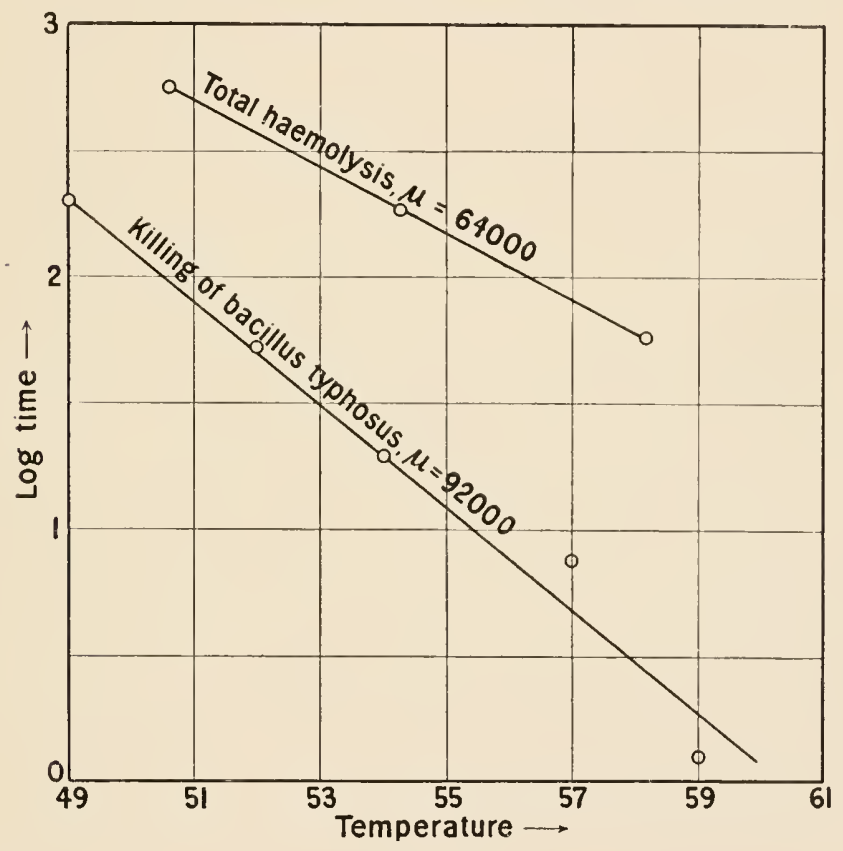

FIG. II.

rather small, $10^{\circ} \mathrm{C}$. or less, they give a straight line, within the rather great errors of observation, and a value of $\mu=92,000$. This is about twice as great as the $\mu$-value $=48,600$ found for disinfection of Bacillus paratyphosus by means of phenol (between $6^{\circ}$ and $36^{\circ}$ C.). Cf. p. 55 . In the same manner the $\mu$-value for haemolysis by means of hot water 


\section{INFLUENCE OF 'TEMPERA'TURE}

$(\mu=64,000)$ is about double that for haemolysis by means of poisons (acids, bases, lysins ; $\mu=25,000$ to $\mu=30,000)$. Cf. p. 66 .

In the following table we give the results of the determinations of $\mu$ in this field together with some few figures taken for comparison from general chemistry :

Spontancous Destructions.

Dibromsuccinic acid

Compound haemolysin

Tetanolysin

Vibriolysin

Rennet, 2 per cent

Pepsin, 2 per cent

Trypsin, 2 per cent

Emulsin, 0.5 per cent .

dry .

Lipase from castor-beans, heterogeneous

Invertase from yeast

$$
\begin{array}{rr}
\mu= & 22,200 \\
\text {. } & 198,500 \\
\text {. } & 162,000 \\
\text {. } & 128,000 \\
\text {. } & 90,000 \\
\text {. } & 75,600 \\
\text {. } & 62,000 \\
. & 45,000 \\
\text {. } & 26,300 \\
\text {. } & 26,000 \\
. & 72,000
\end{array}
$$

\section{1)igestions.}

Casein by trypsin

37,500

Coli-agglutinin by trypsin

16,500

Gelatin by trypsin

I 0,570

pepsin

Egg-white by pepsin .

l'owdered casein by trypsin

I 0,750

15,570

7,400

Saponifications.

Ethyl acetate by bases

11,150 acicls

Cotton oil by powdered castor-beans

17,400

7,540

Triacetin

". juice

16,700

I 3,600

Coagulation, Precipitation.

Egg-white by heat

135,600

60,100

Haemoglobin by heat .

Milk by rennet

20,650 
Egg-white by sulphuric acid

I I , OOO

" precipitin from rabbits . . 6,300

Agglutination of coli-bacilli . . . 30, roo

" typhoid-bacilli . . 37,200

Different Processes.

Hydrolysis of cane-sugar by acids . . 25,600

invertase . $\quad$ I I,000

starch by amylase . . 12,300

Destruction of $\mathrm{H}_{2} \mathrm{O}_{2}$ by catalase . 6,200

Alcoholic fermentation by yeast-cells . . I 5,600

Haemolysis (by bases, acids, lysins) . 25,000 to 30,000

Assimilation by plants . . . I 2,000

Respiration by plants . . . . I 4,800

Cell-division in eggs (mean value) . . I 4, Ioo

Heart-beats of pacific terrapin . . . I6,060

Haemolysis by means of hot water . . 64,000

Bacteriolysis (B. typhosus) in hot water . 92,000

" (B. paratyphosus) in phenol . 48,600

From the tabulated values of $\mu$ we may conclude that $\mu$ is in general greater for spontaneous decompositions, among which we may reckon the coagulations by heat, than for processes in which a substance acts on another catalytically. The value of $\mu$ for dry emulsin lies also much below that which holds for solutions of this enzyme. This behaviour is probably general. Very remarkable also is the fact that different vital processes, alcoholic fermentation by means of yeast, assimilation and respiration of plants, cell-division in eggs and the heart-beats of a tortoise possess very nearly the same value of $\mu$, namely between 12,000 and 16,000 , which is of the same order of magnitude as the corresponding values for the hydrolysis of cane-sugar by invertase, or of starch by amylase, or the saponification of ethyl acetate by bases, or of triacetin by powdered 


\section{INFLUENCE OF 'TEMPERA'TURE}

castor-beans, or of yolk of egg by pancreatic juice. We may therefore say that the vital processes are in this special case very similar to processes in general chemistry.

It has often been said that there is a great difference between vital and ordinary chemical processes with respect to the influence of temperature upon them. It is a very common feature that vital and even enzymatic processes show an optimum of temperature. For instance, the assimilation process in plants goes on with a maximum velocity at about $37^{\circ} \mathrm{C}$., as is indicated by the investigations of Miss Gabrielle Matthaei (see Fig. i $2 a$ ). A very similar thing holds good for the inversion of canesugar by invertase, according to KJELdAHL (Fig. I $2 d$ ), and the coagulation of milk by rennet, according to FuLD's experiments (Fig. I $2 b$ ). The explanation of this fact is in reality very simple. The spontaneous destruction of, e.g., the saponifying lipase in castor-beans has a value of $\mu=26,000$, which is much greater than the corresponding value 7540 for the saponification of cotton oil by means of this lipase (according to Nicroux's measurements). Therefore at sufficiently high temperatures the enzyme is destroyed during the preliminary heating to this temperature before it is able to exert a sensible action on cotton oil. Hence a maximum effect of the lipase must occur at a temperature below that given.

Further, the velocity of reaction must in this special case decrease with time; at very low 


\section{INFLUENCE OF TEMPERATURE 57}

temperatures this peculiarity is insensible, but it

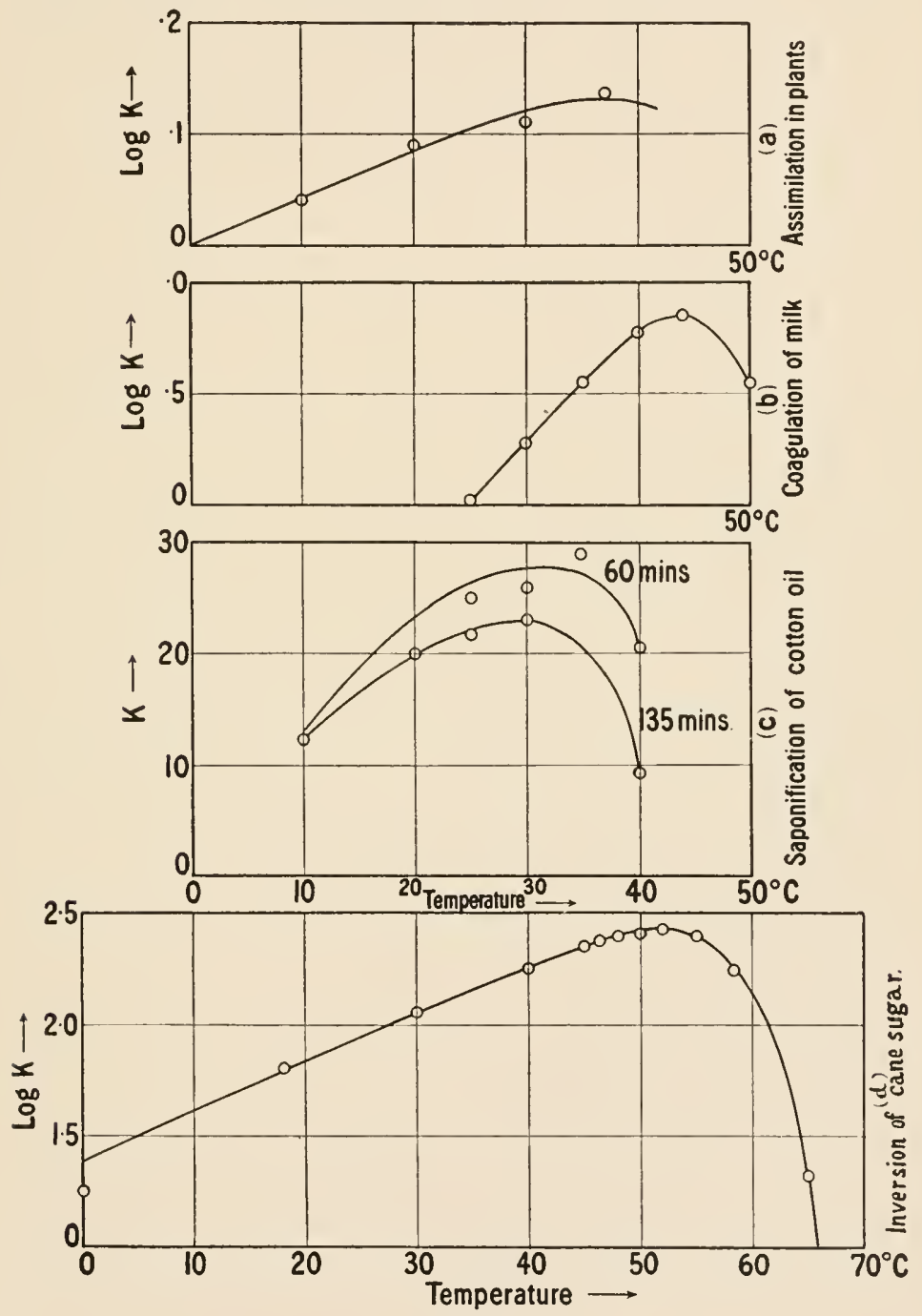

FIG. 12.

increases rapidly with temperature. This is seen 
from the diagram (Fig. I 2 c), representing observations of Nicloux, made 30,90 and I So minutes after the mixing of the cotton oil and the lipase. The mean velocity of reaction calculated from these figures corresponds to about 60 and I 35 minutes. The optimum falls at about $33^{\circ}$ and $30^{\circ} \mathrm{C}$. respectively at the two times of observation. From this observation it is quite clear why different authors give different values for the optimum temperature. They have not observed the influence of the time of heating. If this time were zero (which is impossible to realise) we would not observe any optimum. As is seen from the different curves of $\log \mathrm{K}$ or $\mathrm{K}$ (this last for Nicloux's figures) the fall of the $\mathrm{K}$-curve is exceedingly rapid when the temperature rises above the optimum one.

Regarding vital processes, it may be observed that the chief substance of living cells, the protoplasm, generally suffers at temperatures above $40^{\circ} \mathrm{C}$. and in most cases is killed above $55^{\circ}$ or $60^{\circ} \mathrm{C}$. Hence it is obvious that vital processes become hampered by temperatures above about $40^{\circ} \mathrm{C}$. A similar remark may be made regarding low temperatures. At about zero the aqueous solutions in the cell freeze and the life-processes are brought to a standstill. But even if freezing does not occur the vital processes are much hindered in the neighbourhood of zero.

As a general result of our investigation we may say that the influence of temperature on the velocity of different processes in which enzymes, organic 
products such as egg-white, or living cells, such as blood-corpuscles, bacilli, or even higher organisms such as eggs or plants are involved, follows the same law as is found for the influence of temperature on ordinary chemical processes. Attention may be drawn to the very high values of $\mu$ in

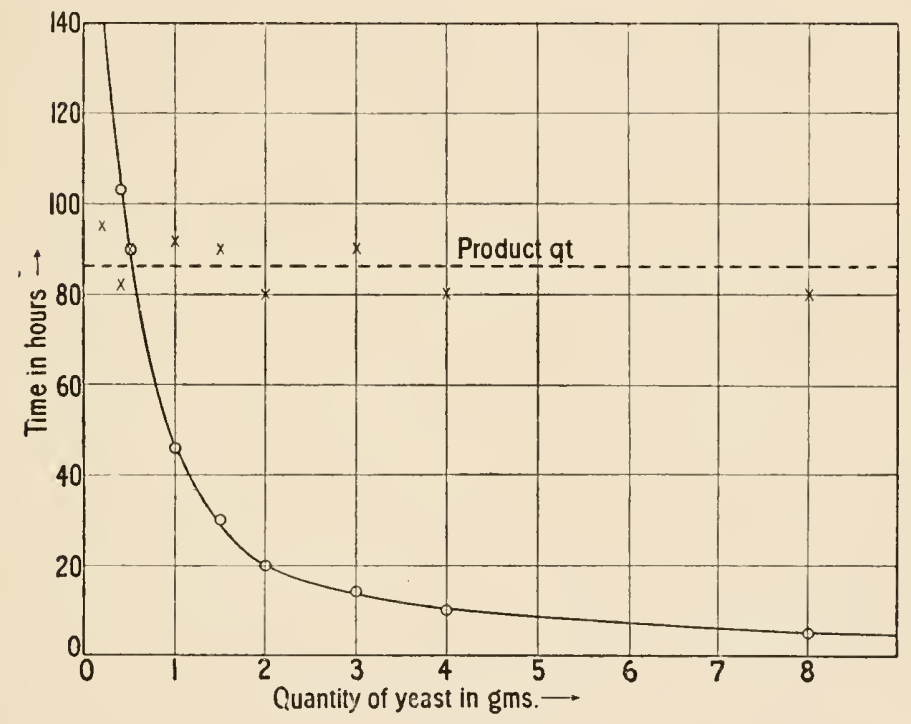

FIG. I3.

some cases of spontaneous destruction, coagulation or destruction of living cells (blood-corpuscles, bacteria).

The peculiarity that in many cases optimum temperatures are observed in life-processes or enzymatic actions is easily explained by the destructive influence of high temperatures on living cells or enzymes. No essential difference exists between 
the processes studied in general chemistry and those produced by living organisms or enzymes.

We are now in a position to consider some chemical processes in which simple cells such as yeast-cells, blood-corpuscles or bacteria act upon or are treated with chemical reagents, namely, the fermentation process by yeast-cells, the haemolysis by means of haemolytic poisons, the agglutination of bacilli by means of agglutinins or their killing by poisons (so-called disinfectants).

JODLBAUER determined the time which is necessary for the fermentation of a certain quantity of sugar ( $2 \mathrm{~g}$. in $50 \mathrm{cc}$.) when different quantities of yeast (in grammes) were added to the sugar solution. He found that the time necessary increases when the quantity of yeast decreases, and in such a manner that the product of these two quantities is constant, as is seen from the following table and the accompanying diagram (Fig. I 3 ). The $q$ t-law holds good, which indicates that the reaction is monomolecular.

Time of Fermentation (JodlbaUer)

\begin{tabular}{|l|r|r|}
\hline $\begin{array}{c}\text { Quantity } \\
\text { of Yeast. }\end{array}$ & $\begin{array}{c}\text { Hours of } \\
\text { Fermentation. }\end{array}$ & Product. \\
\hline 8 & 5 & 40 \\
4 & 10 & 40 \\
3 & 15 & 45 \\
2 & 20 & 40 \\
I.5 & 30 & 45 \\
I & 46 & 46 \\
.5 & 90 & 45 \\
.4 & 103 & 41 \\
.2 & 240 & 48 \\
\hline
\end{tabular}


RUBNER has carried out a much more elaborate series of experiments at $30^{\circ} \mathrm{C}$. He took the heat evolved, determined calorimetrically, as a measure of the quantity of sugar decomposed. He used in four different experiments the following quantities

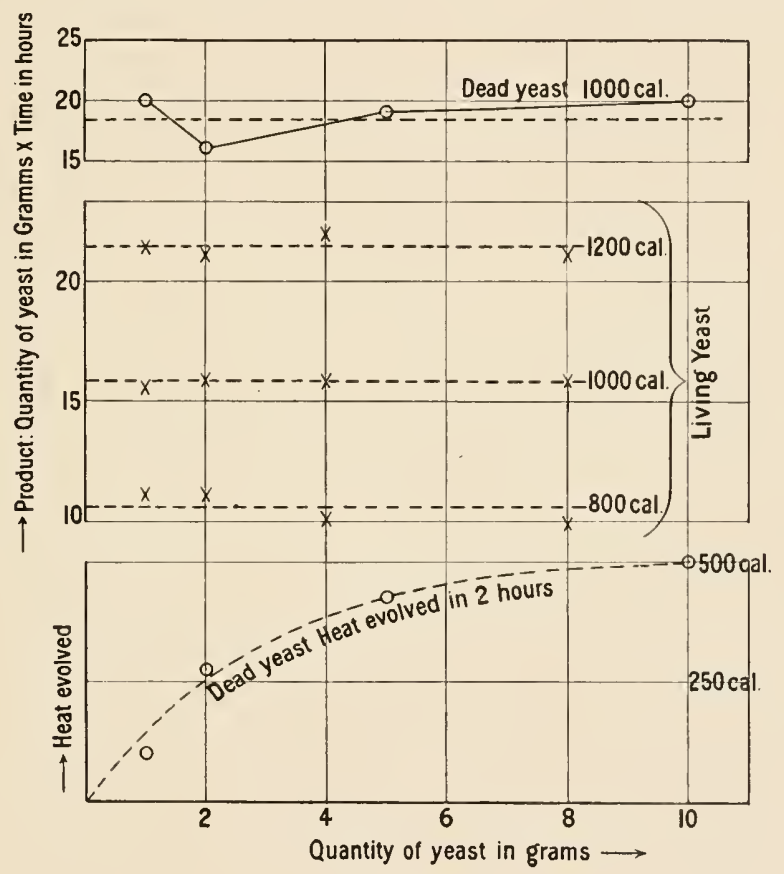

FIG. 14.

of yeast: I gramme, 2 grammes, 4 grammes and 8 grammes for a given quantity of cane sugar (50 grammes in $250 \mathrm{cc}$. solution), and found, as indicated by the figures below and the accompanying diagram (Fig. 14), that for a certain degree of decomposition, corresponding to an evolution of 800 or I 000 or I 200 gramme-calories, the product of quantity 
of yeast and time is nearly constant. According to these figures the rule of ScHürz nearly corresponds to reality. For if we take the mean values of the products in the three cases they are $21 \cdot 3,15.9$ and 10.4 , which are nearly proportional to the squares of I 200, I000 and 800 . If we divide the first figures by I.44, I.00 and 0.64 we find I $4 . S$, I 5.9 and 16.2, which lie very near to each other. In other experiments this regularity is less evident.

LIVING YEAST-CELLS (RUBNER)

\begin{tabular}{|c|c|c|}
\hline $\begin{array}{l}\text { Quantity } \\
\text { of Y'east. }\end{array}$ & Hours. & Product. \\
\hline 8 & 2.6 & 20.8 \\
\hline 4 & $5 \cdot 5$ & 22 \\
\hline 2 & 10.5 & 21 \\
\hline I & $21 \cdot 5$ & $2 \mathrm{I} \cdot 5$ \\
\hline 8 & 2 & 16 \\
\hline 4 & 4 & 16 \\
\hline 2 & 8 & 16 \\
\hline I & 15.5 & 15.5 \\
\hline 8 & I. 2 & 9.6 \\
\hline 4 & 2.5 & 10 \\
\hline 2 & $5 \cdot 5$ & II \\
\hline I & II & II \\
\hline
\end{tabular}

DEAD YEAST (RUINER) IOOO CALORIES

\begin{tabular}{|c|c|c}
\hline $\begin{array}{c}\text { Quantity } \\
\text { of Y'east. }\end{array}$ & Hours. & I'roduct. \\
\hline 10 & 2 & 20 \\
\hline 5 & $3 \cdot 5$ & 19 \\
2 & 5 & 16 \\
1 & 20 & 20 \\
\hline
\end{tabular}


For dead yeast (killed by means of toluol) the figures are rather irregular, as is seen from the diagram giving the product $q t$ corresponding to the evolution of 1000 gramme-calories, but still we might conclude that the $q t$-rule is valid. The lowest curve represents the heat evolved during the lapse of two hours, when different quantities of dead yeast ( I, 2, 5 or 10 grammes) act upon the same quantity of sugar-solution ( $50 \mathrm{~g}$. in $250 \mathrm{cc}$. solution). Here there is no indication that the rule of ScHüTz might be applicable.

Another vital phenomenon has been investigated by MADSEN and myself, namely the decomposition of red blood-corpuscles by means of haemolytic poisons such as ammonia, sodium hydrate or tetanolysin. The experiments were carried out at $0^{\circ} \mathrm{C}$. As example I give the figures for ammonia.

The longer the process goes on the greater is the number of the blood-corpuscles killed; they give up their red colouring matter, the haemoglobin, to the surrounding solution, which is in most cases the so-called physiological salt solution, i.e. 0.9 per cent $\mathrm{NaCl}$-solution in water. The said number is reckoned in per cent of the total number of bloodcorpuscles and called the degree of haemolysis. The solutions contained 5 per cent of blood-corpuscles, and different concentrations of ammonia were used; the concentration I denotes $0.00 \mathrm{I}$ normal $\mathrm{NH}_{3}$. The following figures giving the time necessary for reaching a certain given degree of haemolysis were obtained. Immediately after the observed figures, 
representing the time in minutes, calculated figures are given in brackets, which were obtained by dividing the observed figures for the concentration I by the concentration used, which is indicated in the first column.

\begin{tabular}{|c|c|c|c|c|c|}
\hline \multirow{2}{*}{ Concentration. } & \multicolumn{5}{|c|}{ Degree of Haemolysis in Per Cent. } \\
\hline & 3. & 10. & 20. & 3०. & 40. \\
\hline I & $13(13)$ & $26(26)$ & $35(35)$ & $44(44)$ & $53(53)$ \\
\hline $2 \cdot 27$ & $6(5 \cdot 7)$ & $\mathrm{IO}(\mathrm{I} \mathrm{I} \cdot 5)$ & $15(15 \cdot 4)$ & $18(19 \cdot 4)$ & $23(23 \cdot 3)$ \\
\hline $4 \cdot 35$ & ... & $5 \cdot 5(6 \cdot 0)$ & $9(8 \cdot 0)$ & $12(10 \cdot 1)$ & $14(12 \cdot 2)$ \\
\hline $7 \cdot 5$ & ... & $\ldots$ & $4(4 \cdot 7)$ & $6 \cdot 2(5 \cdot 9)$ & $S(7 \cdot 1)$ \\
\hline
\end{tabular}

If the calculated values agree with the observed ones-as is really the case within the somewhat large errors of experiment in these very difficult investigations - this indicates that the qt-rule is applicable, i.e. that the reaction is monomolecular. If we try to follow the progress of this reaction, we find a rather irregular result, which is partly caused by the circumstance that during the first period no reaction is visible, which is due to the so-called time of incubation. This phenomenon is very common with life-processes, but is also observed in some cases in general chemistry, for instance in the action of light on a mixture of hydrogen and chlorine (Bunsen and Roscoe).

Now, when we know that the qt-rule holds good for the haemolysis by means of ammonia, we may investigate the effect of temperature on this process by determining the quantities of ammonia which are necessary to produce the same degree of haemolysis 
in a given time, e.g. Io minutes. If, for instance, we find that the fourfold quantity is necessary for reaching the same haemolytic effect at $29^{\circ} \mathrm{C}$. as at $39^{\circ} \mathrm{C}$, we may say that-according to the $q t$-rulethe same quantity of ammonia would occupy a time four times as long to produce the same effect at $29^{\circ}$ C. as at $39^{\circ} \mathrm{C}$.

Such determinations have been carried out on a very large scale with different haemolytic agents by Madsen and his co-workers Walbum and Noguchi. As an instance, I give a series for ammonia with a time of action of 10 minutes. $t$ is the temperature, $q$ the necessary quantity in cc. of a 0.5 normal $\mathrm{NH}_{3}$ solution. The total quantity was $S \mathrm{cc}$. containing I per cent of red blood-corpuscles from a horse. $q_{\text {obs., }}$ is the observed, $q_{\text {calc., }}$ a calculated quantity evaluated by means of the general formula for the influence of temperature on the velocity of reactions. The degree of haemolysis was I 7 per cent.

\section{HAEMOLySis BY MEANS OF AMMONIA AT DIFFERENT \\ TEMPERATURES}

\begin{tabular}{|c|l|l|}
\hline \multicolumn{1}{|c|}{$t}$. & $q_{\text {obs. }}$ & $q_{\text {calc. }}$ \\
\cline { 1 - 3 } 21.0 & 0.60 & 0.64 \\
25.9 & 0.30 & 0.30 \\
29.7 & 0.17 & 0.17 \\
34.8 & 0.085 & 0.083 \\
39.5 & 0.04 & 0.043 \\
\hline
\end{tabular}

The value of $\mu$ used for the calculation, which agrees very well with the observation, is 26,760 . 
Now it ought to be observed that with increasing time the effect tends to a limiting value, and this the more rapidly the higher the temperature. Thus, for instance, at $39^{\circ} \mathrm{C}$. the values of $q_{\text {obs., }}$ for 60 minutes and for I So minutes are o.O 9 and o.O I 5 respectively. Instead of being in the proportion 3 to $\mathrm{I}$, these figures are as $\mathrm{I} \cdot 3$ to I. Below $30^{\circ} \mathrm{C}$. the proportion is, within the errors of experiment, as 2 to I for the times of action 10 minutes and 20 minutes. In consequence of this behaviour the $\mu$-value seems to sink with increasing time. The right value of $\mu$ is the limit-value for the time of action o, which is found by extrapolation from the values observed with different times, $z(z=10, z=20, z=30, z=60$, etc. $)$. It is about 29,000. For acetic, propionic, and butyric acid we find in the same manner values lying round about 26,000 . The same figure is given by vibriolysin. It seems as if weak acids or bases, and lysins of bacterial origin give nearly the same value for $\mu$, for very short time of action. Strong acids and bases give too low values of $\mu$, probably because their attack is too rapid.

Sodium oleate behaves in quite a different manner. Here $\mu$ ( Io minutes of action) does not reach a value higher than 3800 , so that the velocity of reaction is only double as great at $36.3^{\circ} \mathrm{C}$. as at $4^{\circ} \mathrm{C}$. Cobra poison acts nearly independently of the temperature, and the poison of the water moccasin seems to act I.5 times more slowly even at $39^{\circ} \mathrm{C}$. than at $11^{\circ} \mathrm{C}$. These apparent anomalies seem to merit a closer investigation. 
The agglutinins in their action on bacteria seem to behave very nearly in the same manner as the haemolysins in regard to red blood-corpuscles. The following figures of MADSEN, who observed the time $t$ which was necessary for producing a given degree of agglutination of Bacillus coli at $37^{\circ} \mathrm{C}$. when a given quantity $q$ of coli-agglutinin acted upon this bacillus, show that the $q t$-rule is very nearly obeyed.

\section{Agglutinating Action of Different Quantities of \\ Coli-Agglutinin at $37^{\circ} \mathrm{C}$.}

\begin{tabular}{|c|c|c|}
\hline$q$. & $t$ (Min.). & $q t$. \\
\hline 3.5 & 30 & I O 5 \\
2.5 & 45 & I I I \\
1.7 & 60 & 1 02 \\
1.2 & 90 & 108 \\
0.8 & 120 & 96 \\
0.5 & 180 & 90 \\
0.4 & 240 & 96 \\
0.3 & 300 & 90 \\
0.27 & 360 & 97 \\
& & Mean 99 \\
\hline
\end{tabular}

The value of $q t$ decreases a little with decreasing quantity. But on the whole the $q t$-rule holds pretty well.

The dependence of the action of this agglutinin on temperature is shown by the following table. It gives the quantity, $q_{\text {obs. }}$, of agglutinin, necessary for producing a given degree of agglutination in 10 minutes at the temperature written in the first column. The calculated values, $q_{\text {calc. }}$, are found by means of the formula on p. 49. 
Action of Coli-Agglutinin DURing 10 MinUtes at DIFFERENT TEMPERATURES.

\begin{tabular}{|c|c|c|}
\hline Temp. ${ }^{\circ} \mathrm{C}$. & Yolss. & $q_{\text {calc. }}$ \\
\hline 12.9 & 30 & 30 \\
\hline $21 \cdot 2$ & $6 \cdot 5$ & 6.8 \\
\hline 24.9 & $4 \cdot 5$ & $4 \cdot 2$ \\
\hline $30 \cdot 9$ & $1 \cdot 5$ & $1 \cdot 4$ \\
\hline $3+\cdot 9$ & 0.55 & 0.72 \\
\hline 38.6 & 0.5 & 0.43 \\
\hline
\end{tabular}

The experiments and the calculations are carried out by MaDsen in the same manner as those for the action of temperature on the velocity of reaction of haemolysins ; $\mu$ is put equal to 30,000 .

For typhoid-agglutinin (10 minutes' action) Madsen and WaLbum found a value of $\mu=37,200$, i.e. of the same order of magnitude as for coli-agglutinin but 24 per cent higher.

Generally speaking, we may say that the action of agglutinins on bacteria proceeds very nearly in the same manner as that of haemolysins on red bloodcorpuscles.

A certain similarity to this investigation is exhibited by the disinfecting action, practically so important, of certain poisons or hot water on bacteria, which are thereby killed. KRönig and PAUL in 1897 investigated the disinfecting action of different mercuric salts on anthrax bacilli and found that the chief acting substance is probably the mercuric ion, for the different salts at the same concentration were effective according to their degree of electrolytic 
dissociation. The same is true for the hydrogen ion of acids or the hydroxyl ion of bases. They also determined the progress of the disinfection with time. Madsen and Nyman found that this progress corresponds to a monomolecular reaction, and showed that this is also the case when hot water acts on anthrax spores (1907). At about the same time (igo8 and i9io) Miss Harriette Chick carried out a very elaborate research on this question and came to similar results when different poisons were used, such as phenol, mercuric chloride, hot water, and normal rabbit's serum. Even when bacteria are killed by drying, the monomolecular law is followed, as PAUL found when he kept dried staphylococci at ordinary room temperature. In contrast with this the bacteria remained alive for months at the temperature of boiling liquid air. Miss $\mathrm{CHICK}_{\mathrm{H}}$ has also calculated some figures given by $C_{\text {LARK }}$ and $\mathrm{G}_{\text {AGE }}$ (1903) regarding the killing of bacteria in sunlight, and even there found the law of monomolecular reactions to hold good.

In order to prove this I borrow some diagrams from Miss Chick's paper delivered to the Eighth International Congress of Applied Chemistry (vol. xxvi. p. I67, I912). These diagrams concern the killing of anthrax spores with 5 per cent phenol at $33.3^{\circ} \mathrm{C}$. (Miss H. Chick, Fig. I 5 ), or with o. I I per cent mercuric chloride at I $8^{\circ} \mathrm{C}$. (KRöNIG and PAUL, Fig. I6), the killing of Bacillus typhosus with 0.6 per cent phenol at $20^{\circ} \mathrm{C}$. (Miss H. CHick, Fig. I 7), the killing of this bacterium by means of hot water at 


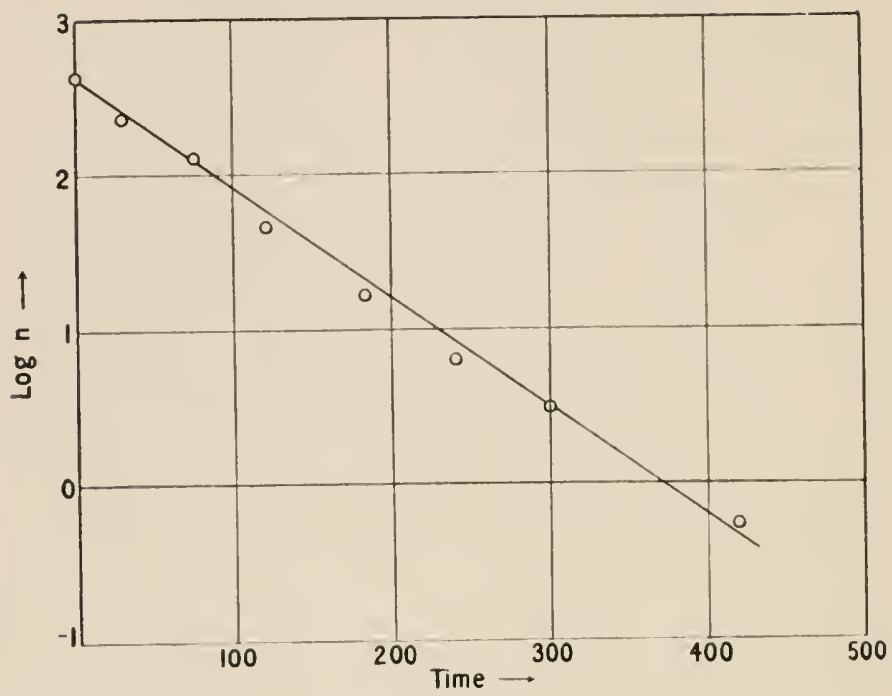

F1G. 15.

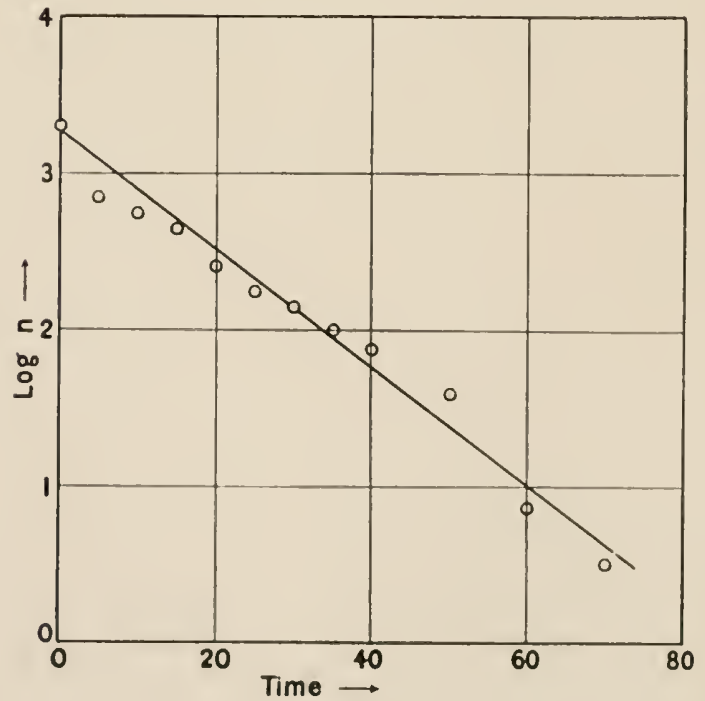

FIG. 16. 
REAC'TION OF CELLS

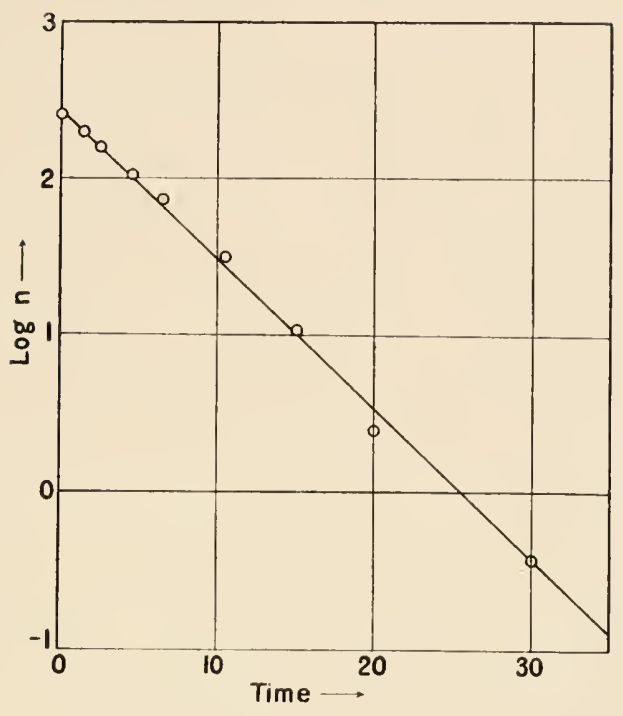

FIG. 17.

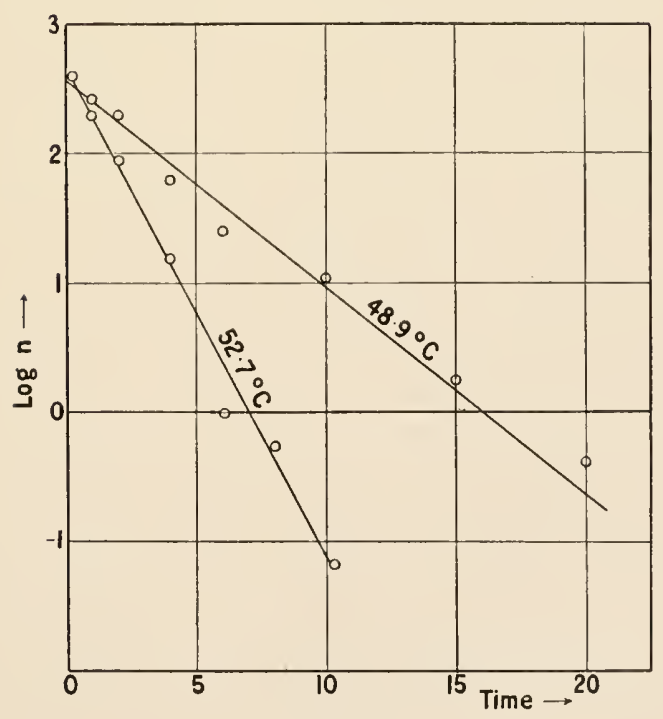

FIG. I8. 
$48.9^{\circ} \mathrm{C}$. and at $52.7^{\circ} \mathrm{C}$. (Miss H. CHick, Fig. I 8), and the killing of Bacterium coli commune by sunlight (Clark and GAGE, Fig. I9). In all these figures the time in minutes $(t)$ is taken as abscissa; the ordinates represent $\log n$, where $n$ is the number of surviving bacteria in one drop of the culture.

These results are very interesting. In the case of yeast-cells the approximative validity of Scıürz's

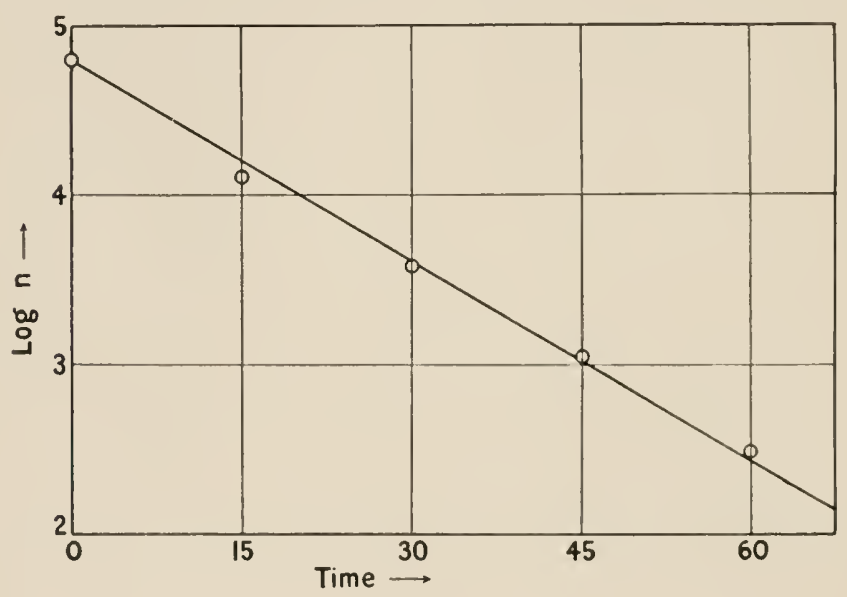

FIG. I9.

rule indicates that the products of the fermentation in some way hinder the process. Now it is true that the alcohol produced diminishes the activity of the yeast-cell, but not with such regularity that we might expect Scuürz's rule to hold good. There are also other listurbing agents in this case which act in an opposite direction, for instance the incubation phenomenon. But still both in this complicated case and in that of the killing of red blood-corpuscles 
by different haemolytic agents the $q$ t-rule is followed, that is, if we diminish the quantity of the acting substance in a certain proportion to reach the given effect, we must increase the time of action in the

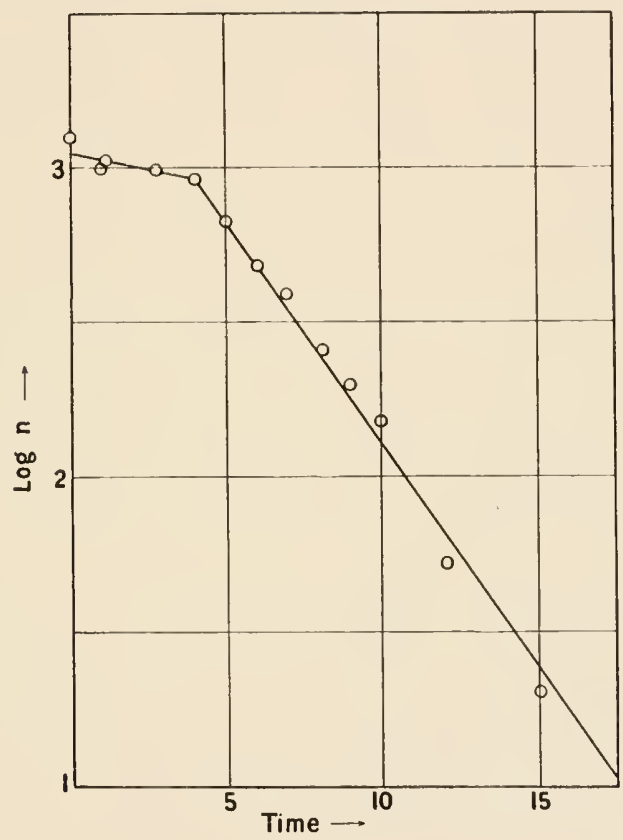

FIG. 20.

same proportion. This rule indicates that the reaction is of the monomolecular kind.

The figures concerning bacteria show this in a much more pronounced manner. In some cases, for instance regarding Staphylococcus pyogenes aureus (Fig. 20) or Bacillus paratyphosus, Miss $\mathrm{CHICK}$ found some irregularities at the commencement of the process. For the staphylococcus the 
velocity is less in the first four minutes than later on, which probably depends on a kind of incubation ; for the paratyphosus bacillus the irregularity seems to indicate some accidental irregular influence. But on the whole these reactions show such a regular progress with time, that their monomolecular nature is obvious. This circumstance indicates that every bacterium or yeast-cell or red blood-corpuscle acts as if it were a single molecule in regard to the substance reacting upon them. This seems from a biological point of view extremely difficult to understand. We will come back to this question later on.

According to investigations by HARveY, not only bacteria, but even higher organisms, such as Chlamydomonas, are subject to the same regularity. He determined the number of moving Chlamydomonas at certain times, 5 to 25 minutes after he had added hydrochloric acid in the small quantity of 0.009 per cent to the water in which the monads swam round. At the beginning of the experiment this number was I I 3 , after five minutes it had sunk to 67 , after further five minutes to 30 , at the next observation five minutes later to I 4 , and still five minutes later to 6 . The logarithm of this number as a function of the time of observation is represented by a straight line as the figure (Fig. $2 \mathrm{I}$ ) indicates.

According to a quotation given by Miss $H$. CHICK, even seeds of barley are killed by poisons or hot water according to the law for monomolecular processes, as shown by experiments of Miss DARIVIN and P'rofessor BlaCKMAN. 
The explanation of this peculiarity is the same as that which I have given for the rapid change of velocity of reaction with increase of temperature, in which case I specially considered the inversion of cane-sugar. Only a very small number of the cane-

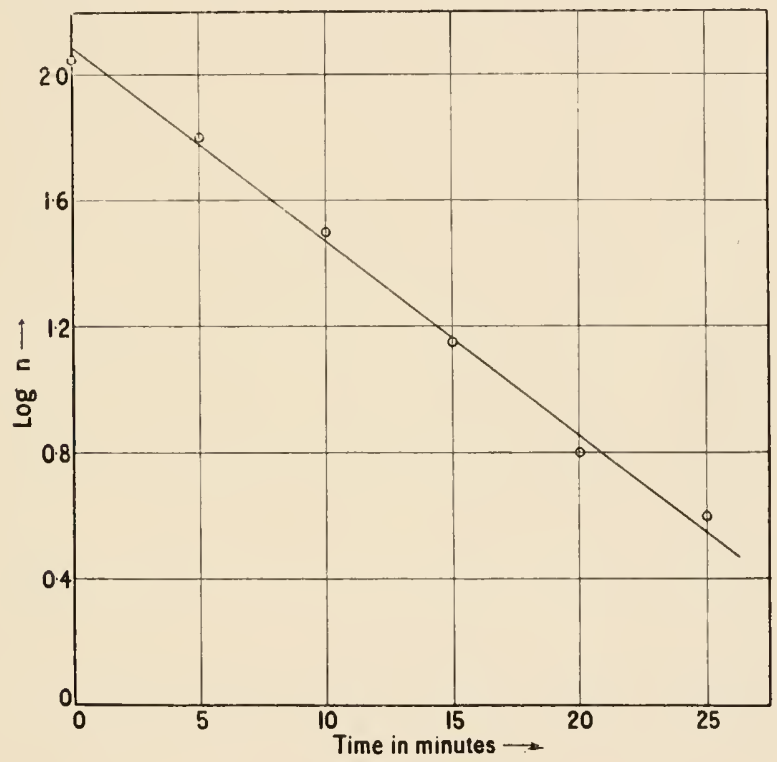

FIG. 2 I.

sugar molecules are at a given time in such a modified state that they are liable to be decomposed, and every molecule of sugar enters at some time into this state, so that at constant temperature molecules of the said "active" kind are always present in the same fraction of the total number. Therefore the number of molecules decomposed per second is proportional to the total number of sugar-molecules present. 
The radio-active substances decompose according to the same law. This law is evidently of very farreaching importance.

There is no doubt that the different cells in a sample of bacteria or red blood-corpuscles possess a different power of resistance to deleterious substances. We may, as an instance, take the red blood-corpuscles, which have been most closely examined. If we add different quantities of a poison, e.g. vibriolysin, to an emulsion of $\mathrm{I} \cdot 6$ per cent horse erythrocytes in Io cc. of physiological salt-solution (0.9 per cent $\mathrm{NaCl}$ ) and keep the mixture at $37^{\circ} \mathrm{C}$. for two hours, we find that no action is observed until more than 5 cubic millimeters of the poison is added. With the doses indicated we obtain the degree of haemolysis given below :

Cubic mm. of poison : $5102030405060708090100 \quad$ I 10 Degree of haemolysis : $\begin{array}{llllllllllllll}0 & 0.6 & 4 & 16 & 34 & 52 & 67 & 78 & 86 & 93 & 98 & 100\end{array}$

This table gives the sensibility of the erythrocytes, 25 per cent are killed by $35 \mathrm{c} . \mathrm{mm}$., 50 per cent by 49 c.mm., 75 per cent by $67 \mathrm{c} . \mathrm{mm}$. and no cell resists I IO $\mathrm{c} . \mathrm{mm}$.

From two different series I have calculated the relative number of erythrocytes of a certain sensibility and constructed a curve giving the frequency of the erythrocytes of a certain sensibility, where the maximum is placed above the value 4 of the abscissa. The zero-point is placed on the ordinate Io (upper curve on Fig. 22). Below this curve the ordinary curve of probabilities $(e . g$. for the fre- 
quency of a certain velocity amongst gas-molecules, according to MAxwELL) is drawn with the same height of the maximum ordinate. The two curves run nearly parallel to each other at a distance of ten units. Only at high values of the abscissa, where the probable error of a determination is very great in the case of haemolysis, is there a little

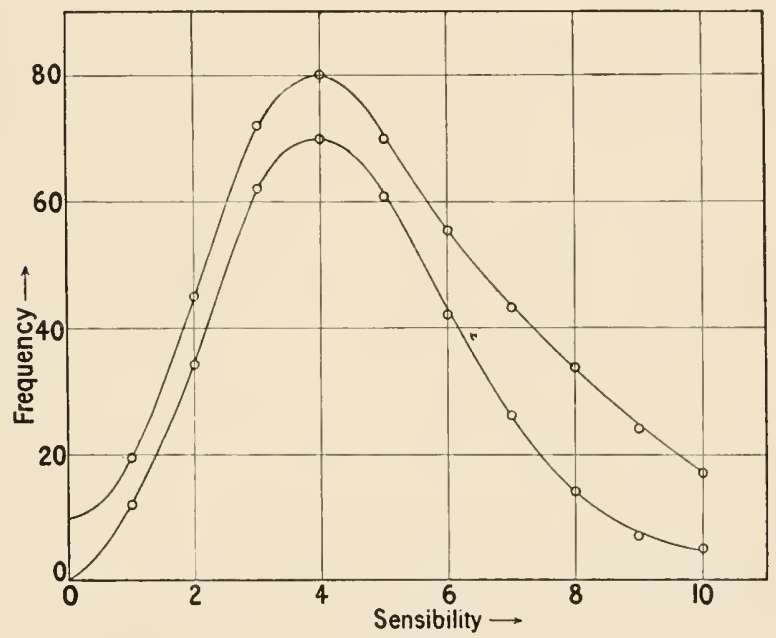

FIG. 22.

deviation from parallelism. The parallelism, within the errors of observation, indicates that the sensibility of the erythrocytes is distributed in accordance with the law of probabilities, which is the most regular distribution we could expect.

Even for erythrocytes some observers have found that their destruction by means of haemolytic agents goes on according to the monomolecular law with progress of time. This law is proved with a 
very high degree of accuracy by experiments on the killing of bacteria by means of different disinfectants. Without doubt the bacteria behave in this case just as the erythrocytes at haemolysis. If now the different time necessary for killing the different bacteria was due to their natural resistance, we might expect that the velocity of reaction would be zero

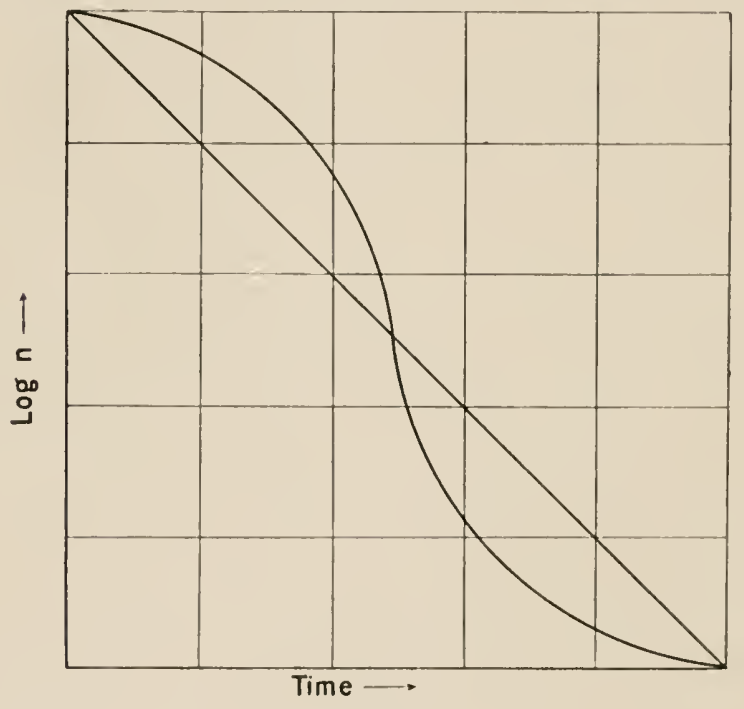

FIG. 22A.

to begin with, to increase subsequently and run through a maximum when about 50 per cent were killed, and after that to fall again to zero when nearly all bacteria were dead. The characteristic line would be expressed by a curved line with an inflexion-point as in Fig. $22 \mathrm{~A}$. Instead of this we find the straight line in this figure representing the phenomenon, The different lifetime of the different 
bacteria does not, therefore, depend in a sensible degree on their different ability to resist the destructive action of the poison. Instead of this a certain fraction of the bacilli still living dies in one second, independent of the time during which they have been in contact with the poison.

In order to understand this we make the following observation. In a I per cent solution of acetic acid only I per cent of the molecules are in a dissociated state (at $25^{\circ} \mathrm{C}$.). It is not the same molecules which remain constantly in the dissociated state, but every molecule is dissociated during one unit of time and undissociated during ninety-nine units. The reactivity of the ions is much greater than that of the whole molecules. We suppose for simplicity that the ions alone react. Then at any moment only I per cent of the acetic acid molecules are in state to react. The proteids contained in the living protoplasm are amphoteric electrolytes. Only a thousandth part (we suppose this figure for simplicity) of the proteid molecules has split off its $\mathrm{H}$-ions, and perhaps only a millionth part its $\mathrm{OH}$-ions. Then probably one part in a thousand millions has split off both its $\mathrm{H}$-ions and its $\mathrm{OH}$-ions. Perhaps it is only living protoplasm containing one or two such ions which is able to react with the poison. At every moment only this small fraction is open to attack, and at this moment a molecule of poison must be present for the cell proteid to be destroyed. Probably the cell only dies after a certain number of its proteid molecules 
have entered in reaction with the poison. In this way we may represent to ourselves the manner in which it happens that in every second a certain fraction of the cells is killed by the poison, and that this fraction is independent of the time of action of the poison.

It may here be worth while to make a little reservation. It is a fact very often observed that immediately after it has been added to the cellemulsion the poison has a very small action, or none at all. This is easily understood, for it is necessary for the poison to diffuse through the cellular membrane before it is able to act upon the cell. This takes a certain time, which is called the time of incubation. Different bacteria may possess membranes which are rather different in regard to their permeability for the poison, and it may also be different for different poisons. It is probably for this caluse that the time of incubation is insensible in many of Miss CHick's experiments. Only in the case of phenol acting on staphylococci a clear indication of the incubation phenomenon may be observed (Fig. 20). But even here the action of the poison is not zero during the four minutes of incubation, but only very small. During this time the cells with the weakest membranes are attacked, and in this manner the small action of the poison is understood. With red blood-corpuscles the said effect is very pronounced, as the experiments of MADSEN and myself indicate. 


\section{CHAPTER IV}

THE QUANTITATIVE LAWS OF DIGESTION AND

RESORPTION

WE now proceed to consider life-processes, in which not simple cells but higher organisms are involved. The question which has been investigated in this field because of its extreme importance is the digestion of food in higher animals. For the experiments dogs have been usually examined.

When we consider digestion in the stomach of an animal, we find the circumstances rather different from those for digestion in vitro. Our chief knowledge we owe to the investigations of PAwLow in Petrograd and his school, especially Professor London. He gave me his figures for calculation, and I found some very pronounced regularities in them, which also occur in the observations of KHIGINE and other pupils of PAwLow. A short review of the chief results which may be expressed by quantitative laws may not be out of place here.

The observations were made in the following manner. Fistulae were opened to different parts of the digestive canal of the observed animal. After the introduction of food into the stomach-which 


\section{$8 \cdot 2$ \\ DIGESTION AND RESORP'TION}

could be done in two different ways, either by giving the food to the animal, generally a dog, to eat, or by putting the food into the stomach direct, by a tube ending in the stomach-the different juices, gastric, pancreatic or enteric, are secreted by the animal. These different juices may be collected by tubes introduced into the different fistulae.

The production of gastric juice begins about ten minutes after the introduction of food. The total time of secretion is observed and the quantity of juice secreted during this time. Very often the quantity of juice secreted during a certain time, c.g. one hour or three hours, reckoned from the beginning of the process, is also given. The quantity of undigested food may in the same manner be taken out from the stomach after a given time and analysed, in which case a correction is applied for the quantity of accompanying gastric juice, determined from the acidity of the content in the stomach. In order to study the stomachical secretion free from the food taken, another method has been used. A small part of the stomach is separated from the rest of the stomach by sewing, whereby a tube is formed, which is open so that its secretions may be collected in calibrated tubes. Special experiments have shown that the juice secreted from the "small stomach," or portion thus separated off, is of the same composition as that secreted from the corresponding part-the fundus part or the pyloric one of the stomach-and that it is always the same fraction of the total secretion. This method has been used by LüNNQUisT and 
Khigine. The "small stomach" of the dog used by LöNNQUIST secreted about 4 per cent of the total secretion.

Professor London and Dr. Lönnquist have investigated the content of gastric juice in the stomach after a meal or after introduction of food through a tube. In the first case the content is nearly constant during four hours, and subsequently, when digestion is nearly completed, sinks rapidly. In the second case the content of juice and pepsin is at first very small, but increases rapidly afterwards. For the calculations I have made the simplified hypothesis that the concentration of pepsin is proportional to the time of digestion, which agrees fairly well with the experiments of KHIGine and LoBASOFF.

After these preliminary remarks we will consider the interesting results of KHIGINe's experiments given in the table below. Different quantities of the commonest food-stuffs (recorded in the first column) were given the dog to eat, or introduced into the stomach by means of a tube. It is very obvious that the total quantity of gastric juice (tabulated in the third column) is proportional to the quantity of food (tabulated in the second column), if this is of the same kind. KHIGINe has also drawn this conclusion, according to which the calculated values in the fourth column are evaluated. The good agreement between these figures and the corresponding observed values gives a proof of the said proportionality. 


\section{DIGES'IION AND RESORP'TION}

KHIGINe's Experimexts on Digestion BY a Dog

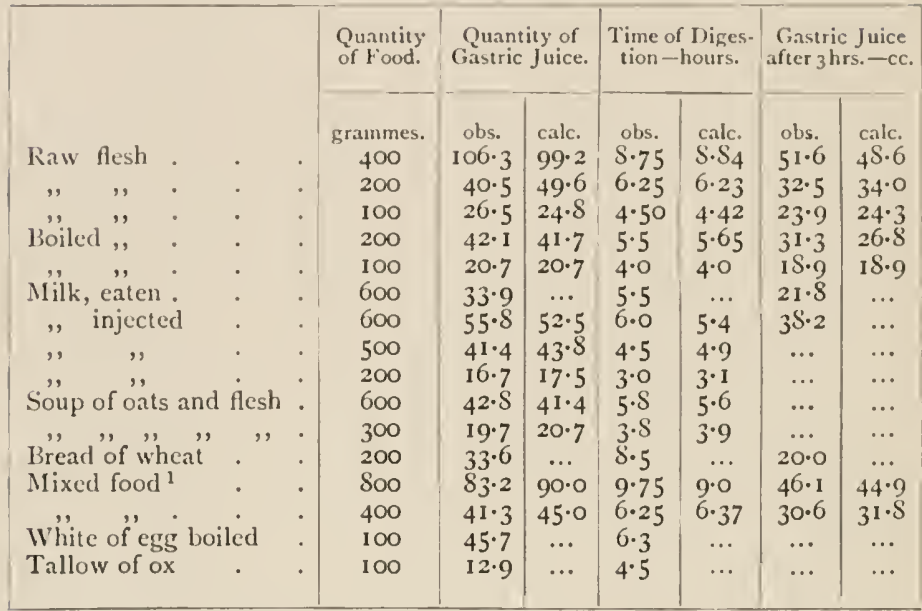

1 100 grammes boiled flesh, 100 grammes bread of wheat, and 600 grammes milk.

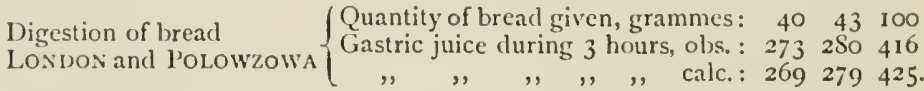

This circumstance may at the first glance seem very peculiar, for we know from the experiments in vitro that a small quantity of pepsin (together with hydrochloric acid) is able to digest a great quantity of food. Why does not Nature make use of this property of peptic digestion? It is easy to see that, according to the rule of Scrütz for peptic digestion, the length of time necessary for digesting a certain quantity would increase nearly proportionally to the square of this quantity. Therefore if 4.42 hours are necessary for the digestion of 100 grammes of raw flesh, a time about 16 times longer, i.e. 70 hours, would be necessary for the digestion of 400 grammes, and a meal of 1000 grammes would take 442 hours 
or 18 days. This would be not at all favourable for the animal. Then Nature would proceed in a much more advantageous manner if it digested the food in portions successively. This is in fact the case. If an animal takes a certain quantity of solid food, e.g. flesh, it is spread over the interior of the stomach in layers, so that the food first taken forms the layer nearest to the walls of the stomach and the innermost layer contains the food eaten at the end. This is shown in experiments by Ellenberger and Grützner. The gastric juice, secreted from glands in the stomachical walls, diffuses extremely slowly into the interior parts of the food. Therefore at first the outermost layer is digested and carried away through the pylorus, after which the digestion of the second layer is carried to an end and its digestion products carried away, and so forth until the innermost layer is also ready. After this the secretion of the gastric juice, which has gone on during this whole time, comes to an abrupt end. In this process also a part of undigested food is carried away and without doubt digested later on in the digestive tract. Therefore when the calculation indicates that only a small quantity of food is left undigested in the stomach, the experiment shows that the stomach is really empty. This occurs, for instance, in the experiments of LONDON with dogs of 25 kilogrammes when less than 3 grammes of flesh are left.

From an inspection of column 5 in the table giving KHIGINE's experiments we find that the time 
of digestion is very nearly proportional to the square root of the quantity of food. How well this law agrees with reality is seen from a comparison of the fifth and sixth columns, which latter is calculated according to the said law. In practice it is rather difficult to observe when the secretion of juice is at an end. The square root regularity might not be expected if the secretion of gastric juice or, better, of pepsin and hydrochloric acid were independent of the quantity of food. But if the secretion during a given time increased nearly proportionally to the square root of the quantity of food itself, the said regularity would look natural. That this condition is very nearly fulfilled we see from the two last columns. The calculated figures are proportional to the square root of the quantity of food, and agree very well with the quantity of gastric juice collected during the lapse of three hours from the beginning of the secretion. We must therefore conclude that the food in the mouth and in the stomach acts upon the nerves of the secreting glands in such a manner that their activity is nearly proportional to the square root of the quantity of food in question. The time for the digestion of mixed food is in accordance with the square-root rule calculated from the formula:

$$
t=\sqrt{t_{1}^{2}+t_{2}^{2}+t_{3}^{2}}
$$

where $t_{1}$ is the time for the flesh, $t_{2}$ that for the bread, and $t_{3}$ the time of digestion for the given quantity of milk. 
The acidity of the gastric juice is about 0.5 per cent of hydrochloric acid, and varies, according to Khigine, from 0.56 for the soup given to 0.47 for bread-for ox-tallow an abnormously low value of 0.4 was found; the fats, except milk-fat, remain nearly unchanged in the stomach. The strength of pepsin in the gastric juice is very different, about half as great for milk as for flesh or soup, and a fifth of that for bread.

The longer the time of digestion of a food-stuff the more indigestible is it. Boiled flesh is about Io per cent more easily digestible than raw flesh (for dogs). If regard is paid to its great content of water, which is indifferent to the digestion, milk seems to be less digestible than flesh, and soup of oats and flesh less digestible than milk. With milk we observe the influence of eating as compared with introduction through a tube. This depends upon the slow secretion of gastric juice in the beginning in this latter case. The difference is still more pronounced in the figures for the quantity of gastric juice, which runs nearly parallel to the time of digestion. The slow digestion of coagulated (boiled) egg-white is very pronounced. BoldyrefF has shown that fish needs about 30 per cent more stomachical juice than horse-flesh.

For bread K Higrne has only one figure. London and Polowzowa have varied the quantity of bread given to their dog. The quantity of juice secreted during the first three hours follows the squareroot rule. The high value of this quantity in their 
experiments depends upon the circumstance that they have considered the whole quantity secreted to the stomach, whereas KuIGINe has observed the quantity delivered by a "small stomach," which is only a small fraction of that given to the chief part of the stomach.

London has carried out a great many experiments regarding the quantity of undigested flesh in a dog's stomach three hours after the food had been given. The quantity of flesh given varied between 100 and 1000 grammes. The dog's weight was 25.2 kilogrammes. When I calculated these figures, I observed that the whole progress of digestion might be expressed by the following formula :

$$
d x: d t=\mathrm{I} 25\left(\mathrm{I}-e^{-0.0068 x}\right)
$$

in which $x$ is the quantity of undigested flesh in grammes. $d x: d t$ gives the quantity digested in one hour.

This formula is graphically represented in the following diagram (Fig. 23). The uppermost curve refers to the digestion of I000 grammes flesh. The curve for Soo grammes is obtained from that for Iooo grammes simply by transposing the zero-point of time by $\mathrm{I} \cdot 6$ hours, i.c. to the point where the I000 grammes-curve cuts a horizontal line, $y=S o 0$, and so on for smaller quantities of food-in the diagram the curves for $600,400,200$ and 100 grammes are drawn. The dotted curve is found with the same dog some time later. Its digestive power was then diminished in the proportion I :0.S, so that the 600 
grammes of flesh given were digested at the same rate as 750 grammes according to the drawn curves. The values calculated according to this assumption agree very closely with the observed ones. This observation shows that the same dog at different stages of health digests in a different manner. A

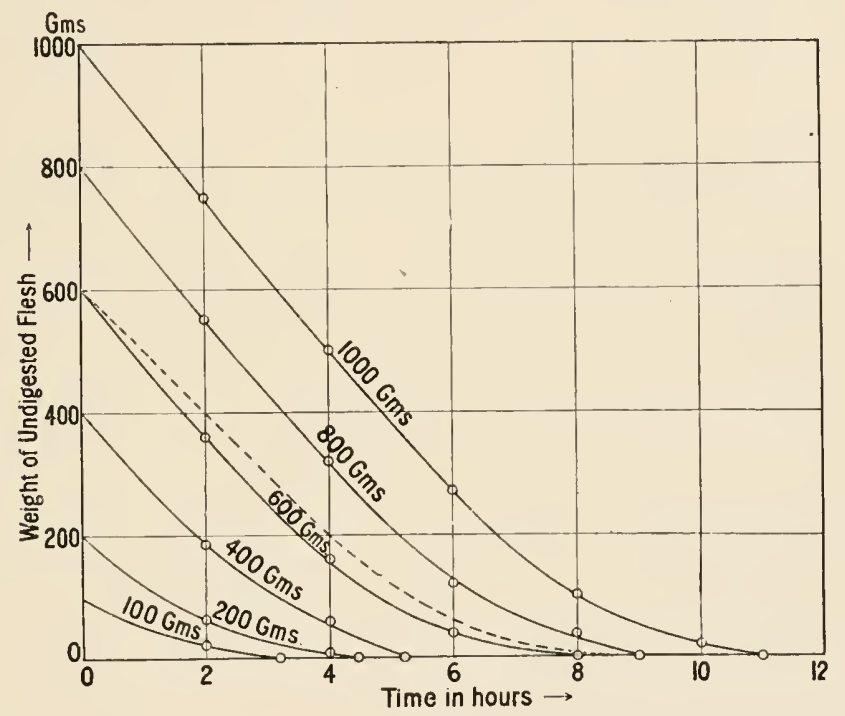

FIG. 23.

dog of I 2.6 kilogrammes weight will probably digest 500 grammes at the same rate as the observed dog, weighing $25 \cdot 2$ kilogrammes, digests 1000 grammes. It is probable that by changing the value of the ordinates in a certain proportion the diagram will be applicable for representing the rate of digestion of flesh for any dog. The figures representing this diagram are given in the following table: 
Digestion OF Flesh by a DOG (LONDON)

\begin{tabular}{|c|c|c|c|c|c|}
\hline $\begin{array}{l}\text { Time } \\
\text { (hours). }\end{array}$ & Undigested. & د. & $\begin{array}{c}\text { Time } \\
\text { (hours). }\end{array}$ & Undigested. & s. \\
\hline 0 & 1000 grs. & & 6 & 275 grs. & I I 2 \\
\hline I & 875, & 125 & 7 & I 78, & 97 \\
\hline 2 & $750 \quad$, & I 25 & 8 & 102 & 76 \\
\hline 3 & 627 & I 23 & 9 & $5 I$ & $5 I$ \\
\hline 4 & $506 "$ & 121 & Io & 23 & 28 \\
\hline 5 & 387, & 119 & I I & 12 & I I \\
\hline
\end{tabular}

It indicates that the rate of digestion, if I 000 grammes are given, is very nearly constant till about 250 grammes are left. Then it diminishes very rapidly, as is seen from the figures given in the third column, representing the quantity $\Delta$ digested during one hour. If we regard the digestion as ended, when all but 3 grammes have been digested in the stomach, we find the following times necessary for digesting different quantities of flesh written in the fourth column. If we compare them with

Progress of Digestion with Time (London)

\begin{tabular}{|c|c|c|c|c|}
\hline \multirow{2}{*}{$\begin{array}{l}\text { Quantity of tlesh } \\
\text { taken. }\end{array}$} & \multicolumn{2}{|c|}{$\begin{array}{l}\text { Digested Quantity after three } \\
\text { Hours. }\end{array}$} & \multicolumn{2}{|c|}{ Time of Digestion (Ilours) } \\
\hline & Ots. & Calc. & Obs. & Calc. \\
\hline I oo grs. & $92 \cdot 2$ & 93.3 & 3.5 & $3 \cdot 4$ \\
\hline $200 " 1$ & I $68 \cdot 1$ & $17+1$ & $4 \cdot 7$ & $4 \cdot 8$ \\
\hline 300, & $226 \cdot 0$ & $239 \cdot 5$ & $5 \cdot 7$ & $5 \cdot 9$ \\
\hline 400, & 288.5 & 288.7 & 6.6 & 6.8 \\
\hline $500 "$ & $317 \cdot 3$ & $323 \cdot 2$ & $7 \cdot 4$ & $7 \cdot 6$ \\
\hline 600, & $357 \cdot 8$ & $3+5 \cdot 8$ & $8 \cdot 3$ & $8 \cdot 4$ \\
\hline 800, & 366.8 & $367 \cdot 4$ & 9.9 & $9 \cdot 7$ \\
\hline $1000, "$ & $369 \cdot 5$ & 373.4 & II $\cdot 5$ & 10.8 \\
\hline
\end{tabular}




\section{DIGESTION AND RESORP'TION 91}

figures calculated according to the square-root rule (fifth column) we find an excellent agreement. There is an indication that with great quantities of food the digestion proceeds a little slower than is given by the square-root rule. This is a sign of incipient overstrain which LoNDON observed with still larger meals given to the dog. How well the formula agrees with the observations of LONDON regarding the quantity digested after three hours is seen from a comparison of the second and third columns of the last table. The differences between the observed and the calculated values all fall within the limits of accidental deviations from the mean value. It must be conceded that the process of digestion goes on in a much more regular way than might have been expected, i.e. that uncontrolled influences-e.g. the psychical state of the dog, which is very important according to the highly interesting studies of PAwLow - exert a much smaller perturbing influence than generally presumed.

As we have seen above, the digestion proceeds very much slower if the flesh is introduced directly into the stomach than when the dog has chewed it. London gives two series of observations regarding digestion of food without chewing, and for comparison one with chewing, for all of which the same dog was used. In the first series (I.) the eyes and the nose of the dog were tightly covered, in the second (II.) they were uncovered. No sensible difference, due to the psychical influence of the 
sight or smell of the food was observed. The figures are given in the table below, in which the mean

DIGESTION OF FLESH INTRODUCED PER FISTULAM, GOO GRAMMES

\begin{tabular}{|c|c|c|c|c|}
\hline $\begin{array}{l}\text { Time of } \\
\text { Digestion. }\end{array}$ & \multicolumn{4}{|c|}{ Undigested Quantity per Cent. } \\
\hline $\begin{array}{c}\text { hours. } \\
0\end{array}$ & $\begin{array}{l}1 . \\
100\end{array}$ & $\begin{array}{l}11 . \\
100\end{array}$ & $\begin{array}{l}\text { Mean. } \\
\text { I OO }\end{array}$ & $\begin{array}{l}\text { calc. } \\
\text { I OO ( } 100)\end{array}$ \\
\hline 2 & 84 & 84 & 84 & $84 \quad(67)$ \\
\hline 4 & $5^{6}$ & 53 & 54 & $(36)$ \\
\hline 6 & 20 & 18 & 19 & $21 \quad(10)$ \\
\hline 8 & 7 & 5 & 6 & $6 \quad(0)$ \\
\hline 9 & o & o & o & 3 \\
\hline
\end{tabular}

values from series I. and II. are compared with values calculated from the hypothesis that the concentration of pepsin in the content of the stomach, in accordance with some experiments of KIIIGINE and LobASOFF, is proportional to the lapse of time from the beginning of the digestion. The agreement is nearly perfect, and gives a strong support to the said assumption. The figures for chewed flesh are written in brackets. It is easily seen how much more rapidly the digestion proceeds in this case. This depends upon the secretion of gastric juice caused by the psychical influence induced by the chewing. The secretion begins about ten minutes after the food has been given to the dog.

The secretion of pancreatic juice shows the same regularity as that of gastric juice. Dolinsky introduced $250 \mathrm{cc}$. of hydrochloric acid of different concentrations into the stomach of a dog and found that 
the pancreatic juice secreted in forty minutes was nearly proportional to the square root of the concentration of the hydrochloric acid, as is seen from the following table, where the calculated values are found by means of the square-root rule. The time

Secreted Pancreatic JUICE in 40 Mins. AFter introdUCTION OF 250 CC. Diluted Hydrochloric ACID

Concentration of the acid $\begin{array}{cccc}0.5 & 0.1 & 0.05 & \text { per cent. }\end{array}$

Pancreatic juice, obs. $\quad \begin{array}{rrrr}80.5 & 28.3 & 20.5 & \text { cc. }\end{array}$

$\begin{array}{llllll}\prime \quad \text { calc. } \quad 70.7 & 3 \mathrm{I} .6 & 22.4 \quad\end{array}$

of secretion was also nearly proportional to the same quantity.

For very small quantities of chewed flesh (below 200 grammes) the digestion proceeds nearly according to a monomolecular formula, i.e. the curve given above does not diverge very much from an exponential curve. The same was found by London for the digestion of 200 grammes coagulated egg-white. When the undigested quantity sinks below 20 grammes, the digestion proceeds very much more rapidly than the formula demands. This probably depends on the carrying away of a part of the undigested food with the digestion products.

London has carried out some experiments regarding the resorption of dextrose, which is not subject to any digestion before its assimilation. He introduced a solution of this sugar-generally 200 cc., in some experiments 100,500 or 800 cc. were used, heated to $38^{\circ} \mathrm{C}$. in doses of about $20 \mathrm{cc}$, with intervals of about twelve seconds-in a fistula in the 


\section{DIGES'TION AND RESORP'TION}

duodenum. The fluid moved down by the peristaltic movement to a fistula in the jejunum, I. 5 metre distant from the first one, and was collected through it. After ten to fifteen minutes the whole fluid had passed and was introduced again through the duodenal fistula. The whole experiment lasted in most cases two hours. At the end the concentration had decreased, from which the resorbed quantity was

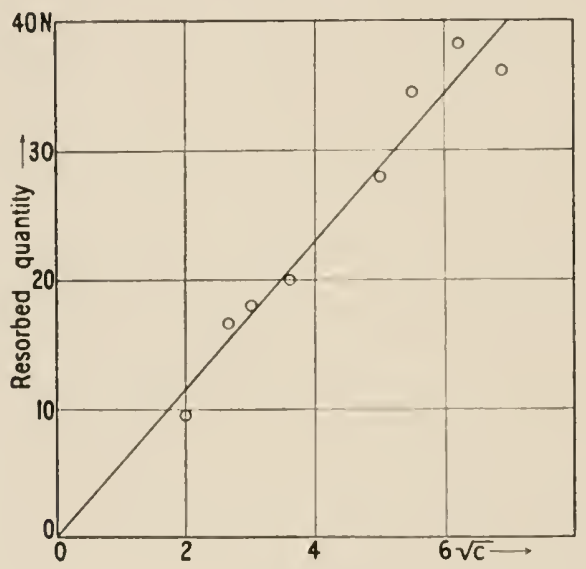

FIG. 24.

calculated. For the calculation of the regularities the mean concentration has been used. As is seen from the diagram, Fig. 24, in which the square root of the mean concentration is taken as abscissa and the resorbed quantity as ordinate, these two quantities are nearly proportional to each other. The few experiments with 500 and 800 cc. seem to indicate that at constant concentration the resorbed quantity is proportional to the volume of the 
solution. This is not true for the quantity Ioo cc. from which a quantity greater by about 20 per cent is taken up than the proportionality demands.

The proportionality of the resorbed quantity to the square root of the concentration indicates that the process is not a question of a simple diffusion, but that the resorbing action of the intestinal wall is excited by the food-stuffs in the moistening fluid. It seems very noteworthy that the exciting influence, just as in the case of the secretion of stomachical or pancreatic juice, is proportional to the square root of the quantity of the exciting substance. Even the quantity of enteric juice secreted is nearly proportional to this square root.

Another experiment of London concerns a carbohydrate, amylodextrin, which must be digested before its resorption. A solution containing 4.8 grammes of amylodextrin was introduced through an upper fistula and carried through to a lower fistula in a certain time, from 8 to 240 minutes. The longer the time the solution remained in the intestine, the smaller the part of it remaining undigested and consequently unresorbed. The quantity of amylodextrin remaining undigested and also unresorbed was determined. The undigested amylodextrin does not reduce a Fehling solution as the digested parts of this carbohydrate do. As is generally true for the digestion of small quantities, that of amylodextrin obeys the monomolecular formula. This is seen from the diagram, Fig. 25 (the lower curve), in which the logarithm of the undigested quantity 
$(\log n)$ is plotted as ordinate against the time as abscissa. Probably the resorption goes on according to the square-root rule. But the unresorbed quantity follows the undigested quantity rather closely, so that the difference-except for the shortest time, $S$ minutes, in which case it is 5 per cent-is nearly constant, sinking from the value 16 per cent

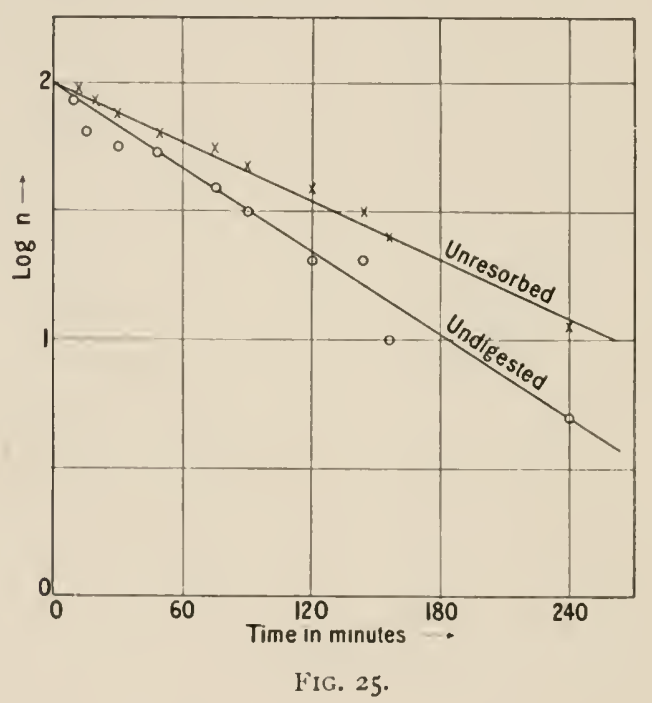

at 15 minutes down to 1 I per cent at 200 minutes. Therefore even the unresorbed quantity nearly follows the square-root rule, as is seen from the upper curve in Fig. 25, in which its logarithm is given as a function of the time of digestion.

The square-root rule finds also its application for the digestion of gliadin, a proteid contained in gluten. This substance was used because its quantity may be determined as glutaminic acid. 
Different quantities of gliadin were given to a dog to eat and the intestinal juice was collected through a fistula about one metre before the caecum. The time of secretion and the quantity of nitrogen in the secreted juice, from which a correction for the nitrogen-content of the gliadin was subtracted, were determined. As is seen from the table below, both the

Secretion of Enteric Juice at Digestion of Gliadin (LONDON AND SANDBERG).

\begin{tabular}{|c|c|c|c|c|c|}
\hline \multirow{2}{*}{$\begin{array}{r}\begin{array}{c}\text { Quantity } \\
\text { given-grs. }\end{array} \\
\text { I } 2.5\end{array}$} & \multicolumn{2}{|c|}{ Time of Secretion-min. } & \multicolumn{3}{|c|}{ Nitrogen in the Juice-grammes. } \\
\hline & $\begin{array}{l}\text { Obs. } \\
\text { I } 25\end{array}$ & $\begin{array}{c}\text { Calc. } \\
\text { I } 08\end{array}$ & $\begin{array}{c}\text { Obs. } \\
\ldots\end{array}$ & $\begin{array}{c}\text { Calc. } \\
\ldots\end{array}$ & $\begin{array}{c}\text { Diff. Smoothed. } \\
\ldots\end{array}$ \\
\hline 25 & 160 & I 52 & .61 & $.4 I$ & $+.20)$ \\
\hline 50 & 205 & 2 I 5 & $\cdot 58$ & .59 & $-.01 j^{+}$ \\
\hline I OO & 275 & 304 & 1.08 & .82 & $+\cdot 26)$ \\
\hline I 50 & 350 & 372 & $\cdot 74$ & $\mathbf{I} \cdot \mathrm{OO}$ & $-.26 \int$ \\
\hline 200 & 4 I 5 & 430 & $\ldots$ & $I \cdot I 6$ & ... \\
\hline 300 & 520 & 527 & $I \cdot O I$ & $1 \cdot 42$ & $-.4 \mathrm{I})$ \\
\hline 400 & 630 & 608 & 2.02 & I. 64 & $+.38\}^{-.11}$ \\
\hline
\end{tabular}

time of secretion and the secreted quantity follow the law of proportionality to the square root of the quantity of gliadin eaten. The determinations are very difficult, because the secretion goes on discontinuously with rather long intervals. For the secreted nitrogen it is necessary to take the mean values of two consecutive observations in order to see the regularity. The sixth observation, (for 200 grammes) is excluded, because this observation, according to the authors London and SANDbERG, is rather unreliable. 


\section{DIGES'TION AND RESORP'TION}

I have entered at some length upon these circumstances, partly because they are of the greatest practical interest, - the digestion seems to proceed in a similar way in the stomach of a dog and of a man-but also in order to show that the differences observed in experiments "in vitro" and "in vivo" are very easily explicable from the different experimental conditions and in some cases do not exist. On the other hand, a closer inspection of the experimental data regarding digestion, secretion, and resorption in an animal's body shows a great number of very simple regularities, the existence of which in such "vital" processes, which depend to a very high degree on psychical effects, was deemed impossible. It is precisely the negation of the possibility of applying for the study of vital processes quantitative methods in the same manner as in exact science, which is the chief argument of the vitalists. According to this opinion, forces which are unknown to us from physics and chemistry ought to interfere with the measurements and spoil their value. 


\section{CHAPTER V}

CHEMICAL EQUILIBRIA

WE have now to investigate the equilibria of enzymatic processes and to compare them with the equilibria in physical chemistry. VAN 'T HoFf expressed in 1898 the opinion that it might be possible by the aid of enzymes, which decompose certain substances, to synthesise these substances from their products of decomposition. This opinion presupposes that an equilibrium exists between these products and their compound just as between an ester (with water) and its products of decomposition, acid and alcohol; in this case the equilibrium is reached when about $\frac{2}{3}$ of the ester are decomposed. On the other hand, if we invert cane-sugar by the aid of an acid, the equilibrium lies so very near to the end, where the sugar is totally decomposed, that we have no hope of synthesising the sugar from its products, dextrose and laevulose. As a matter of fact it has been repeatedly maintained that this synthesis has met with success, both by means of acids and by means of invertase, but Hudson has proved that these assertions depend upon errors of observation. 
Chemists have succeeded in producing esters, such as ethyl butyrate, glyceryl butyrate, glyceryl triacetate, and fats from their alcohols and acids in presence of lipases from pancreatic juice or castor beans. Even glucosides, such as amygdalin, and carbohydrates, e.g. amylose, have been synthesised in an analogous manner. Perhaps the most interesting case is the synthesis of proteins. DANILEWSKI and his pupils precipitated so-called plasteins from concentrated solutions of peptones or albumoses, to which rennet or pepsin had been added. The plasteins exhibit the reactions of proteins, but contain less nitrogen.

A. E. TAYLOR hydrolysed protamine sulphate by means of trypsin, and after having separated the products, he synthesised them again with the aid of trypsin. In such cases it is not certain that the original substance is restored, e.g. such is not the case in the plastein formation from the products of casein. But in one very important case this has succeeded, namely, with the paranuclein which was prepared by T. B. RoBERTSON by the action of pepsin on the hydrolytic products of casein. The hydrolytic products into which paranuclein may be split up do not bind the antibody which F. P. GAY and Robertson obtained by injection of paranuclein or casein into guinea-pigs. But if these hydrolytic products were synthesised by pepsin the product bound anti-paranuclein, i.c. it was paranuclein. In other words, the authors used the strict specificity of the antibody to discover the presence of its 
antigen (see p. 17). The specificity is not absolute as we see in this case, for the antibody reacts both against paranuclein and against casein, notwithstanding that these substances are not identical.

The first observation in this direction was made by Croft Hill in I 898, who found that maltase from yeast, acting for a month on a 40 per cent solution of glucose, gives a substance similar to maltose, which latter may itself be decomposed by maltase into glucose. This was regarded as a synthesis of maltose due to an equilibrium. But later on it was proved that the substance obtained by CROFT Hill was not maltose, but isomaltose, which is itself not decomposed by maltase. In an analogous manner Emil Fischer and E. F. Armstrong synthesised, with the aid of lactase from kephir, from galactose and glucose, the hydrolytic products of lactose, not lactose but isolactose, which in contradistinction to lactose is not attacked by lactase. And Armstrong found that emulsin has the opposite effect to maltase ; it hydrolyzes isomaltose and builds up maltose from glucose. It is therefore clear that here we are not dealing with syntheses of substances in equilibrium with their products of decomposition, as was at first believed. The observed peculiarity is probably due to a binding of the different substances to the enzymes, whereby different equilibria are produced by different enzymes.

A real equilibrium of a very instructive kind, in which enzymes are acting, has been investigated by Bourquelot and Bridel (Journal de Pharmacie et 
de Chimic, 7 ser., 9, Pp. I 4 , I 55, and 230, I9I4). They investigated two different glucosides of methyl or ethyl, called $a$-glucosides and $\beta$-glucosides. The first are decomposed by a glucosidase contained in air-dried under-yeast, the second by emulsin (from almonds). The equilibrium was reached from both sides, when 76.6 per cent of the $a$-glucoside or $67 \cdot 4$ per cent of the $\beta$-glucoside were decomposed into glucose and alcohol (in this case ethyl alcohol). The progress of the decomposition or synthesis may be followed by means of a polarimeter $\left(a_{0}\right.$ is for $a$ glucoside + I $50.6^{\circ}$, for $\beta$-glucoside $-35.8^{\circ}$, and for glucose $52 \cdot 5^{\circ}$ at $20^{\circ} \mathrm{C}$.).

Here we have a quite regular and characteristic case. Each glucoside is only attacked or synthesised by its specific ferment. The degree of decomposition is different in the two cases, but does not, as in most cases investigated, lic so near to Ioo per cent that the equilibrium cannot be determined. And further, just as with common katalysers, the equilibrium may be reached from both sides, whether we let the ferment act upon the glucoside or upon a mixture of alcohol and glucose. The authors let the equilibrium be reached at room temperatureone month was sufficient for it-and then disturbed it by adding one of the acting substances. The end result always agreed with the calculations according to the figures given above.

By far the simplest equilibrium occurs in the partition of a substance between two phases. If the substance retains the same molecular weight in 
both phases, for instance a blood-corpuscle and the surrounding fluid, then the concentration in the one phase shall be in a constant proportion to that in the other phase. This is even true if the substance enters into compounds which contain or correspond to just one molecule of the substance. For instance a lysin, e.g. tetanolysin or vibriolysin, probably enters into a compound with some proteid in the red bloodcorpuscles. If for the production of one molecule of this compound precisely one molecule of the lysin in the surrounding fluid is used up, then the concentration of the lysin in the surrounding fluid and in the red blood-corpuscle shall be in a constant proportion. This occurs for vibriolysin according to the following figures for solutions containing $9.84 \mathrm{cc}$. of 0.9 per cent $\mathrm{NaCl}$-solution, and $0.16 \mathrm{cc}$. of red blood-corpuscles in emulsion. Different quantities of vibriolysin were added (but always so that the total volume was Io cc.), and by haemolytic experiments it was determined how much was taken up by the red blood-corpuscles and how much remained in the solution. The experiments carried out by MADSEN and TeruUchi and calculated by myself gave the following results : 


\begin{tabular}{|c|l|l|l|l|}
\hline $\begin{array}{c}\text { Quantity. of Ly'sin } \\
\text { added, in cc. }\end{array}$ & $\begin{array}{c}\text { Lysin in } \\
\text { Solution. }\end{array}$ & \multicolumn{2}{|c|}{ Ly'sin in Corpuscles. } & Difference. \\
\cline { 1 - 4 } & & Observed. & Calculated. & \\
\hline 0.2 & 0.032 & 0.168 & 0.165 & +0.003 \\
0.4 & 0.075 & 0.325 & 0.329 & -0.004 \\
0.6 & 0.103 & 0.497 & 0.494 & +0.003 \\
0.8 & 0.137 & 0.663 & 0.658 & +0.005 \\
1.0 & 0.180 & 0.820 & 0.823 & -0.003 \\
1.5 & 0.255 & 1.245 & 1.235 & +0.010 \\
2.0 & 0.395 & 1.605 & 1.644 & -0.039 \\
\hline
\end{tabular}

The figures for the two highest concentrations are more uncertain than the others. The agreement between the observed figures and the calculated ones, which are evaluated on the assumption that the concentration of the lysin is 286 times greater in the blood-corpuscles than in the surrounding salt-solution, may be regarded as extremely satisfactory.

I have determined the partition coefficient of different substances between red blood-corpuscles and an isotonic aqueous solution, in most cases 0.9 per cent $\mathrm{NaCl}$-solution, but for the experiments with silver nitrate 7.5 per cent cane-sugar solution. The surrounding solution must be isotonic with, that is possess the same osmotic pressure as, the red bloodcorpuscles, otherwise they may be haemolyzed by the solution. The red blood-corpuscles take up more of the investigated substances, all of which possess haemolytic properties, than the surrounding solution, therefore the partition coefficient, that is the proportion of the concentration of the investigated substance 
in the blood-corpuscles to the concentration in the solution, is greater than $\mathrm{I}$.

The following figures were obtained :

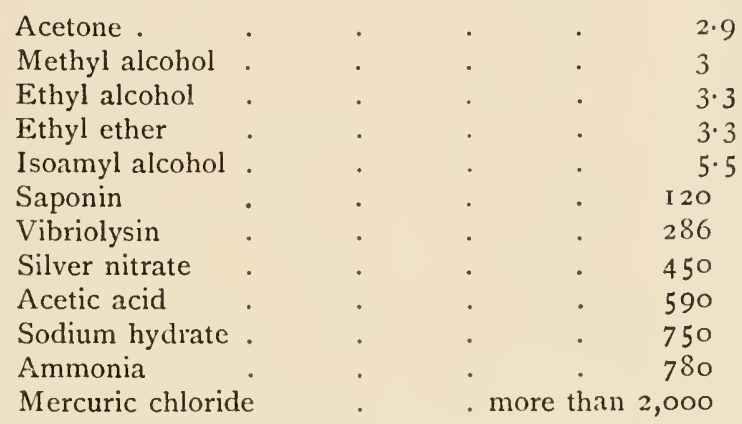

Evidently the substances may be divided in two groups, of which the latter (from saponin) show a strong affinity for the proteids contained in the corpuscles. Without doubt they enter into combinations with them, which are the less dissociated, the higher the value of the partition coefficient is.

In some few cases, as for the absorption of agglutinins in their specific bacilli and for the absorption of so-called amboceptors (see p. I28) in their specific erythrocytes, I have found, in calculating the figures observed by EISENBERG and VOLK, that the ratio of the two concentrations in this case in the bacteria and in the surrounding fluid is not constant. The result of these calculations is that the concentration $\mathrm{B}$ of the agglutinin in the bacilli is proportional to the $\frac{2}{3}$ power of the concentration in the surrounding fluid. This regularity is indicated by the diagrams Figs. 26-29 regarding the absorption of two agglutinins (typhoid, Fig. 26, and cholera, 


\section{CHEMICAL EQUILIBRIA}

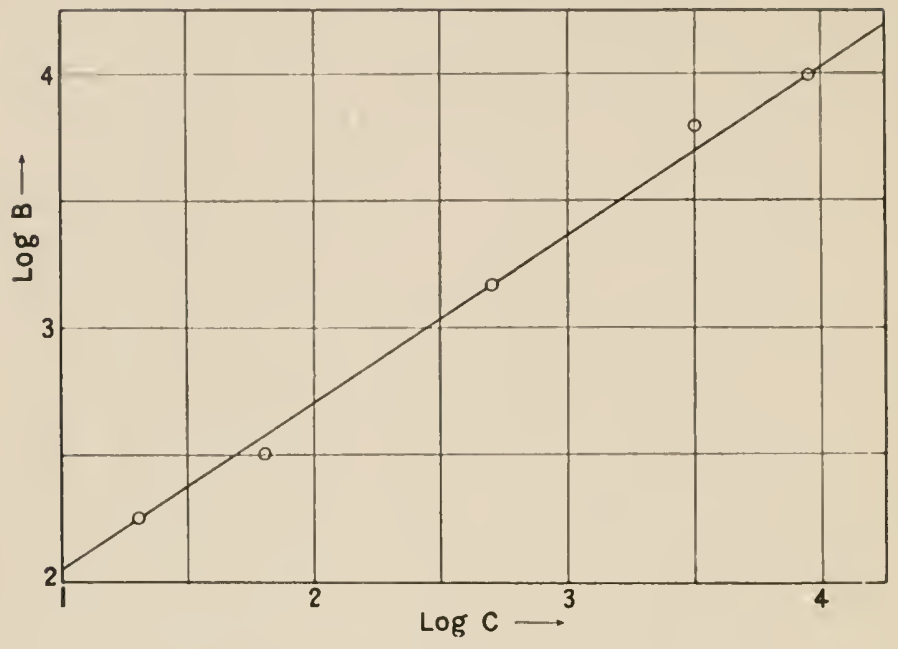

FIG. 26.

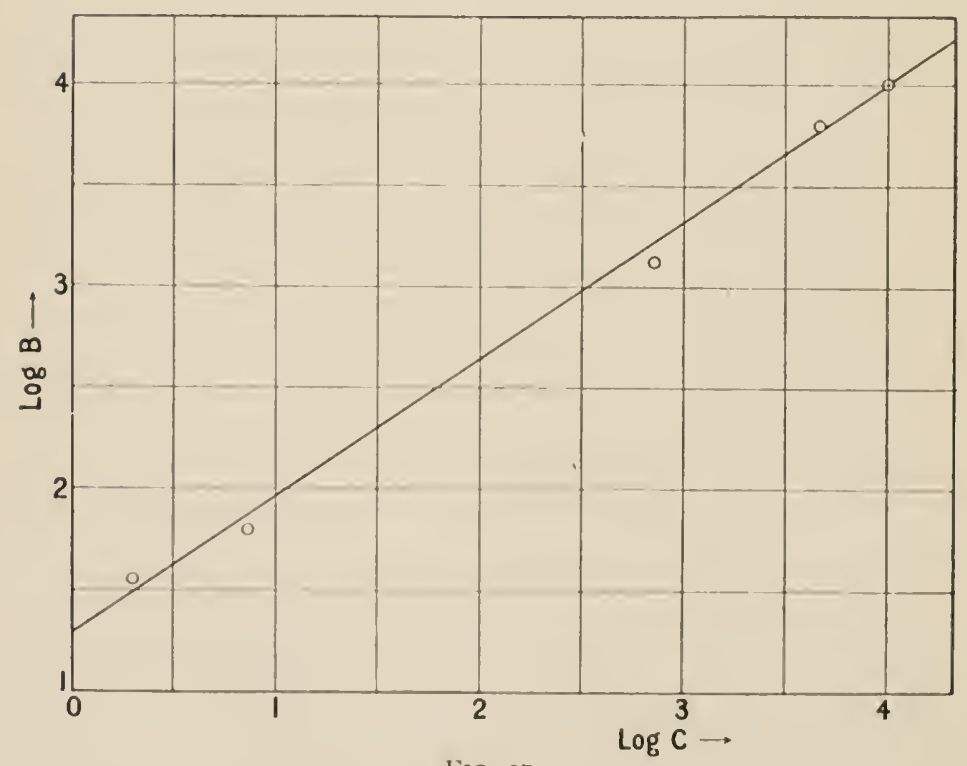

FIG. 27. 
CHEMICAL EQUILIBRIA 107

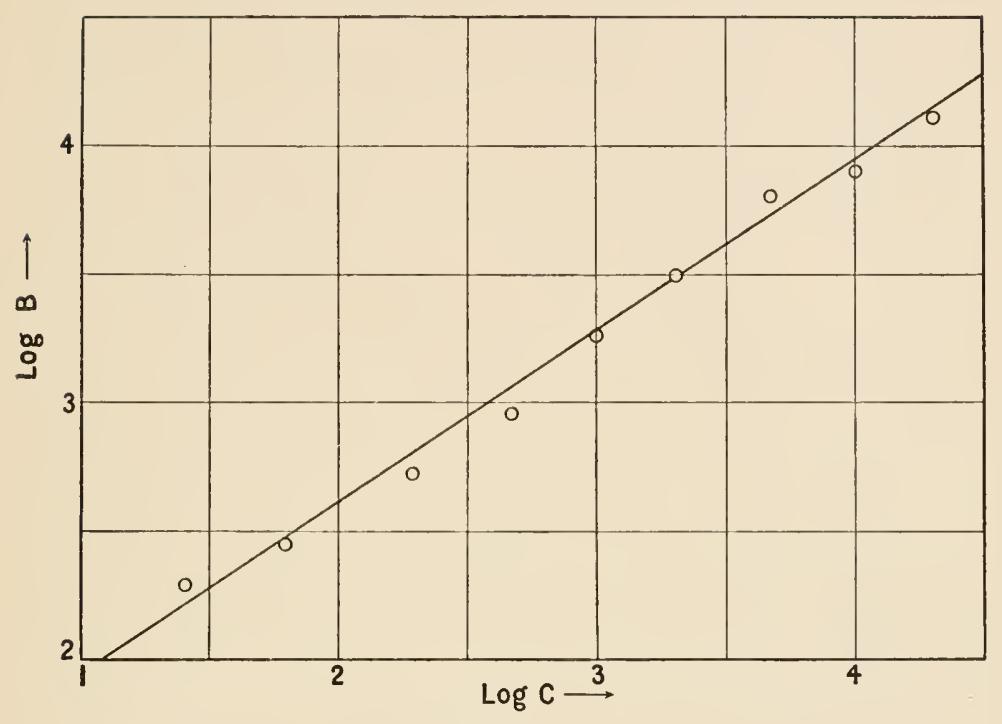

FIG. 28.

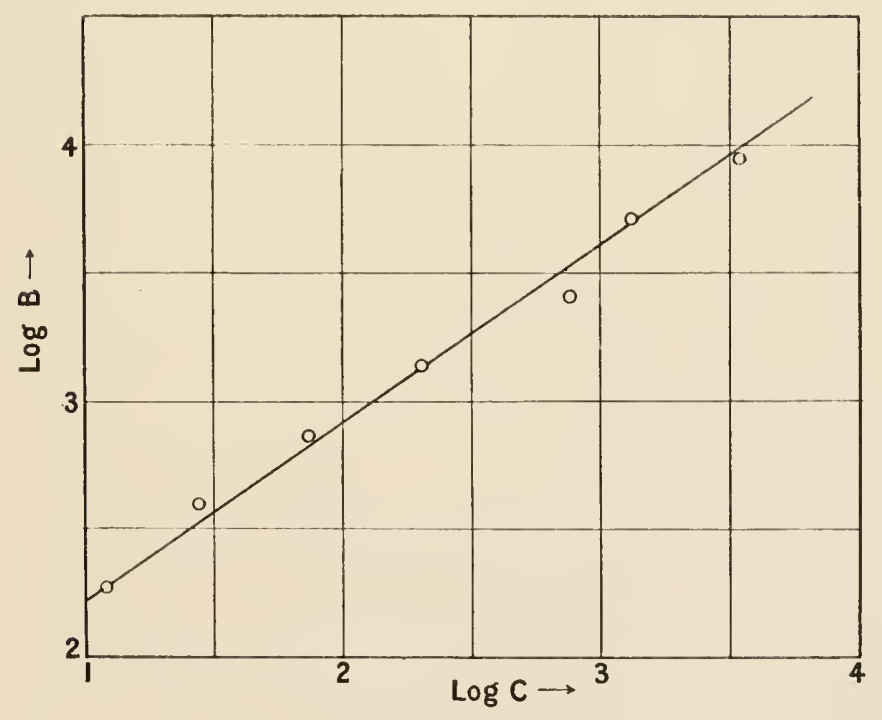

FIr. 29. 
Fig. 27) and two amboceptors (from rabbit, Fig. $2 S$, and from goat, Fig. 29). It is evident that, very nearly, $\log \mathrm{B}=\mathrm{A}+\frac{2}{3} \log \mathrm{C}$.

It may be that this circumstance is due to some disturbing action, similar to that which obscures the monomolecular law for coagulating egg-white (cf. p. 29 above). In reality, agglutination may be regarded as a kind of coagulation.

Madsen and Teruuchi have investigated the condensation of vibriolysin on coagulated and finely divided egg-white suspended in a solution containing that poison. They found the following figures, in which $c_{0}$ indicates the concentration of the poison in the solution-the concentration is expressed in cubic millimetres of a standard solution per $10 \mathrm{cc}$. of fluid or egg-white $-c_{1}$ the corresponding concentration in the egg-white. As the content of poison in the standard solution is very small, the value of $c_{1}$ may naturally be expressed by a very large number. For comparison the square-root $\sqrt{\bar{c}_{0}}$ of $c_{0}$ and the ratio $c_{1}: \sqrt{c_{0}}$ are tabulated:

\begin{tabular}{|c|c|c|c|}
\hline$c_{0}$. & $c_{1}$. & $\sqrt{c_{0}}$. & $\frac{\Omega}{\sqrt{ } c_{0}}$. \\
\hline $\begin{array}{r}7 \\
16 \\
26 \\
51 \\
73 \\
89\end{array}$ & $\begin{array}{r}6,200 \\
8,930 \\
11,600 \\
16,670 \\
21,900 \\
27,500\end{array}$ & $\begin{array}{l}2.64 \\
4.00 \\
5.10 \\
7 \cdot 14 \\
8.54 \\
9.43 \\
\text { Average }\end{array}$ & $\begin{array}{l}2343 \\
2233 \\
2275 \\
2333 \\
2563 \\
2915 \\
2444\end{array}$ \\
\hline
\end{tabular}

As we see from the values tabulated in the last 
column, $c$ is very nearly proportional to $\sqrt{c_{0}}$. This points to the circumstance that we here observe a phenomenon of adsorption, for, when the concentrations $c_{0}$ are small, such a law as that found above is found to hold good in similar cases.

As an instance of a case of adsorption, we reproduce here some figures of PALme (Hoppe-Seyler's Zeitschrift f. physiol. Chemie, 92, I84, 1914). He added a certain quantity, generally 2 grammes, of casein to $50 \mathrm{cc}$. of a solution of ferrocyanic acid of known concentration. PALME observed that a quantity of up to 37.8 milligrammes is bound chemically by the casein. After this further quantities of the ferrocyanic acid are taken up in the casein by means of adsorption. The law of adsorption follows the same formula as the extended rule of Schütz (see p. 42), if we let $t$ denote the concentration and $x$ the adsorbed quantity, which approaches asymptotically to a maximum A with increasing $t$. The following table gives the observed values of $t$ and $x$, which latter are compared with values $x_{\text {calc. }}$ found on the supposition that $\mathrm{K} q=0.0333$, $A$ is just equal to 150 milligrammes.

Adsorption of Ferrocyanic Acid on Casein

\begin{tabular}{|c|c|c|c|c|c|}
\hline$t$ & $x$ obs. & $x_{\text {calc. }}$ & $t$ & $x_{\text {obs. }}$ & $x_{\text {calc. }}$ \\
\hline $\begin{array}{l}0.0005 \\
0.0164 \\
0.0238 \\
0.1148\end{array}$ & $\begin{array}{r}5 \cdot 4 \\
16 \cdot 7 \\
20 \cdot 6 \\
37 \cdot 4\end{array}$ & $\begin{array}{r}2.7 \\
15.2 \\
18 \cdot 1 \\
37.8\end{array}$ & $\begin{array}{l}0.2746 \\
0.8876 \\
\mathrm{I} \cdot 8396\end{array}$ & $\begin{array}{r}57 \cdot 5 \\
86 \cdot I \\
\text { I I } 6 \cdot I\end{array}$ & $\begin{array}{r}55 \cdot 2 \\
87 \cdot 6 \\
\text { I I } 2 \cdot 1\end{array}$ \\
\hline
\end{tabular}

The agreement seems to be perfect within the errors 
of observation. The first observed value of $x_{\text {obs. }}$ 5.4 is much too high, probably due to the dissociation of the compound of ferrocyanic acid and casein. The close coincidence of the $x_{\text {obs. }}$ with the $x_{\text {calc. }}$ indicates that we really have to do with an adsorption phenomenon.

In general it is supposed that adsorption phenomena play a very important rôle in biochemical reactions. Without doubt their existence is proved in many cases, but the predominant influence which is ascribed by the school of colloidal chemistry to these phenomena seems to be greatly over-estimated.

The equilibria between highly organized products similar to the enzymes, namely the toxins, their antibodies and their compounds, have been investigated at some length, because of the extreme importance of these substances in therapy. Eirlicir was the first to subject the neutralization of toxins to a quantitative study. He was especially interested in the behaviour of diphtheria poison, when it was neutralized by adding antidiphtheric serum. He took a certain quantity of poison containing 100 lethal doses, i.e. enough for killing 100 guinea-pigs in between three and four days. He added a quantity $A$ of antidiphtheric serum which was sufficient to neutralize 25 per cent of the poison, so that the mixture contained only 75 lethal doses. He then added the quantity $\mathrm{A}$ again, and repeated that a certain number of times, say until $6 \mathrm{~A}$ were added. It was in this manner that Julius Thomsen investigated the evolution of heat on successive 
partial neutralizations of the acids in order to find out if they were dibasic, tribasic, etc., in which case the evolution of heat was not constant at the different measurements, but only as long as the same valency of the acid was neutralized. For weak acids, such as silicic or boracic acid, heat is evolved even after equivalent quantities of bases (generally $\mathrm{NaOH}$ ) have been added if still further base is introduced into the mixture.

Ehrlich observed that the neutralization proceeded very irregularly, so that sometimes the second addition of $\mathrm{A}$ neutralized more poison than the first one (this he supposed to correspond to the greater evolution of heat at neutralizing the second valency of sulphuric acid as compared with the first). But the very last portions of antitoxin always neutralized very little of the toxin. Sometimes even the first portion of the antitoxin had no neutralizing effect at all. Different specimens of poison differed in the highest degree from each other: In order to elucidate this question I asked Dr. Madsen to sum up all his experiments from the Danish States Serum Institute, which I subjected to calculation, using not only the data for deaths between 3 and 4 days, as was done before, but even those in which the death of the guinea-pigs occurred at other times. The decrease in weight of the animals was also used for determining the toxicity of the injected mixture of toxin and antitoxin. The results are given in the table below. Two series of observations are given there for the same poison, the first one (toxicity $T_{1}$ ) 
was carried out in February I 902, the second (toxicity $\left.T_{11}\right) 19$ months later, i.e. in September 1903. As is seen, they agree very closely with each other, so that

Neutralization of one Equivalent of Diphitiferia Poison by $n$ Equivalents of ANTidiphtheric SERUM

\begin{tabular}{|c|c|c|c|}
\hline$n$. & $T_{1}$ & $T_{11}$ & $\mathbf{T}_{\text {calc. }}$ \\
\hline o & 100 & 100 & 100 \\
\hline .25 & 73 & 75 & 75 \\
\hline$\cdot 375$ & 58 & 63 & $62 \cdot 7$ \\
\hline & 50 & 48 & $50 \cdot 5$ \\
\hline .675 & 32 & 45 & $38 \cdot 4$ \\
\hline .75 & 28 & 26 & 27 \\
\hline .875 & $17 \cdot 2$ & $17 \cdot 3$ & 16.5 \\
\hline $1 \cdot 0$ & I I. I & $9 \cdot 6$ & 8.8 \\
\hline 1.125 & $5 \cdot 6$ & $5 \cdot 3$ & 4.9 \\
\hline $1 \cdot 25$ & $1 \cdot 2$ & 3.1 & 3.1 \\
\hline 1.5 & $\ldots$ & $1 \cdot 6$ & $1 \cdot 7$ \\
\hline 2 & $\ldots$ & $\ldots$ & .9 \\
\hline 3 & $\cdots$ & $\cdots$ & $\cdot 3$ \\
\hline
\end{tabular}

$$
\mathrm{K}=0.0093
$$

the discrepancy between them is without doubt due to experimental errors. After the observed values $T_{1}$ and $T_{11}$ are given values calculated according to the law of Guldberg and WAaGe, if two molecules of the compound are formed from one molecule of the poison and one molecule of the antitoxin. The formula is :

(Conc. of frec toxin) (Conc. of frec antitoxin) $=\mathrm{K}$ (Conc. of neutralized toxin) ${ }^{2}$.

As is seen, they agree perfectly with the observed figures within the errors of observation, which may be estimated from the differences between the two 


\section{CHEMICAL,EQUILIBRIA}

sets of observations. Strangely enough there are two observations for $n=0.675$ which differ from each other by not less than a third of the value, but the mean value is in perfect accordance with the calculated value. If we now take $n=0.25$ as the value of $A$, we find that the first addition of $A$ neutralizes 25 lethal doses (obs. 26), the second 24.5 (obs. 25), the third 23.5 (obs. 22), the fourth 18.2 (obs. I $6 \cdot 7$ ), the fifth $5 \cdot 7$ (obs. $8 \cdot 2$ ), and the sixth only

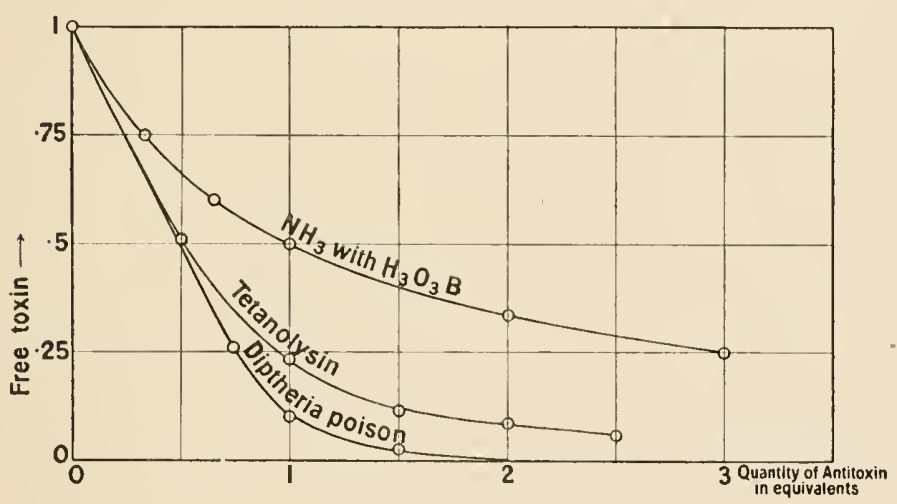

FIG. 30.

I. 4 (obs. 0.6) lethal doses. This different action of the different quantities of antitoxin is termed Eirilich's phenomenon. This peculiarity is just what we might expect if the bond is rather weak, so that a part of the compound is dissociated. The progress of neutralization is represented by the undermost curve in the diagram, Fig. 30.

These figures were not the first calculated in the said manner. There were some experiments on tetanolysin, a poison produced by the lock-jaw 
bacillus. This poison has the not uncommon property of killing the red blood-corpuscles in such a way that the haemoglobin leaves them and enters into the surrounding solution. The experiments are made in test-tubes, containing red blood-corpuscles, to which the mixtures of lysin and antilysin are added in given quantities (the total volume being Io cc. filled up with 0.9 per cent $\mathrm{NaCl}$ solution), and the blood is haemolyzed in the higher degree the more free toxin is present. Now every test-tube contains hundreds of thousands of red blood-corpuscles, so that every observation gives a statistical mean value for so many individuals, of which specimens with very different sensibilities in regard to the lysin occur (see p. 76 above). With guineapigs each figure is the mean of only some ten observations on as many individual animals - the method commonly used is content with only one or two observations for each figure. Therefore the haemolytic experiments give in general much better values than experiments with living animals. Consequently the agreement with calculation is in the case of haemolysins better, therefore they play an important rôle in the doctrine of immunity. When I worked in Dr. Mansen's institute I observed the very pronounced similarity between the partial neutralization of a weak acid by a weak basis, and the neutralization of tetanolysin by its antilysin according to MADSEN's experiments (represented in Fig. 30, middle curve) made in EmRlich's institute. Now the bases are lysins; I therefore proposed that 
we should investigate the neutralization of ammonia regarded as a lysin, i.e. measured by its haemolytic activity, by means of boracic acid, and of sodium hydrate by hydrochloric acid.

The result of the experiments was in perfect accordance with what I expected. The simplest case is the neutralization of one equivalent of sodium hydrate by hydrochloric acid. The salt formed is absolutely innocuous. Say that we have O. I normal solutions of $\mathrm{NaOH}$ and $\mathrm{HCl}$; if we add O. I cc. of the alkali to Io cc. of a 2.5 per cent emulsion of red blood-corpuscles, this dose gives a certain degree of haemolysis (after 2 hours at $37^{\circ} \mathrm{C}$.). Now we mix $0.5 \mathrm{cc}$. $\mathrm{HCl}$ with I cc. $\mathrm{NaOH}$ and investigate which quantity of this mixture gives the same degree of haemolysis. Evidently in $\mathrm{I} \cdot 5 \mathrm{cc}$. of the mixture there is as much free sodium hydrate as in $0.5 \mathrm{cc}$. of the original solution. We must therefore now take $0.3 \mathrm{cc}$. of the mixture for obtaining the said effect, and so forth. The diagram (Fig. 3I) representing this behaviour is a straight line, which cuts the $x$-axis at I corresponding to addition of a quantity of acid equivalent to the quantity of base used. In reality the line of neutralization cuts the $x$-axis a little before, because the corpuscles sustain a certain minimal quantity of free alkali before any haemolysis is observed. If we add more acid we observe a similar small region of acidity which does not attack the corpuscles, and then haemolysis occurs again and the haemolytic power of the solution is proportional to the excess 
of added acid over this point of first acid action. The smaller angle between the line marked Acid and the $x$-axis indicates that acids have about half as great haemolytic power as bases.

The neutralization of cobra lysin (poison from the cobra) by its antibody, the so-called antivenin, behaves in nearly the same manner (see Fig. 31 , upper line). But there is really a small degree of

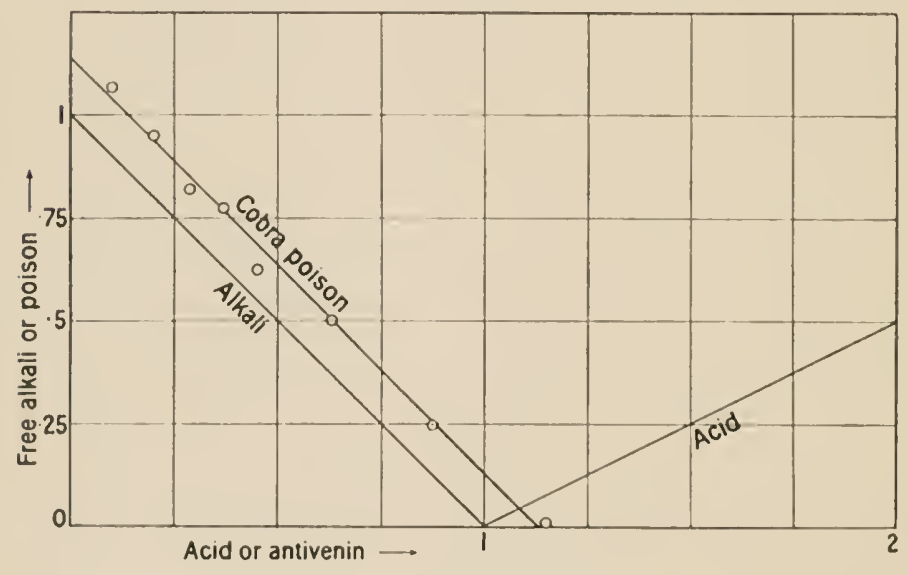

FIG. 3I.

dissociation, for when an equivalent quantity of antivenin is added to the venom still 3.3 per cent of its toxicity remains, according to the observations of MADSEN and Nogucin, from which we may calculate the dissociation constant to be $\mathrm{K}=0.0014$ or the seventh part of that for diphtheria poison. Another snake venom from the water-moccasin (Ancistrodon piscivorus) gives the value $K=0.006$, and that from Crotalus only $K=0.0006$. Their 
neutralization products (with their specific antitoxins) are consequently less dissociated than the corresponding products of diphtheria toxin.

If we now consider the neutralization of ammonia with boracic acid, which is tabulated below, we find that the toxicity, when equivalent quantities are mixed, has been reduced to only about 50 per cent, and, even if the double quantity of boracic acid has

Neutralization of the Haemolytic action (T) of I Mol.

$\mathrm{NH}_{3}$ THROUGH $n$ EquiValentS OF $\mathrm{H}_{3} \mathrm{O}_{3} \mathrm{~B}$

\begin{tabular}{|c|c|c|c|c|}
\hline$n$. & $T_{\text {obs. }}$ & $\mathrm{T}_{\text {calc. }}$ & $\frac{\Delta \mathrm{T}}{\Delta n}$ obs. & $\frac{\Delta T}{\Delta n}$ calc. \\
\hline o & 100 & 100 & $\ldots$ & $\ldots$ \\
\hline 0.333 & 82 & 75 & .54 & .75 \\
\hline 0.667 & 63 & $60 \cdot 3$ & .57 & $\cdot 44$ \\
\hline I & $47 \cdot 5$ & $50 \cdot 3$ & $\cdot 47$ & $\cdot 30$ \\
\hline I. 333 & 43.7 & $43 \cdot 2$ & - I I & $\cdot 21$ \\
\hline I. 667 & $36 \cdot 0$ & $37 \cdot 6$ & .23 & 17 \\
\hline 2 & 33.5 & 33.5 & .08 & I 2 \\
\hline 3 & ... & 25 & $\ldots$ & .09 \\
\hline 5 & $\ldots$ & 17 & $\ldots$ & .04 \\
\hline IO & $\ldots$ & 9 & ... & . O I 6 \\
\hline 50 & $\ldots$ & 2 & $\ldots$ & .002 \\
\hline
\end{tabular}

$\mathrm{K}=\mathrm{I} \cdot 02$ ( $1 \cdot 04$ Lundén).

been used, still 33.5 per cent of the ammonia is not neutralized(compare Fig. 30, uppermostcurve). From the figures observed we calculate $\mathrm{K}=\mathrm{I} \cdot 02$ or about I Io times as much as for diphtheria serum. Here EHRLICH's phenomenon is extremely pronounced. If we now represent $\Delta \mathrm{T}: \Delta u$ from the observations, as EhrLich did in his so-called "poison spectra," 
we find that one equivalent of the first dose (0.333 equivalents) neutralizes $54(=3 \cdot \mathrm{I} S)$ per cent. $\Delta \mathrm{T}=\mathrm{I} \cdot \mathrm{OO}-.82=\cdot \mathrm{I} S$ and $\Delta u=\cdot 333 ;$ hence $\frac{\Delta \mathrm{T}}{\Delta u}=\cdot 54$. The second dose corresponds to 57 per cent, and so forth. The poison spectrum of ammonia should therefore be represented as in the diagram, Fig. 32, and we ought therefrom to conclude that ammonia contains not less than six different "partial poisons,"

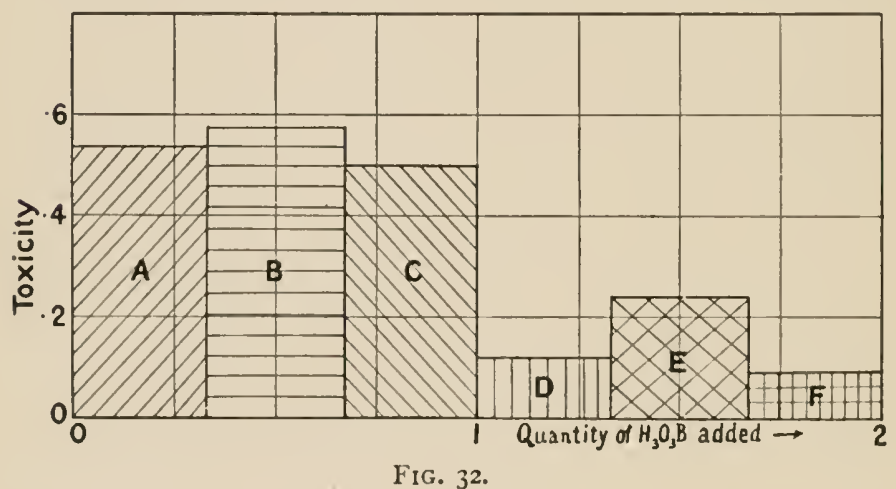

if we used the same reasoning as EHRLICH regarding the diphtheria poison, which he and SACHS have in this manner divided up in not less than ten different "toxins" and "toxoids." Of course this is not true for ammonia, and, after all, not more for the diphtheria toxin; the conclusion is based only on the relatively great errors of observation. This is easily secn from the figures for ammonia, which agree with the calculated figures within the possible errors of observation.

After the determination of $K=1.02$ from the 
experiments of MADSEN and myself regarding the haemolytic action of mixtures of $\mathrm{NH}_{3}$ with $\mathrm{H}_{3} \mathrm{O}_{3} \mathrm{~B}$, LUNDÉN measured it according to the methods used in physical chemistry and found it to be $\mathrm{K}=\mathrm{I} .04$ at the same temperature $\left(37^{\circ} \mathrm{C}\right.$.), which is an extremely good control on the validity of the theory adopted.

According to the same method and formula I calculated the figures of MADSEN for tetanolysin and found $\mathrm{K}=0.1 \mathrm{I} 5$ at $37^{\circ} \mathrm{C}$. At $16^{\circ} \mathrm{C}$. it is $\mathrm{I} \cdot 9 \mathrm{I}$ times smaller, from which we may calculate that at the binding of one gram-molecule tetanolysin to one gram-molecule antilysin there are formed two molecules of their compound with an evolution of 54 So calories. The curve representing the neutralization falls between that characteristic for ammonia with boracic acid, and that for diphtheria toxin with its antiserum. The agreement between observation and calculation is very good and wholly within the errors of observation (see Fig. 30, middle curve, and the following table). 
TOXICITY $q$ OF 0.04 cc. TETANOI,YSIN AFTER ADDITION OF $n$ cc. ( $n_{1}$ EQUivalents) OF ANTILYSIN (MADSEN)

\begin{tabular}{|l|c|c|c|}
\hline \multicolumn{2}{|c|}{ Quantity of Antilysin. } & \multicolumn{2}{|c|}{ Toxicity (Free Poison in Per Cent). } \\
\hline$n$ cc. & $n_{1}$ Equiv. & 2 obs. & q calc. \\
\hline & & & \\
\hline 0 & 0 & 100 & 100 \\
0.05 & 0.18 & 82 & 82 \\
0.1 & 0.36 & 70 & 66 \\
0.15 & 0.54 & 52 & 52 \\
0.2 & 0.72 & 36 & 38 \\
0.3 & 1.09 & 22 & 23 \\
0.4 & 1.45 & 14.2 & 13.9 \\
0.5 & 1.81 & 10.1 & 10.4 \\
0.7 & 2.54 & 6.1 & 6.3 \\
1.0 & 3.26 & 4.0 & 4.0 \\
1.3 & 4.35 & 2.7 & 2.9 \\
1.6 & 5.44 & 2.0 & 2.5 \\
2.0 & 6.52 & 1.8 & 1.9 \\
\hline
\end{tabular}

$\mathrm{K}=0.115$ at $37^{\circ} \mathrm{C}$.

It is quite clear that it is impossible to determine the quantity of antidiphtheric serum which is equivalent to a given quantity of diphtheria poison by looking for how much serum must be added to the said quantity of poison in order that the mixture shall be innocuous, as is usually done. In medical practice it is of course necessary to give a moderate excess of antiserum in order to be certain of the innocuity. Even if we mix the double equivalent quantity of antidiphtheric serum with roo lethal doses of diphtheria poison, still 9 lethal doses are free, and with the five-fold quantity of antitoxin (in equivalents) 2.7 lethal doses are not bound. The only 
method of determining the equivalent proportions is to draw the tangent to the neutralization curve (Fig. 30) at its highest point. The point of intersection of this tangent with the $x$-axis gives the quantity of serum equivalent to the quantity of poison used (in this special case $0.276 \mathrm{cc}$. of antitoxin are equivalent to $0.04 \mathrm{cc}$. of toxin).

In many cases it is said to have been observed that the first dose of antitoxin exerts no neutralizing action upon the poison examined. From the theory we might conclude that it should exert a greater action than the following equal doses. The diphtheria poison spoken of above, when it was first examined by MADSEN in the usual manner, seemed to show the phenomenon that the first parts of antitoxin added did not act as a neutralizer. In this case only those observations were taken into account in which the guinea-pigs examined were killed in three to four days. When I made the recalculation I used all the observations in which the animals died in less than a fortnight and also the observed decrease in weight of the animals. In this way I had a material about ten times greater than that used by MADSEN, and then the first admixtures of antitoxin showed themselves to be of a stronger neutralizing action than the following (see table, p. I I 2), when the same quantity of antitoxin was used. In order to explain the old observations Madsen supposed, as EHrLicir had done before, that the diphtheria toxin contains an innocuous substance called prototoxoid, which binds the antitoxin with stronger forces than the toxin itself, 
and therefore takes away the first part of antitoxin added and hinders it from neutralizing the poison. It is quite clear that, in MADSEn's case, the errors of observation caused the spurious effect. EnrLicil has also found "prototoxoids" only in some of his diphtheria poisons, which differ rather much from each other, and I have no doubt that the errors of observation have caused the observed anomalies.

The only poison for which MADSEN, in his extensive investigations on the neutralization of poisons, has stated the presence of a prototoxoid is ricin. This poison gives with its antitoxin a flocculent precipitate of the compound, so that in GULdBERGWAAGE's formula the concentration of this compound enters in the form of a constant. The calculation gives very concordant results with the observation, if this peculiarity is observed. But before a precipitate is formed the compound remains in a dissolved state and is probably nearly wholly dissociated. Therefore the toxicity does not diminish until enough antiricin is added to give a precipitate. This limit is not very constant according to Madsen's experiments, which may be due to supersaturation or to the presence of foreign substances, e.g. hydrogen ions, in different quantities.

Even at the end of the neutralization EnrLich observed that the nixtures had lost their lethal effect but were not innocuous and gave different symptoms from the pure poison. It seems to me not very strange that a poison gives different symptoms according to its strength, for similar cases are 
observed with inorganic poisons. But EHrLich concluded that the diphtheric poison contains a substance, called epitoxoid or toxon, which has a less avidity for the antidiphtheric serum than the chief poison, the toxin, and therefore remains unneutralized, after the toxin has been made innocuous. Madsen and Dreyer have pointed to the absence of these "toxons" in some of his diphtheria poisons. After all we should not accept their existence without more convincing proofs.

In his investigation of the diphtheria poison mentioned on p. I I I MADSen observed that it was only half as violent in September 1903 as in February 1902. The poison had lost half its toxicity during the lapse of nineteen months, but still it neutralized the same quantity of antitoxin and the dissociation constant had remained unchanged. Similar observations had been made before by Eirricir. In order to explain this peculiarity it seems necessary to suppose that the half number of the molecules of the poison had been transformed in an innocuous modification, which retained the properties of the poison in regard to the antitoxin. Such an innocuous substance may be called "syntoxoid" in accordance with EHRLICH's nomenclature.

Quite recently Calmetre and Massol described a cobra poison(Comptes Rendus, I 59, I 52, Paris, I 914 ), which had lost five-sixths of its toxicity from 1907 till 1913 and still retained its property of binding the specific antivenin unweakened. It had been kept in darkness and in a closed tube. Powdered 
poison is more rapidly weakened than poison in larger lumps. The antivenin had not changed its power sensibly during the six years. The innocuous precipitate which is formed by the combination of cobra poison with antivenin gave back the whole quantity of its toxin content unweakened when heated to $72^{\circ}$ with a small quantity of hydrochloric acid, even after storage for five years.

The adherents of the old EHRLici theory object to the use of the laws of equilibria on the binding. of toxins, that the processes in this case are not reversible, because the compound of toxin and antitoxin changes with time, so that it becomes less dissociable. This last assertion is not true in some cases, as that told of by Calmette, but in other cases it is true, as we shall soon see. But on the same ground we might oppose the use of reversible processes for the calculations in thermo-dynamics, because ideal reversible processes are in general not realized in nature. Every physicist knows that such opposition is unjustified. Such an irreversible process was discovered by Danysz in the so-called Danysz phenomenon. DANvsz found in experiments with ricin or with diphtheria poison that if we have a certain quantity of poison and a (not too small) quantity of its antibody and mix them at once, the mixture possesses a less degree of toxicity than the mixture which results if we take only a part, say 50 per cent, of the poison and mix it with the total quantity of antitoxin and after a time add 
the rest of the poison. This phenomenon was said to be without analogy in general chemistry, and was therefore said to overthrow all calculations based on the existence of an equilibrium between the said reagents.

Thephenomenon recalls an observation of BORDET. We take enough lysin just to haemolyze completely a certain quantity of red blood-corpuscles; divide this quantity in two equal portions and add the lysin to the one part, adding the remaining part of the blood-corpuscles later. Then we find that the haemolysis is far from complete. This effect depends evidently upon the well-known capacity of the proteins in the corpuscles to bind a greater quantity of poison than that just necessary for complete haemolysis. The second half part of the corpuscles therefore receive scarcely any lysin and the haemolysis becomes incomplete.

From general chemistry we are familiar with a similar phenomenon. Monochloracetic acid may be regarded as a lysin and $\mathrm{NaOH}$ as its antilysin. If we add I cc. of I $n$ monochloracetic acid to the same volume of I $n \mathrm{NaOH}$, the haemolytic effect is wholly neutralized, and if we heat the solution for a long time to $70^{\circ} \mathrm{C}$. the mixture remains innocuous. But if we add only $0.5 \mathrm{cc}$. of the acid to I cc. of $\mathrm{NaOH}$ and keep it at $70^{\circ} \mathrm{C}$. during a sufficient time the $\mathrm{NaOH}$ at first forms the $\mathrm{Na}$-salt of the acid and the half part of the base is free. This free base slowly transforms the $\mathrm{Na}$-salt to $\mathrm{Na}$ glycolate and gives $\mathrm{NaCl}$ with the chlorine from 
the Na-monochloracetate. After a sufficient time the whole quantity of $\mathrm{NaOH}$ is bound, and if we then add the remaining $0.5 \mathrm{cc}$. of monochloracetic acid, the mixture has haemolytic properties. This is precisely the Danysz effect.

Madsen and WaLbUm made a very large number of experiments on the DANYsz effect with tetanolysin. We are here concerned with the difference, often very small, in toxicity between the two mixtures, and owing to the difficulties of the experiments it was necessary to repeat every observation many times and take the mean values to be certain of the validity of the observations. For this purpose thousands of observations were necessary. At $37^{\circ} \mathrm{C}$. about eight hours were necessary for reaching the end-value. The process was monomolecular and increased in the proportion $1.86: \mathrm{I}$ in an interval of $10^{\circ} \mathrm{C}$., corresponding to a value of $\mu=\mathrm{I}$ I 300 .

It is quite clear that if we do not add more $\mathrm{NaOH}$ to the first fraction than is necessary for neutralizing the monochloracetic acid, the effect will be zero. Subsequently the effect will increase proportionally to the excess of $\mathrm{NaOH}$ over the neutralizing quantity till double the neutralizing quantity is reached. This was also found to be the case with the DANysz effect for tetanolysin, except that the effect was not limited to the interval between equivalent and double equivalent quantities of the antitoxin. The perfect concordance between the observed and calculated values of the end effect is shown by the following observations: 
The Danysz EFFect For Tetanolysin

(MADSEN AND WALBUM)

\begin{tabular}{|c|c|c|c|}
\hline First Fraction. & Free A. & \multicolumn{2}{|c|}{ Danysz Effect. } \\
\hline $0.2 \mathrm{cc} . \mathrm{A}+\mathrm{I} \mathrm{cc}, \mathrm{L}$ & $0.02 \mathrm{cc}$ & $\begin{array}{c}\text { Obs. } \\
5\end{array}$ & $\begin{array}{c}\text { Calc. } \\
2\end{array}$ \\
\hline 0.4 cc. $\mathrm{A}+\mathrm{I}$ cc. $\mathrm{L}$ & $0.22 \mathrm{cc}$. & 23 & 22 \\
\hline $0.6 \mathrm{cc} . \mathrm{A}+\mathrm{I} \mathrm{cc} . \mathrm{L}$ & $0.42 \mathrm{cc}$. & 39 & 42 \\
\hline 0.8 cc. $\mathrm{A}+\mathrm{I}$ cc. $\mathrm{L}$ & $0.62 \mathrm{cc}$. & 60 & 62 \\
\hline $\mathrm{I} \cdot 2$ cc. $\mathrm{A}+\mathrm{I}$ cc. $\mathrm{L}$ & $\mathrm{I} \cdot \mathrm{O} 2 \mathrm{cc}$. & 97 & 102 \\
\hline
\end{tabular}

$A$ is the solution of antitoxin used; $\mathrm{L}$ the solution of tetanolysin ; I cc. L was by means of special experiments on neutralization found equivalent to $0.18 \mathrm{cc}$. of $\mathrm{A}$. The calculated effect is taken proportional to the free quantity of $\mathrm{A}$.

Experiments have been carried out by von Dungern on the Danysz effect for diphtheria toxin. He has, however, not let the toxin and antitoxin react upon each other for sufficient time to reach the end effect. His figures are therefore only about half as great as they would have been if he had used sufficient time of action.

In order to explain the Danysz effect the EHRLICH school supposes the presence in the toxins of a new kind of substances called epitoxonoids, which are neutralized after the "toxons." Of course the supposition of one new substance corresponds to the introduction of two new hypotheses, the one regarding its toxicity, the other regarding its quantity. Sachs believed he had found at least two "epitoxonoids."

In his epoch-making Dialogue regarding the 
Two Greatest Systems of the World Galilei makes his representative SALviati say that the hypothesis of a daily motion of the earth is much better than the many hypotheses regarding the Ptolemaic epicycles and cite the words of Aristoteles: "Frustra fit per plura quod potest fieri per pauciora," or, freely translated: "We ought to use as few hypotheses as possible in our explanations." This principle, which is also adopted by Newton in his Principia, is fundamental in all scientific work, and it will also give the decision regarding the "pluralityhypothesis" in immuno-chemistry regarding antidiphtheric serum.

If we inject the red blood-corpuscles from an animal into the veins of an animal of another species, we find after a certain time of incubation-three days or more (cp. p. I 5) - an antibody which haemolyzes blood-corpuscles of the same kind as the injected ones in this animal's bloodserum. If we heat this haemolysin to $55^{\circ} \mathrm{C}$. for some minutes it is "inactivated," i.c. it loses its haemolytic power. But this inactivated fluid still contains some active substance, for it regains its haemolytic power after addition of a normal serumin most cases fresh serum from guinea-pigs is usedwhich itself possesses a very small haemolytic power. Some substance in this fresh serum is not specific, but acts against all kinds of erythrocytes, "completes" the inactivated serum, and is therefore called the "complement," whereas the active substance in the inactivated serum, which is specific against the in- 
jected erythrocytes, is called the "immune body" or "amboceptor" (EHRLICH).

The amboceptor is absorbed very rapidly and in great quantity by the red blood-corpuscles against which it is specific (cf. p. I05). These are not haemolyzed by it. If they are mixed (in physiological salt solution) with fresh blood-corpuscles of the same kind, these slowly take up a part of the amboceptor. Blood-corpuscles which are loaded with a quantity of amboceptor not too small become laked when brought into contact with complement.

BORDET, who was the first investigator of this field, supposed that the amboceptor acts as a "sensitiser" of the blood-corpuscles when they are attacked by the complement. EHRLICH, on the other hand, supposed that the amboceptor binds the complement and that the addition product is a socalled "compound haemolysin." This question could evidently be decided by quantitative measurements, and EhrLich invited me to carry out the necessary determinations in his laboratory. In the following table I reproduce as example a series of observations on the haemolysis of erythrocytes of an ox. The emulsion contained 2 per cent of erythrocytes and had a total volume of $2.5 \mathrm{cc}$. In it were dissolved $a$ cubic millimetres of the inactivated goat serum, which contained the amboceptor specific against blood-corpuscles from oxen, and $b$ cubic millimetres of the complement, natural serum from guinea-pigs. The quantity of haemolysin is called $x$ and is taken to be proportional to the square root 
of the observed degree of haemolysis in accordance with experiments of MANWARING. The quantity of haemolysin necessary for complete lysis is termed IOO.

Equilibrium between Amboceptor from GoAt, Complement AND HaEmolysin For Ox ERYTHRocytes

The tabulated quantity is the concentration $x$ of haemolysin.

\begin{tabular}{|c|c|c|c|c|c|}
\hline$b$. & $a=10$. & $a=30$. & $a=100$. & $a=300$. & $a=900$. \\
\hline 60 & $40(46)$ & $\ldots$ & $\cdots$ & $\ldots$ & $\ldots$ \\
\hline 40 & $37(45)$ & $\ldots$ & $\ldots$ & $\ldots$ & $\ldots$ \\
\hline 25 & $3^{S}(42)$ & $\ldots$ & $\ldots$ & $\ldots$ & $\ldots$ \\
\hline 15 & $39(37)$ & $\ldots$ & & $\ldots$ & $\ldots$ \\
\hline 10 & $38(33)$ & $71\left(8_{4}\right)$ & $98(100)$ & $100(100)$ & $\ldots$ \\
\hline 6 & $22(25)$ & $59(60)$ & $85(9 \delta)$ & $98(100)$ & $\ldots$ \\
\hline 4 & $20(20)$ & $45(44)$ & $75(66)$ & $82(73)$ & $\ldots$ \\
\hline $2 \cdot 5$ & $\ldots$ & $24(29)$ & $51(43)$ & $47(47)$ & \\
\hline$I \cdot 5$ & $\ldots$ & $15(18)$ & $25(25)$ & $22(28)$ & $24(29)$ \\
\hline I & $\ldots$ & $\ldots$ & $15(17)$ & $15(19)$ & IS (20) \\
\hline 0.6 & $\ldots$ & $\ldots$ & II (IO) & I3 (II) & $13(12)$ \\
\hline
\end{tabular}

In brackets are written values calculated from the formula

$$
(5 a-x)(20 b-x)=90 x .
$$

The agreement between the observed and the calculated quantities is quite sufficient, considering the rather large errors of observation. It is quite clear that the quantity of haemolysin increases both with the quantity of amboceptor and with the quantity of complement used. But even with the greatest quantity of complement $(b=60)$ we do not reach complete haemolysis $(x=100)$ if there is not a sufficient quantity of amboceptor $(a=20)$ present. In this case $x$ according to the formula cannot ex- 
ceed $5^{a}$, i.e. 50 - the observation gives not more than 40. In the same manner if $b$ is small, e.g. 0.6 or $\mathrm{I}$, the quantity of haemolysin does not reach 100 even with the greatest excess of amboceptor $(a=900)$. According to the formula $x$ cannot in this case exceed a maximum $x=20$, i.e. 12 or 20 , in perfect accordance with the observation. This circumstance indicates that neither the amboceptor nor the complement acts as a katalyser or sensitiser. (The test-tubes containing the mixtures were kept at $37^{\circ} \mathrm{C}$. for two hours and subsequently for seventeen hours at $2^{\circ} \mathrm{C}$., so that the final equilibrium was probably nearly reached.)

The agreement of the formula with the observations indicates that a binding really takes place, so that when roo units of haemolysin are formed the quantity of amboceptor in 20 cubic millimetres of the goat serum and the content of complement in 5 cubic millimetres of guinea-pig serum are consumed.

The fact that total haemolysis is not reached even with very great quantities of amboceptor or complement if the other component is not present in a sufficient degree had beeh proved by Morgenroth and SACHS in 1902.

Two other combinations were tried. The one of them in which amboceptor from goat and guineapig serum acted upon red blood-corpuscles from sheep gave the formula

$$
(40 a-x)(25 b-x)=1900 x .
$$

The second with red blood-corpuscles from ox 
and amboceptor from rabbit with guinea-pig serum corresponded to the formula

$$
(\text { I } 0 \circ a-x)^{3}(1 \circ b-x)=1 \cdot 8 x^{2} .
$$

In the first of these two we find amboceptor from goat and guinea-pig serum just as in the example given in detail above (p. I 29). The only difference is that the red blood-corpuscles were taken from sheep in the one case and from ox in the other case. The sheep is much more nearly related to the goat than the ox is. This relationship finds its expression in the dissociation constant 1900 for the combination sheep-goat as compared with the dissociation constant 90 for the combination ox-goat. The higher the dissociation constant the less is the tendency to form the compound haemolysin. The more the animal in which the erythrocytes are injected differs from that which has supplied the erythrocytes, the easier is the formation of the haemolysin. The attempt to produce a haemolysin by injection of red blood-corpuscles of one animal into the blood of another animal of the same species, therefore, seldom meets with success. Still there are some reports that so-called isolysins have been obtained with such a treatment (EHRLich and MorGenroth, I900). But in this last case, with goat serum, it was necessary to use thirty times as much amboceptor for reaching complete haemolysis of goat corpuscles as with goat serum against ox corpuscles, which makes an extremely high dissociation constant probable. 
In the last example with rabbit serum acting on ox erythrocytes we find that the quantity of amboceptor enters in the formula to the power $\frac{2}{3}$. This is probably due to the so-called diversion of the complement, which is observed by myself just for this special combination. With an excess of amboceptor this binds the complement so strongly in the solution that a very small fraction of it remains in a free state. Therefore the diffusion of complement into the amboceptor-loaded erythrocytes goes on very slowly, and the reaction does not reach its end during the time of action.-It is only the haemolysin contained in the blood-corpuscles themselves which acts haemolytically.-The retardation increases with the quantity $a$ and makes itself apparent in diminishing the power to which the term containing $a$ enters in the formula. It is therefore quite possible that this power ought to be $\mathrm{I}$ if the said disturbance did not take place.

Great interest was evoked by the discovery that cobra poison, which is only slightly haemolytic, is activated in a very high degree by the presence of lecithin. The lecithin was regarded as a complement in this special case. When I investigated this case I found that the observations were expressed by the following formula

$$
C(L-\mathrm{I} \cdot 5)^{\frac{2}{3}}=6 \cdot 67 x^{2} .
$$

A certain quantity of lecithin $(L)$, namely o.0I 5 cubic millimetres, was necessary before any haemolytic action was observed, but neither the cobra poison, 
$C$, nor the lecithin, $L$, was consumed by the haemolytic agent $x$. In this case BORDET is right: the lecithin acts as a sensitiser. It is not only for cobra poison that lecithin acts in this manner, but even for other haemolytic agents, such as mercuric chloride and acids.

A very important group of antibodies from serum are the precipitins, so called because they form a precipitate with the substances injected in the veins. In this manner lactoserum is prepared by the injection of skimmed milk (casein), and a serum against egg-white by the injection of egg-white. These two antibodies precipitate their specific antigens.

The precipitins have evoked a very great interest. They are used for deciding from which kind of animal a blood-trace is derived. This method has been developed especially in Germany by Uillenhutil, Wassermann, and others. It is mostly applied for investigating if blood-spots on clothes or knives are of human or animal origin, and has rendered great services to justice. Another employment of precipitins is for determining the relationship of animals or plants. The greatest merits in this field belong to NutTal., who has written a great monograph on Blood Immunity and Blood Kelationship (Cambridge, 1904).

NutT $A$ LL was the first to use a quantitative method in this field by measuring the quantity of the precipitate collected in a capillary tube. As example, the results of some experiments in which O.IO cc. of antiserum against human blood was mixed with 
5 cc. of different blood-sera are given here. The quantity of the precipitate was with :

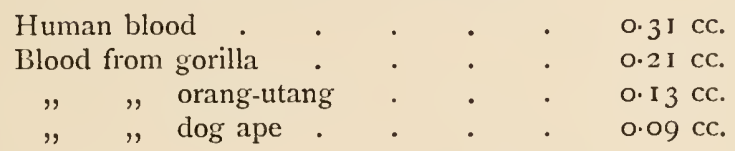

Blood from half-apes (lemurides) gave no precipitate. These animals have very little relationship with man. In the same manner the whales (cetaceans) were shown to be in relation with the hoofed animals (ungulata) and the reptiles with the birds. About I 6,000 measurements were carried out. In a similar manner the plants have been examined, especiaily by Friedenthal and Magnus. Their experiments indicated, for instance, a relationship between yeast and truffle.

HAMBURGER has made some quantitative measurements of the quantity of precipitate formed by centrifuging it in a tube which ended in a very narrow graduated tube-I degree of the scale corresponded to 0.4 cubic millimetres. These measurements were given me for calculation.

The simplest case was found with sheep serum and the precipitin obtained by its injection in the veins of a rabbit. Of the fabbit's serum containing the precipitin always $0.4 \mathrm{cc}$. were mixed with a variable quantity (A cc.) of the sheep serum diluted in the proportion $\mathrm{I}: 49$ with 0.9 per cent salt solution. The quantity of precipitate $\mathrm{P}$ was measured (in the unit $0.0004 \mathrm{cc}$.). At the side of the observed quantities I have written calculated values obtained from the formula 


$$
\frac{(40 \mathrm{~A}-\mathrm{P})}{\nu} \frac{(\mathrm{I} 2 \mathrm{O}-\mathrm{P})}{v}=\mathrm{K}=250 .
$$

In this case when a precipitate is formed the product of the concentrations $\frac{(40 \mathrm{~A}-\mathrm{P})}{v}$ of the sheep serum and $\frac{(120-\mathrm{P})}{v}$ of the rabbit's serum, in which $v$ is the total volume of the mixture, should be a constant $\mathrm{K}$, which is found equal to 250 . The formula indicates that in I cc. of the diluted sheep serum there is enough material to give 40 units of precipitate and that $0.4 \mathrm{cc}$. of the rabbit's serum is enough to give 120 units of precipitate. On the formation of precipitate equivalent quantities of sheep serum and of its specific precipitin disappear from the solution.

The results are embodied in the following table:

\begin{tabular}{|c|c|c|c|c|c|}
\hline A. & $P$ obs. & P calc. & A. & P obs. & $P$ calc. \\
\hline 0.02 & I & 0.5 & 5 & 64 & 65 \\
\hline 0.04 & 2 & I. 3 & 7 & $5^{8}$ & $5^{8}$ \\
\hline o. I & 3 & $3 \cdot 5$ & IO & 49 & 46 \\
\hline o. 15 & 6 & $5 \cdot 3$ & I 5 & IO? & 19 \\
\hline 0.2 & 7 & $7 \cdot 2$ & 18 & 5 & 3 \\
\hline 0.6 & 2 I & $2 I \cdot 5$ & 20 & 2 & o \\
\hline I & 35 & 34 & $I+I B$ & 28 & 25 \\
\hline I. 5 & $39 ?$ & 48 & $5+13$ & 57 & 51 \\
\hline 2 & 60 & 57 & $10+13$ & $4 I$ & 32 \\
\hline 3 & 67 & 66 max. & & & \\
\hline
\end{tabular}

13 denotes I cc. of phy'siological, i.e. 0.9 per cent salt solution. By the addition of this the dilution of the sheep serum was still more increased.

The agreement between the observed and the 
calculated figures may be regarded as very satisfactory, if we except two observations (marked with a ?) which do not fit in at all with their surroundings. For all the observations in which physiological salt solution has been added the calculated values are too low, which perhaps is due to a lower solubility of the precipitate in salt solution than in serum.

The quantity $\mathrm{P}$ has a maximum between $\mathrm{A}=3$ and $A=5$; the calculation indicates the maximum to be 67 at $A=3.75$. The maximum depends upon the dilution of the precipitin increasing with the increasing addition of diluted sheep serum.

The said precipitin does not only give a precipitate with serum from sheep, but also with serum from related animals such as goats and cattle. In these cases the normal sera contain enough precipitinogen per c.c. to give 40 units of precipitate just as did the normal sheep serum. But the rabbit's serum does not contain more precipitin than is necessary for the formation of 85 (for goat's) and 35 units (for cattle serum) of precipitate, whereas the corresponding figure for the sheep serum is $\mathrm{I} 2 \mathrm{O}$. The constant $\mathrm{K}$ sinks from 250 for the sheep serum to $\mathrm{I} 80$ for the goat serum and to 90 for the serum from cattle. These figures give a measure of the relationship of sheep to sheep, which may be taken as unit, as compared with that of sheep to goat (0.72) and for that of sheep to cattle (0.29 and 0.36 : mean value $0 \cdot 33$ ).

If we add casein in increasing quantities to lactoserum a precipitin is formed at first which 
reaches a maximum value when the two substances are mixed in about equivalent quantities, to be redissolved on further addition of casein. This action is supposed to be due to a formation of a soluble compound containing more casein relatively to the precipitin than the precipitate. This case has not been thoroughly examined, but a similar case was observed by HAMBURGER, when he investigated the precipitate from a mixture of normal horse serum with immune serum from a calf. In this case it is not the increasing dilution on adding increasing quantities of horse serum which causes the observed maximum of precipitate, but the calculation indicates that at first a precipitate is formed from one molecule of precipitinogen and one molecule of precipitin. This precipitate gives with one or two molecules of precipitinogen a new compound which is relatively soluble. In this case, as in the three others observed by HAMBURGER, the calculation gives a very good agreement with the observation.

In the study of agglutinins similar observations have been made, namely that in some cases the agglutination at first increases with the quantity of agglutinin added, and then subsequently decreases when the quantity of agglutinin is increased. In general the agglutinins behave much in the same way as the precipitins or the precipitinogens, and it is therefore probable that the agglutination is a special manifestation of the precipitation.

The formation of precipitates plays an important rôle in the modern development of the doctrine of 
immunity because they carry down with them the complements, as was at first demonstrated by Bordet and his pupil GAY. This effect is called diversion of complements, and has been of a very great use for diagnostic purposes, as in the WASSERMANN reaction and similar cases.

The formation of precipitates and their redissolution by addition of greater quantities of the precipitating substance is very common in general chemistry. Thus for instance salts of aluminium are at first precipitated and then redissolved by alkalies, and the same is the case with the salts of a great number of other metals. In this case the precipitate is the hydrate of the metal, and the dissolution depends on the formation of an aluminate or an analogous salt.

I hope that this short exposition has been sufficient to prove that the very same laws are valid for the equilibria in which the antibodies and antigens enter as for the equilibria studied in general chemistry. The quantitative determination of these equilibria leads to the conclusion that the antibodies are not analogous to enzymes or katalyzers, as was often maintained before, but really take part in the equilibrium. 


\section{CHAPTER VI}

\section{IMMUNIZATION}

THE antitoxins and other antibodies are of the greatest importance to the animal body. On them the so-called serum-therapy is founded. In order to protect against illnesses antitoxin is injected in the body-diphtheria, for instance, is treated in this manner-or micro-organisms, living or dead, or their products are injected, after which the patient himself produces antitoxin-this treatment is used against smallpox, for instance. EnrLici gave the name passive immunization to the first kind of treatment, active immunization to the latter one.

It is of high interest to know the fate of these foreign substances in the body. For this purpose animals have been treated in the said manner, and samples of their blood have been taken at different times and their content of antibodies investigated. Some rather remarkable regularities have been observed which will be spoken of in the following pages.

To begin with we may consider passive immunization. Antidiphtheric serum, or other antibodies, 
may be introduced into the body in different ways, by direct injection into the veins, or under the skin, so-called subcutaneous injection, or in the muscles, intramuscular injection. From the point of injection the antitoxin more or less rapidly finds its way into the blood-it is therefore said to be haemotropic. After intravenous injection the blood contains the antibody from the time of injection onwards. Madsen and JöRGENSEN have made a great number of measurements regarding the blood's content of agglutinin immediately after its injection into the veins of goats, cats, or rabbits. They found that the agglutinin was rapidly spread in the blood so that the content was just as great as if the agglutinin had been evenly distributed in the animal's blood-mass. Only rabbits made an exception. They behaved as if 23 per cent of the agglutinin had been lost immediately. As we will see later on, the antibodies rapidly vanish from the blood in the time just after the injection, but such an immediate decrease as in this special case with rabbits has only been observed with these animals.

The change of the concentration of diphtheria antitoxin in a goat's blood after intramuscular or subcutaneous injection is shown by the diagram (Fig. 33) given by Levin. It indicates that the blood's content of antitoxin after ten hours is about 25 times greater when the injection has been intramuscular than if it has been subcutaneous. After twenty hours the intramuscular injection still has the fourfold effect of the subcutaneous one. Only after 60 
hours do the two different methods show the same effect, and after that time the effect of the subcutaneous injection seems to be a little (about ro per cent) higher.

Now it is of extreme importance in the case of an attack of diphtheria that the remedy should act as rapidly as possible. Therefore the intramuscular in-

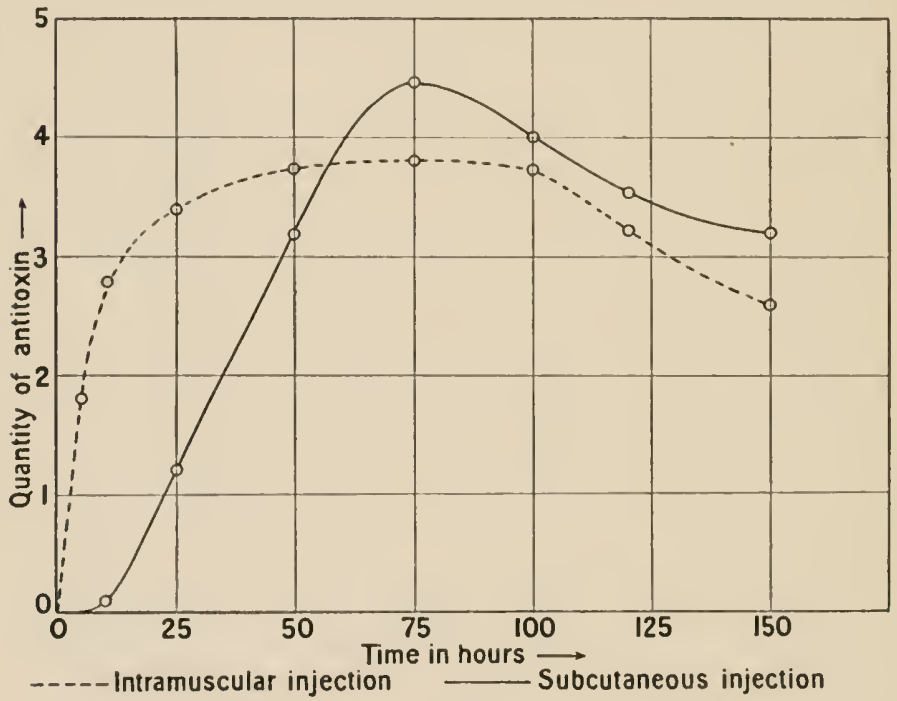

FIG. 33 .

jection should be recommended for therapeutic cases and not the subcutaneous one, which has hitherto been used in most cases. Against the most rapidly acting intravenous injection some objections of practical signification may be raised.

After a maximum content of antitoxin has been reached about 75 hours after the injection a regular slow decrease takes place. This decrease has been 
investigated by Bomstein with dogs and guinea-pigs in 1897. He injected, for instance, a dog with a certain quantity of antidiphtheric serum - this quantity he termed 7 . The next day he took a sample of the blood and subsequently every four days until the content was too small to be measured with certainty. For the measurement Bonstein used the method of EhrLich; he mixed different

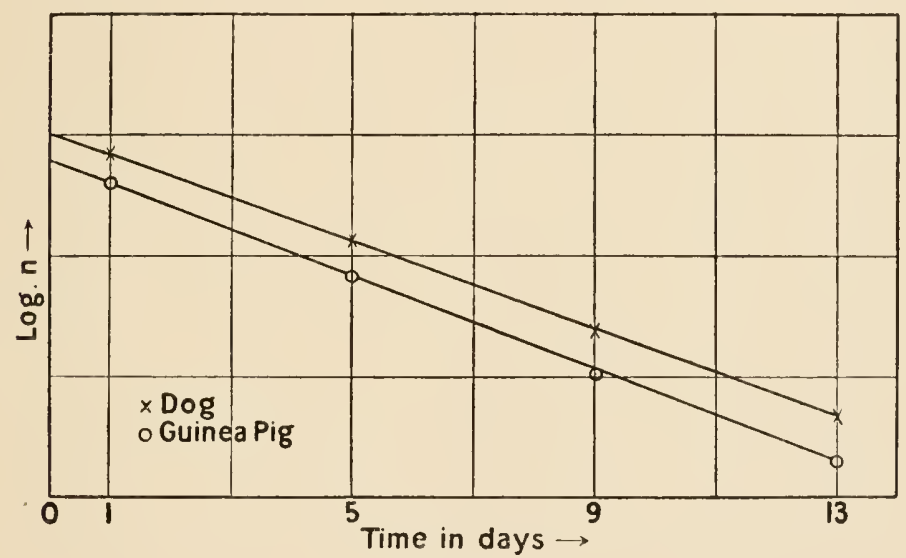

FIG. 34 .

quantities of blood serum with a given quantity of diphtheric poison and investigated how much serum was necessary to render the poison innocuous to guinea-pigs. From this he could calculate the total quantity of antitoxin in the dog's blood, for which he supposed that the total blood-mass was the thirteenth part of the dog's weight. The results found in this manner are contained in the following table and represented in Fig. 34, where $\log n$ is plotted against time; $n$ is the content of antitoxin. 
According to this evidently $\log n=a-b t$, where $t$ is the time (in days). In other words the decay of the antitoxin goes on at the same rate as a monomolecular reaction. Bonstern also maintained that the quantity of antitoxin decreased to the same fraction in four days independently of its absolute quantity. The decrease goes on so that in 3.25 days for the dogs, of which three specimens were examined, and in 3 days for the guinea-pig, the quantity of antitoxin sank to the half quantity. After the observed value a calculated value is written which, as is easily seen, agrees very well-and within the errors of observation-with the observed one. The magnitude of the errors of observation may be estimated from the differences between the observed values for the three dogs.

Passive Iminnization witil Antidiphtheric Serum (BOMSTEIN)

\begin{tabular}{|c|c|c|c|c|c|c|c|}
\hline \multirow{2}{*}{ 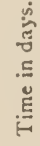 } & \multicolumn{4}{|c|}{ Observed total quantity of antibody. } & \multirow{2}{*}{ 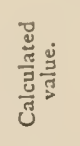 } & \multirow{2}{*}{ 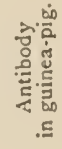 } & \multirow{2}{*}{ 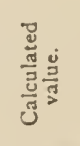 } \\
\hline & $\operatorname{Dog} x$ & $\operatorname{Dog} 2$. & (1) Dog 3 . & Mlean. & & & \\
\hline o & 7 & 7 & 7 & 7 & $(3.47)$ & 7 & $(2.65)$ \\
\hline I & 3 & 3 & $2 \cdot 5$ & 2.83 & $2 \cdot 80$ & $2 \cdot 1$ & $2 \cdot 1$ \\
\hline 5 & $1 \cdot 5$ & I & I & $1 \cdot 17$ & $I \cdot I 9$ & $0 \cdot 8_{4}$ & $0 \cdot 8_{4}$ \\
\hline 9 & 0.6 & 0.5 & 0.4 & 0.5 & $0.5^{1}$ & 0.35 & $0 \cdot 34$ \\
\hline 13 & $0 \cdot 3$ & 0.2 & 0.2 & 0.23 & 0.22 & 0.14 & 0.13 \\
\hline 17 & $\cdots$ & $\cdots$ & $\ldots$ & $\ldots$ & $\ldots$ & 0.07 & 0.053 \\
\hline
\end{tabular}

The table is of great interest because it indicates by a comparison of the observed values for the three dogs with the calculated ones the great improvement effected by forming the mean values of two or 
three observations, as against the results of single observations.

During the first day after the injection the decrease goes on abnormally rapidly. Therefore the calculated values for the first day, which fit in with the regularity found for the decrease during the later period, are written in brackets. Evidently during the time immediately after the injection another process is going on simultaneously with the process which is typical for the following regular decrease. This goes on as a monomolecular process, and the simplest hypothesis would be to suppose a spontaneous destruction, if it was not known that the antitoxins are rather stable at the temperature of the animals investigated. But the formula for monomolecular reactions would also give good results if the antitoxin reacted with some substance present in great excess or which was secreted by the animal's body as soon as it was consumed. In the time just after the injection there must also be some other action of great effectivity.

It is highly probable that the foreign substances introduced are eliminated by some substance produced by the animal in which they have been injected. This is indicated by some interesting experiments of Baron von Dungern. He injected blood-serum of the sea spider (Maja squinado, a Crustacean) into the veins of a rabbit. After three hours it had disappeared (in this case sunk below 25 per cent). Then he introduced the same quantity of Maja serum into the rabbit's blood, and found that 
it did not sink to 25 per cent until after six hours. Still more startling results were obtained if the rabbit had received a moderate dose of serum from the common cuttlefish, Octopus vulgaris, 2.5 hours before the injection of the Maja serum, which then did not sink more than to about 50 per cent during two days. The substance which neutralizes the Maja serum must therefore be bound or hampered in its action by Maja, or still more by Octopus serum, which has been introduced two to three hours before the investigated Maja serum was injected.

The circumstances become still more complicated when we consider that the rabbit at a later stage secretes in its blood a substance, a precipitin, which binds and precipitates the Maja serum. But this substance does not occur in a sensible degree during the first hours after the injection-there is a considerable time of incubation. VON DUNGERN connects the rapid disappearance of the Maja serum from the blood-vessels of the rabbit with its power of secreting the specific precipitin against the Maja serum. If we inject Maja serum into the veins of the cuttlefish Eledone moschata, or into the so-called sea-rabbit, Aplysia depilans, which do not prepare any precipitin or otherantibody against Maja serum in theirveins, we are able to demonstrate the presence of Maja serum in the blood of these animals some weeks after the injection by mixing the blood-serum with precipitin against Maja serum from rabbits. If we inject Maja serum into a rabbit which has had sufficient time to secrete a moderate quantity of the precipitin specific to its 
blood, then the Maja serum disappears much more rapidly than after the injection into a rabbit which has not been treated with Maja serum before. The effect of the previous injection of Maja serum is therefore in this latter case just the opposite of that observed if only some two or three hours have elapsed between the first and the second injection.

The antidiphtheric serum consists of serum from

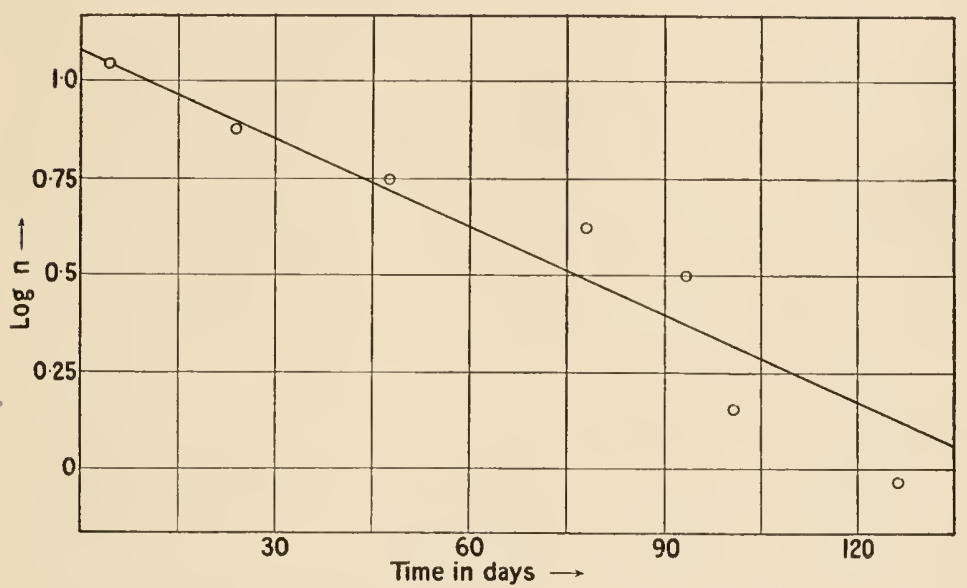

FIG. 35 .

an animal, generally a horse, which has been treated with diphtheria toxin. If this horse-serum is injected into the blood-vessels of another non-related animal, such as a $\operatorname{dog}$ or a guinea-pig, precipitins against horse-serum are secreted and found in the veins of this animal. These precipitins may give precipitates with the injected antidiphtheric horse-serum, which precipitates show a great tendency to absorb substances from the blood. 
This absorption, for instance, plays a very important rôle in the diversion of complement (cf. p. 138 ). If we inject antidiphtheric horse-serum into a nearly related animal such as an ass, we might expect the antitoxin to disappear more slowly than if injected into a dog or a guinea-pig. This experiment has been carried through by Bulloch (in I 898 ). As the following table and the diagram, Fig. 35, indicate, the antitoxin required $37 \cdot 5$ days to sink to the half value, i.e. about twelve times longer than in Boustein's experiments. In this case the injection was subcutaneous, as is seen from the first two values in the table. If the total quantity of antitoxin had spread uniformly in the blood an initial value I9 per cc. ought to have been observed. 'The value 16 after one day reaches nearly this theoretical value 19 .

PASSIVE IMMUNization of an Ass With ANTIDIPHTHERIC

SERUM FROM HORSE (BULlOCH)

\begin{tabular}{|c|c|c|}
\hline \multirow{2}{*}{ Time in Days. } & \multicolumn{2}{|c|}{ Quantity of Antitoxin in x cc. of the Serum. } \\
\cline { 2 - 3 } & Observed. & Calculated. \\
\hline & & \\
\hline 0 & 0 & 0 \\
0.02 & 2 & $(11.8)$ \\
1 & 16 & 11.6 \\
4 & 11 & 11 \\
24 & 7.5 & 7.6 \\
48 & 5.5 & 4.9 \\
60 & 4.5 & 3.9 \\
77 & 3.2 & 2.8 \\
100 & 1.3 & 1.9 \\
126 & 0.9 & 1.2 \\
\hline
\end{tabular}


The observation at the time o was made immediately before the injection. It indicates that the ass possessed no natural immunity against diphtheric poison. Half an hour later about io per cent of the antitoxin had spread to the veins. After the first day the rapid elimination took place. During the three following days the content sank from 16 to I I units, for which decrease at a later stage 20 days would have been needed.

BEHRING has also observed that antitoxins remain longer in the blood of animals of the same kind as that from which the antitoxic serum is taken. MADSEn and Jörgensen found that typhoid agglutinin from a rabbit disappeared 2.5 times more slowly from the veins of a rabbit than from those of a goat.

As the observations referred to above all concern the fate of antidiphtheric serum it may be of interest to reproduce the figures of MADSEN and JöRGENSEN regarding the fate of typhoid agglutinin in the veins of a goat. 
INTRAVENOUS INJECIION OF TYPHOID AGgLUTININ IN A GOAT (MADSEN AND JÖRGENSEN)

\begin{tabular}{|c|c|c|}
\hline \multirow{2}{*}{ lime in Days. } & \multicolumn{2}{|c|}{ Quantity of Agglutinin per cc. Seruin. } \\
\cline { 2 - 3 } & Observed. & Calculated. \\
\hline & & \\
0 & 909 & $(274)$ \\
0.3 & 555 & $(267)$ \\
1 & 333 & $(250)$ \\
3 & 208 & 208 \\
5 & 167 & 173 \\
8 & 125 & 131 \\
11 & 100 & 100 \\
15 & 91 & 69 \\
\hline
\end{tabular}

In the first day we observe a very rapid decrease, which is about I I times greater than the regular monomolecular decay which begins about $1 \cdot 5$ days after the injection (as found by extrapolation from the regular curve) and gives a fall to the half-value in $7 \cdot 5$ days.

Red blood-corpuscles from an animal may be identified by means of a specific haemolysin, obtained by injection of these corpuscles into the veins of another animal. Saciss injected erythrocytes from an $o x$ into the ear vein of a rabbit, and was able to find traces of them after 4 I to 92 (average 57) hours; after 46 to 116 (average 72 ) hours they hat disappeared. On the other hand Tonn and WurTe identified similar erythrocytes injected into an ox after four days.

In his experiments on the injection of ox erythrocytes into the veins of a rabbit $\mathrm{S}_{\Lambda \mathrm{CIIS}}$ 
looked for the first appearance of the corresponding antibody, a haemolysin against ox erythrocytes. He demonstrated the presence of this antibody just after the disappearance of the erythrocytes or perhaps a little before. The time of incubation had therefore a mean value of 72 hours, which agrees completely with an observation of Bulloch. If the erythrocytes were injected subcutaneously the time of incubation was much longer, as we might expect, namely 7 days. An analogous case is found in infectious diseases, which may be regarded as a special case of active immunization. In smallpox the infection generally comes through the respiratory organs, and the time of incubation lasts no less than from io to I4 days, whereas after inoculation of genuine small-pox (variolation) or of weakened virus from cow-pox (vaccination) the time of incubation is only 3 to 5 days. Still shorter sometimes is the time of incubation after repeated vaccination. This circumstance makes it possible for a man, freshly infected with small-pox, to be (partially) protected by vaccination. The antibodies appear after the time of incubation, and this is after vaccination so short that it may be at an end before the incubation time of the genuine small-pox is completed. In this case this latter time of incubation is shortened, and the patient gets an easy form of small-pox, the so-called varioloid, as is generally the case with vaccinated people who are attacked by the genuine small-pox. Still longer is the time of incubation in hydrophobia ; in this case it depends 
on the distance of the infected wound from the central nervous system, and may sometimes last for one month. Owing to this it was possible to Pasteur to check the illness by inoculation of weakened rabies virus.

After active immunization of an animal which has been immunized before against the same bacilli the time of incubation is sometimes characterized by a diminution of the content of antibody-this is the so-called "negative phase." The said decrease is regularly observed with the immunization of horses against diphtheric toxin, whereby antidiphtheric serum is prepared. Thus Salomonsen and Madsen found that the antitoxin content of a horse went down one time from 100 to 65 units, another time from I 20 to 105 units, to rise subsequently above its initial value. A similar clecrease was also observed after every bleeding (at which seven litres of blood were taken for the preparation of antidiphtheric scrum); in one case the fall was from 120 to 105 units, another time from $S_{5}$ to 70 units.

After the end of the time of incubation an enormous increase of the quantity of antitoxin takes place. As an example may be cited the following table from MADSEN'S and JöRGENSEN's investigation, illustrated by the diagram, Fig. 36 . The animal treated was a goat which had been used for similar experiments before, so that it contained a little initial quantity-designated as four units - at the time of injection. This quantity decreases a little -one unit - in the first day; this is the "negative 
phase." After that comes a slow, and later a rapid increase.

AgGlutinin in a Goat, ACtively immunized With a Culture OF CHOLERA ViBRions

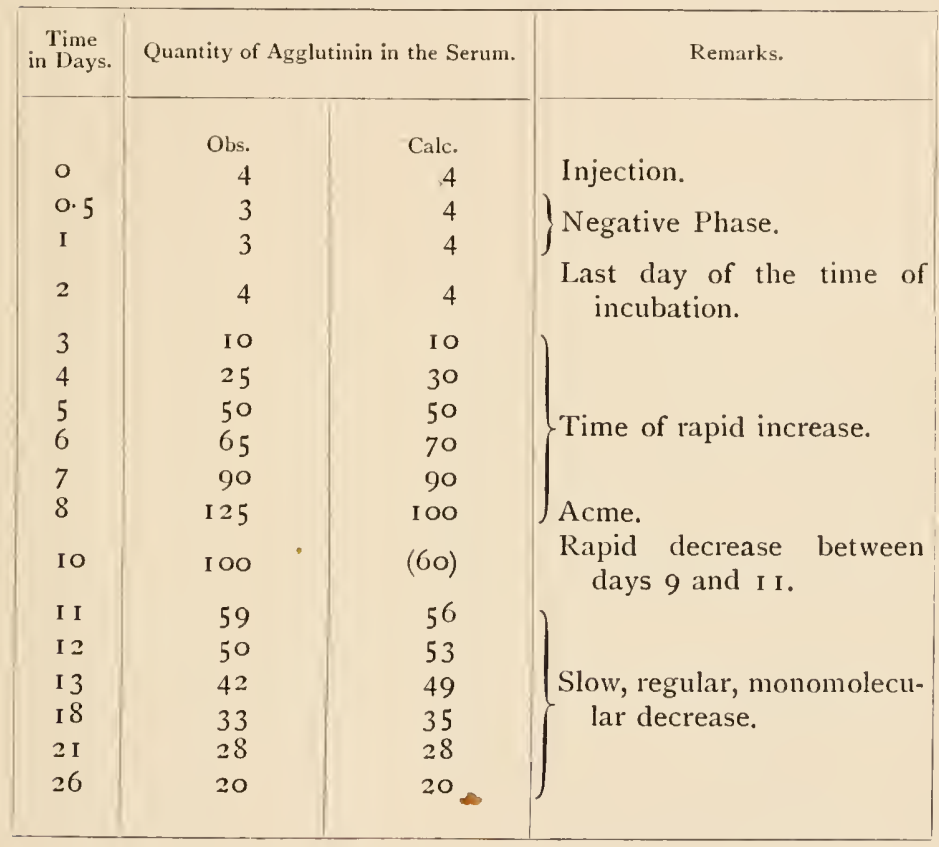

The time of rapid increase, between the time $2 \cdot 5$ days and 9 days, is characterized by the fact that the content of agglutinin increases by nearly the same quantity, 20 units, every day. The process is somewhat similar to the increase of gastric juice in the stomach after introduction of food through a tube (see p. 92). The corresponding stage with increasing illness in small-pox is called the prodromal stage. This stage ends with a maximum, the so-called 
"acme," after which an abrupt decrease of the agglutinin takes place. From this time (the ninth day in our case) the content of antibody is very similar to that after passive immunization. After a rapid decrease comes the regular slow one, which

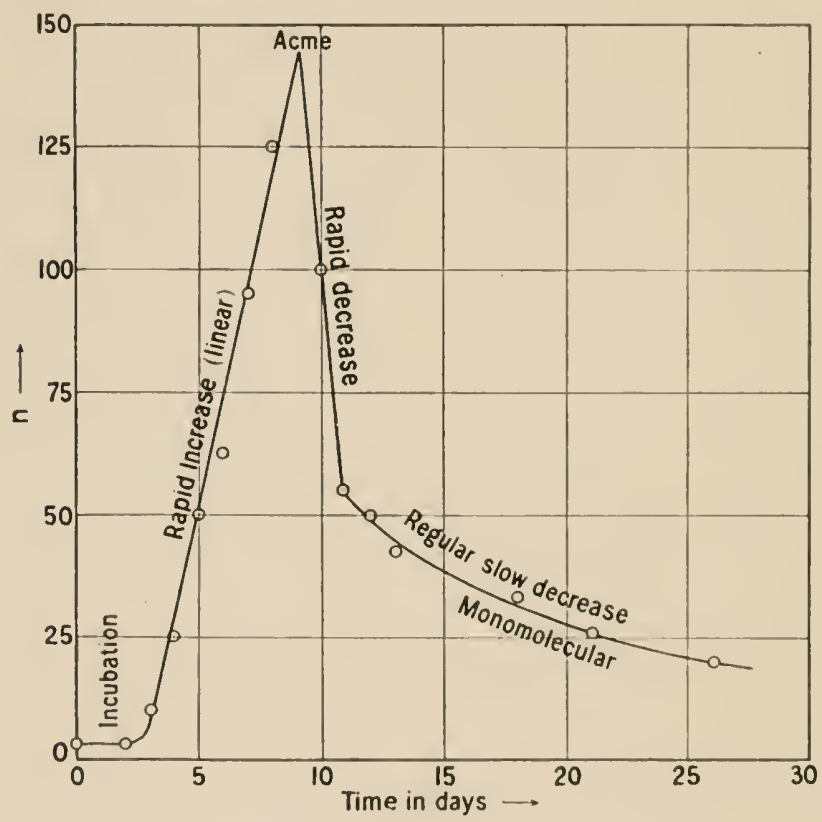

FIG. 36 .

may be calculated as a monomolecular reaction. The calculated values for this time agree very well with the observed ones. The same is the case for the values calculated on the assumption that the quantity of agglutinin increases with constant speed during the time of rapid increase.

In order to corroborate these statements I repro- 
duce some figures given by MADSEN and JöRGENSEN for the content of agglutinin in a goat, which was strongly immunized before the experiment against typhoid bacilli. At the time indicated as o, I cc. of a culture of typhoid bacilli was injected subcutaneously.

Active Immunization of a Goat against Typhoid Bacilli (MADSEN AND JÖRGENSEN)

\begin{tabular}{|c|c|c|c|}
\hline $\begin{array}{l}\text { Time } \\
\text { in Days. }\end{array}$ & \multicolumn{2}{|c|}{ Content of Agglutinin. } & Remarks. \\
\hline $\mathrm{o}$ & $\begin{array}{l}\text { Obs. } \\
\text { I } 36\end{array}$ & $\begin{array}{l}\text { Calc. } \\
\text { I } 36\end{array}$ & Injection. \\
\hline I & I 36 & I 36 & $\begin{array}{l}\text { Incubation time at an end after } 2.7 \\
\text { days. }\end{array}$ \\
\hline 3 & I 88 & I 86 & \\
\hline 5 & 268 & 272 & Time of rapid increase ( 43 units a \\
\hline 7 & 367 & 358 & day). \\
\hline 9 & 442 & 444 & Acme. \\
\hline I I & 323 & 323 & Rapid decrease between the days \\
\hline I 3 & 286 & 285 & \\
\hline 17 & 225 & 221 & Slow, reoular \\
\hline 20 & I 96 & 183 & decrease. \\
\hline 23 & I $5 \mathrm{I}$ & I 5 I & \\
\hline 25 & I I 7 & I 33 & \\
\hline
\end{tabular}

Here the time of incubation is reduced to $2 \cdot 4$ days, which is probably due to the previous strong immunization, I 36 units. The time of rapid increase ( $6 \cdot 6$ days) lasts about as long as in the last case $(6 \cdot 5$ days). The rapid decrease is not so pronounced as in the last case. The final regular decrease causes a sinking of the agglutinin to the half-value in I I days, whereas in the last case the corresponding 
time was Io days, i.e. about the same. The good agreement of the calculated figures with the observed ones during the periods of rapid increase and of regular decrease are strongly pronounced.

In another experiment MADSEN and JöRGENSEN injected $20 \mathrm{cc}$. of a culture of typhoid bacilli subcutaneously into a goat which had not been treated before. The time of incubation with absence of agglutinin lasted for $5 \cdot 5$ days and was much longer than in the two last cases, when the animals had been injected with the same bacilli before. The time of rapid increase for about nine days showed an enormous production of agglutinin-about 2000 units a day. The observations of the regular decrease are very few (only three). They seem to indicate a sinking to the half-value in about five days, i.e. about double as rapidly as in the goats which had been immunized before.

A special case of active immunization, in which till now only the period of regular slow decrease has been observed, concerns the content of agglutinins in the blood of persons who have been attacked by bacterial diseases. In such cases it is often found that the slow decrease goes on much more slowly in the latter part of the observed period than in the first time. As instances I give two series, the one of JöKGENSEN regarding the content of typhoid agglutinin in a patient's blood after typhoid fever, the other of Sir Ammoti WRignt regarding agglutinin specific against the bacillus causing Malta fever. 
Agglutinin in the Blood of a Patient in Typhoid FEVER (JÖRGENSEN)

\begin{tabular}{|c|c|c|}
\hline $\begin{array}{c}\text { Time } \\
\text { in Days. }\end{array}$ & Quantity of Agglutinin. \\
\hline & & \\
\hline 0 & Obs. & Calc. \\
2 & 50 & 60 \\
6 & 36 & 5 I \\
I 0 & 25 & 36 \\
I 5 & I 7 & 26 \\
20 & I 2 & I 7 \\
27 & I O & I I \\
35 & 6.7 & $6 \cdot 2$ \\
42 & 4 & 3.2 \\
& & I.8 \\
\hline
\end{tabular}

Till the twentieth day the decrease of the content of agglutinin in the patient's blood goes on quite regularly, so that it sinks to its half-value in 8.4 days. But in the last 15 days the quantity of agglutinin is rather greater than the calculation indicates. Perhaps this circumstance is partly due to errors of observation, bit the regularity of the figures seems to indicate that the decrease goes on much more slowly than in the former part of the process. In a similar manner it has often been found with strongly immunized animals that they retain the last traces of immunity for a long time undiminished or falling off very slowly. It seems as if a part of the antibodies were stored up in parts of the body, from which it very slowly diffused back to the veins. Still more pronounced is the second instance. 
Agglutinin in the Bloon of a Patient in Malta FEVER (SiR AlMRoTh Viright)

\begin{tabular}{|c|c|c|}
\hline $\begin{array}{c}\text { Time } \\
\text { in Days. }\end{array}$ & \multicolumn{2}{|c|}{ Content of Agglutinin. } \\
\hline 0 & $\begin{array}{l}\text { obs. } \\
1600\end{array}$ & $\begin{array}{l}\text { calc. } \\
1600\end{array}$ \\
\hline 6 & 1000 & 1160 \\
\hline 13 & Soo & SIO \\
\hline 19 & 600 & 602 \\
\hline 25 & 420 & 456 \\
\hline 33 & 320 & 325 \\
\hline 40 & 270 & 250 \\
\hline $4 S$ & 200 & 195 \\
\hline 58 & I 50 & I 53 \\
\hline 71 & 130 & 125 \\
\hline
\end{tabular}

In the first period the agglutinin sinks to its halfquantity in 13 days, at the end 30 days ( 4 I to 71 ) are necessary for a diminution to the half-value. In other words, the rate of sinking is 2.3 times more rapid at the beginning than at the end. Of course it is impossible to calculate these figures in the way used before. I have therefore supposed that the agglutinin content sinks to an end-value above zero, namely 100 units, and treated the excess of the observed value over 100 in the usual manner. The agreement with the observations obtained in this manner is really startling. IVe may therefore say that the content of agglutinin behaves as if it tended to a minimal value of IOO units, which it would retain for any time. But without doubt this value also sinks with the progress of time. Sir Almroth IVrigit has observed a case, in which 
the patient retained a content of agglutinin in his blood, reaching 20 units seven and a half years after his illness (Malta fever). Different patients show in this respect a high degree of individuality. In most cases the agglutinin has disappeared after two years or is only present in very small quantities.

The presence of agglutinins in the blood during and after diseases is of a high diagnostic value (Reaction of Gruber-VIDAL). It is very well known that after some diseases, such as scarlatina, measles, and whooping-cough, the immunity against these diseases lasts for the whole life. It is not clear whether this peculiarity depends upon a small content of antibodies remaining for a long time in the tissues of the patients.

But it seems to me in any case that the study of the active immunity throws much light on the progress of illnesses produced by micro-organisms. It is a very promising feature that we are able to treat the content of antibodies during and after the illness in a strictly quantitative manner, and that we have succeeded in subjecting this extremely important phenomenon to calculations which agree as well with the observed facts as with ideas conceived for the explanation of other parts of chemical science. 



\section{INDEX OF SUBJEC'TS}

Acids, I6, 27-29, 32, 40, 66-68, 82, I I 5 Acme, I 53

Active immunization, I 40, I 5 I-I 58

Active nolecules or cells, $75-80$

Adsorption, I08-1 Io

Alcoholic fermentation, $21,52,55,60-$ 63

Alkalinity, 27, 28, 32, 33

Amboceptor, 105, 108, I28-133

Ammonia, $43,44,63,64$

Amphoteric electrolytes, 40, 79

Amylodextrin, 95

Amianaphylactogen, 16

Antibodies, I5, I 39-I 59

Antigen, 15

Antitoxins, I6, I I0-127

Antivenin, I $16,123,124$

Assimilation, 21, 55-57, 93-95

Atomic theory, I

Bacteria, 53-55, 67-74, I05

Bacteriolysin, I 5

Bacteriolysis, 52

Bases, 66, I I5-1 I6; see also Alkalinity

Biochemistry, 2

Bleeding, I 52

Blood, 20, $2 \mathrm{I}$; content of antibodies, I 4 O-I 59

Blood - corpuscles, 76-78, I03, I I 4 , I 25,150

Blood relationship, 134, 135, 137, 148 , I 49

Boracic acid, with ammonia, I I 7-I I9

Carbohydrates, 2 I

Casein, 100, I01, I09, I37

Castor-beans, 47,56

Cell reactions, $60-80$

Charcoal, $35,50,5 \mathrm{I}$

Chewing, 9 I

Chlamydomonas, 74

Chlorophyll, It

Cholera, 108, I 53
Coagulation, 25-29, 45, 46, 54, 55, I08

Cobra poison, 66, I $16,123,124,133$, I34

Complement, I $23-132$

Compound haemolysins, $16,128-132$, I 5 I

Concentration, influence of, $33^{-4}$

Condensation, 108

Conductivity, electric, $3^{8}$

Crotalus poison, I 16

Danysz's phenomenon, I2 $\boldsymbol{\psi}^{-\mathbf{I} 27}$

Destruction, spontaneous, $24-30,54$

Dextrose, 93, 94

Diagnostic sera, I34, I 39, I 59

Digestion, $33,37-47,54,81-98$

Dilution, 29

Diphtheria toxin, I4, I I I-II3, I I 7, I $20,127, I+0, I+3, I+7$

Dissociation, 79, I $16,119,130-132$

Diversion of complement, I33, I 39, $14^{8}$

Egg-albumen, 25-29, 37-41, 47, 50, $51,93,108,134$

Ehrlich's phenomenon, I I 3-I23

Enteric juice, 13, 82, 97

Enzymes, 34, 35, 37, 58-60, 99-IO2

Epitoxoid, I23, 127

Equilibria, chemical, 99-139

Equivalents, I 20, 12 I

Erepsin, I3, 47

Ethyl acetate, 41-43

Ethyl butyrate, 48

Experimental errors, 3

Fats, I3, 47, 87, 100

Ferrocyanic acid, 109

Fistulae, 8I, 92, 94, 95

Food-stuffs, 83-94

Foreign substances, elimination of, I $45-147$, I 50 


\section{2}

Gelatine, $45,46,5^{2}$

Gliaclin, 96, 97

Glucosides, 100-102

Graphical methorls, $4^{-12}$

Gulrlberg-Waitgc's law, I I2-1 22

11.xemoglobin, 25, 26, 50, 51, 63

I Iaemolysin, 15, 24, 25, 50, 51, 1 27132,151

Hitcmolysis, 52-55, 63-66, 73, 104, $114-120,125,130$

Haemotropism, 141

Heat, erolution of, 119

11 drochloric acicl, $38-40,82,86,87$, 93,115

IIydrogen ion, concentration of, 32, 69 Hydrolysis, fo, 55, 100, 101

Hyclroxyl ion, 69

Inmune borly, 129

Immunization, I +1-159

Inactisation, 128

Incubation, $64,74,80,82,128,15^{1-}$ 156

Instability of organic products, 24

Intramuscular injection, $1+1,1+2$

Intravenous injection, $141,142,151$

Inversion of cane-sugar, 20, 30-34. $5^{6}$

Invertase, 1 3, 14, 99

"In vitro" and "in vivo" reactions, 23. 98

Irreversible processes, $124-127$

Isolactose, to r

Isolysin, $13^{2}$

Isoinaltose, 101

Isotonic solutions, 10.4

Kitalasc, $14,47,48$

Katalyzer, 131, I 39

I_actase, 13,101

lactose, 101

I, actoserui1), 134, 137, 1 38

l.ayers of foorl-stuffs in the stomach, 85

1. ceithin, 16, 133,134

Lifetime, 78

lipase, 12, 14, 48, 56

Licpuid air, 69

Malta fever, 158

Maltase, $13,14,101$

Maltose, 12, 13, 101

Miss, cunstaney of, I

Mcchanistic vicw on life, 20

Mercuric chloricle, 16
Mercuric ion, 68

Milk, $45,46,56,87$

Monochloracetic acicl, I 25, 126

Mutarotation, $3^{1}$

Natural immunity, 149

Negative phase, I 52 - I 54

Neutralization plenomena, I I $0-133$

Oleate, 66

Opsonis, 16

(1)tinum, 56-58

Osmotic pressurc, 10.4

Uxyclase, 14

Pancreatic juice, $13,46,47,82,92,93$

l'apayotin, I4

Paranucleiu, 100, 101

l'artial poisons, 1 I 8

l'artition between two phases, 102-108, 125

Passive immunization, 1 40-1 50, I5t

l'epsin, 12, 32, 37-40, 45, 52,83,84, 100

l'eptone, 39, 40

Peroxide of hydrogen, $32,33,47,48$

l'henol, 69

I'lastem, I 00

Platinum, colloidiıl, 32, 33

Plurality of poisons, 128

Poison spectrunt, I 17, I 18

Precipitation, 54, 55, 122, 1 34-1 39

I'recipitin, 15, $16,50,51,134-138$. I. 6 - 148

Probalility, 76, 77

Prodromal stage, 153

Protamine, roo

l'roteolytic ferments, 13,52

Protoplism, 58,79

Prototoxoid, 121, 122

I'tyalin, 12

Pyocyancus ferment, $4^{6}$

Cl-latw, 40-47, 59-65, 67, 73

Kalies, 151, 152

kedissolntion of precipitates, I 37 - I 39

Reductise, $1 .+$

Relationship), 1 34, 135, 137

Remunt, 29, 45, 46, 52, 56, 100

Resorption, 95, 96

Respiration, 21, 55

Reversible processes, 124, 125

kicin, I22

Saponification, $46-48,54-58$ 
Salivary glands, I 2

Schütz's rule, $37-47,72$, I09

Sedimentation, I7

Seeds of barley, 74

Sensibility, 76-79

Sensitiser, I 29, I 3 I, I 33

Serum-therapy, I $40, I_{42}$

Specificity, I 7, Ioo, I 28, I 36, I 37

Small-pox, I 46, I 5 I, I 53

"Small stomach," $82,83,88$

Square-root rule, $85-86,87,91,94-$ 97

Starch, I 2

Steapsin, 46

Stomachical juice, I2, I3, 47, 82, 8385,92

Subcutaneous injection, I4I, I42, I48, I 5 I, I 55, I 56

Sunlight, 69,72

Synthesis of organic products, 22, 98 I 02

Syntoxoid, I 23
Temperature, influence of, 49-60

Tetanus-poison, $14,24,25,32, \mathrm{IO}_{3}$, I I, I I, I I 9, I 20, I 26, I 27

Toxins, I 4- I 7, I IO-I 27

Toxoids, I 8

Toxon, I23, I 27

Trypsin, I 3, 44, 45, 52

Typhoid bacilli, 53,69, 93, I 08, I 54-I 57

Vaccination, I40, I 5 I

Variolation, I 5 I

Varioloid, I 5 I

Velocity of reactions, I9-59

V'ibriolysin, 28, 35, 50, 51, I03, 108

V'italism, 19,98

Vital processes, $55,57-60,64,81-98$

Water-moccasin, 66, I 16

Weakening of poisons, I23, I 24

Yeast, 14, 30, 60-63, 72, 102

Zymase, It

\section{INDEX OF AUTHORS}

Aristoteles, I 28

Arrhenius, 32, 41, 52, 63, 75, 88, 104, I0 5, I I I, I I 4 , I I 5, I 29, I 35

Armstrong, E. F., IOI

Baeyer, 21, 22

Bayliss, 44

v. Bernecl; 33

Berthelot, D., 2 I

Berthelot, M. , 22

Berzelius, I

Blackman, 74

Boldyreff, 87

Bomstein, I $43,144,148$

Bordet, I 25, I 29, I 34, I 39

Bourquelot, I o I

Bredig, 33

Bridel, I I I

Brown, Adrian, 34

Bulloch, I 48 , I 5 I

Bunsen, 64

Calmette, I23, I 24

Chick, Harriette, 27, 28, 53, 69, 72, $73,74,80$

Clark, 69,72
Dalton, I

Danilewski, IOo

Danysz, 124, I 25, 126

Darwin, 74

Daubeny, 2 I

De la Boë Sylrius, 20

Dolinsky, 92

Draper, 2 I

Duclaux, 2 I

Dumas, 2 I

v. Dungern, I 27, I 45,146

Ehrlich, I 10, I I I, I I 3, I 14, I I 7, I I 8, I 2 I, I 22, I23, I 24, I 26, I 29, I 32, I 43

Eisenberg, I05

Ellenberger, 85

Engelmann, 2 I

Euler, 47

Fischer, Emil, 22, IO I

Friedenthal, I 35

Fuld, 56

Gage, 69, 72

Galilei, 128 
Gay, 100, I 39

Gélis, 22

Graebe, 22

Gros, 52

Gruber, I 59

Grützner, 85

Guldberg, I I 2, I 22

Hamburger, 135, 138

Harvey, 74

van Helniont, 2 I

Ienri, 30, 31, 33

Hill, ro I

Hudson, 31, 99

Jodlbauer, 52, 60

Jörgensell, I 4 I, I 49, I 54, I 55, I 56, I 57

Khigine, $81,83,84,85,87,88,92$

Kjeldahl, 56

Krönig, 68, 69

Lavoisier, I

Levin, $I+I$

Liebermann, 22

Lobasoff, 83,92

London, 81, 84, 85, 87, 88, 91, 93, 95,97

Lönnquist, 82,83

l,undén, I I 7 , I I 9

Madsen, 28, 29, 35, 44, 45, 46, 52, $63,65,67,68,69,80,103,108$, III, IIt, I I 5, I I9-I23, I 26, I I I, $149,152,154,155,156$

Magnus, I 35

Manwaring, 130

Martin, 27, 28

Massol, I23

Matthaei, Gabrielle, 56

Maxwell, 77

Menthen, 34

Michaelis, 34

Morgenroth, I 31 , I32

Newton, 128

Nicloux, 56, $5^{8}$

Noguchi, 65, I I 5

Nuttall, 134
Nyman, 69

O'Sullivan, 3 I

Palne, rog

Paul, 68, 69

Pawlow, 8I, 9 I

Pélouze, 22

Pfeffer, 2 I

Polowzowa, 84,87

Priestley, 21

Pringshein , 2 I

Robertson, T. B., 100

Roscoe, 64

Rubner, 6I, 62

Sachs, Hans, I I 8, I 26, I 31 , I 50

Sachs, Julius, 2 I

Salonionsen, I52

Sandberg, 97

de Saussure, 2 I

Schütz, E., 8, 9, I I, 37, 39, 41, 42 , $43,+7,62,63,72,84,109$

Schiitz, Julius, 37

Senebier, 2 I

Sjöqvist, 37,47

Sörensen, 32, 33

Stoklisa, 2 I

Taylor, A. F., 100

leruuchi, 35, 103, 108

Thonsen, Julius, 1 Io

Todd, I 50

'Tompson, 3 I

Tynclall, 1, 20

Uhlenhuth, I34

Van ' 1 Hoff, 99

Vidal, I 59

Volk, I05

Waage, 112, 122

Walbum, 29, 44, 45, 46, 65, 68, I26

Wassermann, I 34, I 39

White, I 50

Willuelmy, 8

Willstatter, 14

Wühler, 22

Wright, 156,158 



